\title{
1 An atlas of neural crest lineages along the posterior developing zebrafish at 2 single-cell resolution
}

3

4 Aubrey G.A. Howard IV ${ }^{1}$, Phillip A. Baker ${ }^{1}$, Rodrigo Ibarra-García-Padilla, Joshua A. Moore,

5 Lucia J. Rivas, James J. Tallman, Eileen W. Singleton, Jessa L. Westheimer, Julia A.

6 Corteguera and Rosa A. Uribe*

7

8 Department of BioSciences, Rice University, 6100 Main Street, Houson, TX 77005, United

9 States of America

10

11 *corresponding author, email address: rosa.uribe@ rice.edu

$12{ }^{1}$ These authors contributed equally to this work

13

14

15

16

17

18

19

20

21

22

23

24

25

26

27

28

29

30 


\section{ABSTRACT}

39 Neural crest cells (NCCs) are vertebrate stem cells that give rise to various cell types 40 throughout the developing body in early life. Here, we utilized single-cell transcriptomic 41 analyses to delineate NCC-derivatives along the posterior developing vertebrate, zebrafish, 42 during the late embryonic to early larval stage, a period when NCCs are actively differentiating 43 into distinct cellular lineages. We identified several major NCC/NCC-derived cell-types 44 including mesenchyme, neural crest, neural, neuronal, glial, and pigment, from which we 45 resolved over three dozen cellular subtypes. We dissected gene expression signatures of 46 pigment progenitors delineating into chromatophore lineages, mesenchyme subtypes, and 47 enteric NCCs transforming into enteric neurons. Global analysis of NCC derivatives revealed 48 they were demarcated by combinatorial hox gene codes, with distinct profiles within neuronal 49 cells. From these analyses, we present a comprehensive cell-type atlas that can be utilized as a 50 valuable resource for further mechanistic and evolutionary investigations of NCC 51 differentiation.

52

53

54 Key words: neural crest, sox10, single-cell, zebrafish, enteric neuron, hox 


\section{INTRODUCTION}

66 Unique to vertebrates, neural crest cells (NCC) are an embryonic stem cell population 67 characterized as transient, highly migratory, and multipotent. Following their birth from the 68 dorsal neural tube, NCCs migrate extensively, dorsolaterally or ventrally along the main axial

69 levels of the embryo; the cranial, vagal, trunk, and sacral regions (Graham et al., 2004; Le 70 Douarin and Teillet et al., 1974). Depending on the axial level of their origination, NCCs give 71 rise to different cell types within many critical tissues; such as the cornea, craniofacial cartilage 72 and bone, mesenchyme, pigment cells in the skin, as well as neurons and glia that comprise 73 peripheral ganglia (Hutchins et al., 2018; Epstein et al., 1994; Kuo and Erickson, 2011; Hall and 74 Hörstadius, 1988; Le Douarin and Kalcheim, 1999; Theveneau and Mayor, 2012; Williams and 75 Bohnsack, 2015; Yntema and Hammond, 1954).

77 During their development, NCCs undergo dramatic transcriptional changes which lead to 78 diverse cellular lineages, making their transcriptomic profiles highly dynamic (Simões-Costa et 79 al., 2014; Martik et al., 2017; Soldatov et al., 2019; Williams et al., 2019). In support of the 80 model that complex transcriptional programs govern NCC ontogenesis, gene regulatory 81 networks involved in early development of NCCs into broad cell types has been studied at a 82 high level using a combination of transcriptomics, chromatin profiling and enhancer studies, 83 especially during pre-migratory and early migratory NCC specification along cranial axial 84 regions, across amniotes (Martik et al., 2017; Simoes-Costa and Bronner, 2016; Green et al. 85 2016; Lumb et al., 2017; Williams et al., 2019; Hockman et al., 2019). For example, during pre86 migratory stages the transcription factors FoxD3, Tfap2a and Sox9 are important for NCC fate 87 specification and in turn regulate the expression of Sox 10, a conserved transcription factor that 88 is expressed along all axial levels by early migrating NCCs and within many differentiating 89 lineages (Sauka-Spengler and Bronner-Fraser, 2008; Martik et al., 2017). Gene regulatory 90 networks that are important for select NCC cell fates, like melanocytes and chondrocytes, have 91 been well characterized (reviewed in Martik and Bronner, 2017). Recently, the regulatory 92 circuitry behind glial, neuronal, and mesenchymal fates of vagal NCC was described (Ling and 93 Spengler, 2019) where Prrxl and Twistl have been described as key differentiation genes for 94 mesenchymal fate. Despite this progress, however, comprehensive knowledge of the genes that 
95 are expressed and participate in NCC lineage differentiation programs during later phases of

96 embryogenesis remains to be fully characterized, particularly for posterior tissues (reviewed in

97 Hutchins et al., 2018). Indeed, altered gene expression during NCC differentiation can cause

98 several neurocristopathies, such as DiGeorge syndrome, neuroblastoma, Hirschsprung disease,

99 Auriculo-condylar syndrome, and Klein-Waardenburg syndrome (Barlow, 1984; Bolande,

100 1997; Brosens et al., 2016; Escot et al., 2016; Vega-Lopez et al., 2017; Wang et al., 2014),

101 further highlighting the need to understand NCC spatiotemporal gene expression patterns

102 during their differentiation into diverse cellular types.

103

104 Previous single-cell transcriptomic studies in zebrafish have laid a strong foundation to globally

105 map early lineages of a majority of cell types through early to middle embryonic development

106 (Wagner et al. 2018; Tambalo et al. 2020), and recently this has been extended into the larval

107 stage (Farnsworth et al., 2020). With respect to the posterior NCC fates, however, many of

108 these cells undergo differentiation programs during the embryonic to larval transition, a

109 developmental stage that emerges between $48 \mathrm{hpf}$ to 72 hours post fertilization (hpf).

110 Transcriptomic analysis during this transitional phase therefore would enhance our

111 understanding of the dynamic shifts in cell states that may regulate cellular differentiation

112 programs.

113

114 In this study, we leverage the power of single-cell transcriptomics and curate the cellular 115 identities of sox10-expressing and sox10-derived populations along the posterior zebrafish 116 during development. We have utilized the $\operatorname{Tg}(-4.9$ sox10:EGFP) (hereafter referred to as 117 sox 10:GFP) transgenic fish line to identify NCCs and their recent derivatives (Carney et al., 118 2006). Using sox10:GFP ${ }^{+}$48-50 hpf embryos and 68-70 hpf larvae, we identified eight major 119 classes of cells: mesenchyme, NCC, neural, neuronal, glial, pigment, muscle, and otic. Among 120 the major cell types, we annotated over 40 cellular subtypes. By leveraging in depth analysis of 121 each time point separately, we remarkably captured the dynamic transition of several NCC 122 fates, most notably we discovered over a dozen mesenchymal subtypes and captured the 123 progressive differentiation of enteric neural progenitors into maturing enteric neurons. Using 124 Hybridization Chain Reaction (HCR) and in situ hybridization, we validated the spatiotemporal 125 expression patterns of various subtypes. By computationally merging our 48-50 hpf and 68-70

126 hpf datasets, we generated a comprehensive atlas of $\operatorname{sox} 10^{+}$cell types spanning the embryonic 127 to larval transition, which can also be used as a tool to identify novel genes and mechanistically 
128 test their roles in the developmental progression of posterior NCCs. Using the atlas, we

129 characterized a hox signature for each cell type, detecting novel combinatorial expression of hox

130 genes within specific cell types. Our intention is that this careful analysis of posterior NCC fates

131 and resulting atlas will aid the cell and developmental biology communities by advancing our

132 fundamental understanding of the diverging transcriptional landscape during the NCC's

133 extensive cell fate acquisition.

\section{RESULTS}

137 Single-cell profiling of sox10:GFP+ cells along the posterior zebrafish during the embryonic

\section{8 and larval stage transition}

139 To identify sox10-expressing and sox10-derived cells along the posterior zebrafish during the 140 embryonic to larval transition, we utilized the transgenic line sox10:GFP (Figure 1A) (Carney 141 et al., 2006; Kwak et al., 2013). Tissue posterior to the otic vesicle, encompassing the vagal and 142 trunk axial region (Figure 1B), was dissected from 100 embryonic zebrafish at 48-50 hpf and 143100 larval zebrafishes at 68-70 hpf. Dissected tissues were dissociated and immediately 144 subjected to fluorescence-activated cell sorting (FACS) to isolate sox10:GFP ${ }^{+}$cells (Figure 1B;

145 Figure 1-figure supplement 1A,B). Isolated cells were then input into 10X Genomics 146 Chromium scRNA-seq assays and captured at a depth of 2300 cells from the 48-50 hpf time 147 point and 2580 cells from the 68-70 hpf time point (Figure 1C; Figure 1-figure supplement 148 1C). We performed cell filtering and clustering (Figure 1-figure supplement 1D-I) of the 149 scRNA-seq datasets using Seurat (Butler et al., 2018; Stuart et al., 2019) to computationally 150 identify cell populations based on shared transcriptomes, yielding 1608 cells from the $48-50 \mathrm{hpf}$ 151 time point and 2410 cells from the $68-70 \mathrm{hpf}$ time point, totaling 4018 cells for final analysis 152 (Figure 1-figure supplement 1C). We detected cell population clusters with transcriptionally 153 unique signatures, as shown in heatmap summaries that revealed the top enriched gene 154 signatures per cluster, with 19 clusters (0-18) from the 48-50 hpf time point (Figure 1-figure 155 supplement 2A) and 23 clusters (0-22) from the 68-70 hpf time point (Figure 1-figure 156 supplement 2B), totaling 42 clusters across both time points. Datasets were visualized with the 157 t-Distributed Stochastic Neighbor Embedding (tSNE) method, which spatially grouped cells in 158 each cluster, for both time points examined (Figure 1D,E). The top significantly enriched 
159 markers for each cluster at 48-50 and 68-70 hpf are provided in a table in Figure 1-source data 1601.

161

\section{Major classification of sox10:GFP ${ }^{+}$cell states}

163 To assess the proliferative state of sox 10:GFP cells, we determined their $\mathrm{G} 1, \mathrm{~S}$ or G2/M phase 164 occupancy, based on expression of proliferative cell cycle marker genes (Figure 1-figure 165 supplement 3I). At $48-50 \mathrm{hpf}, 52 \%$ of sox 10:GFP ${ }^{+}$cells were in $\mathrm{G} 1$ phase, $31 \%$ were in the $\mathrm{S}$ 166 phase and 17\% in G2/M phase (Figure 1-figure supplement 3G), collectively indicating that $16748 \%$ of the cells in the $48-50 \mathrm{hpf}$ time point were proliferative. At $68-70 \mathrm{hpf}, 64 \%$ of cells were 168 in G1 phase, 24\% of cells were in the S phase and 12\% in G2/M phase (Figure 1-figure 169 supplement 3G), indicating that $36 \%$ of the cells were proliferative. The cell cycle occupancy 170 distributions were visualized in tSNE plots, revealing congregations of proliferative and non171 proliferative sox10: $\mathrm{GFP}^{+}$cells (Figure 1-figure supplement $\mathbf{3 A}, \mathbf{B}$ ); aurkb and mcm3 172 confirmed general occupancy in the G2/M and S phase (Figure 1-figure supplement 3C-F).

173 Together, these data of cell cycle state reflect a general decrease in proliferative cells among 174 sox 10: $\mathrm{GFP}^{+}$populations between 48 and $70 \mathrm{hpf}$, in agreement with prior observations (Rajan et 175 al., 2018).

176

177 Using a combination of gene expression searches of the literature and bioinformatics sources, 178 examination of the scRNA-seq transcriptomes indicated that sox 10: $\mathrm{GFP}^{+}$cells exist in several 179 major cell type categories. Major cell type categories were based on the presence of signature 180 marker genes (Figure 1F,G; Figure 1-figure supplement 2E,F). These major cell type 181 categories included: neural, neuronal, glial, mesenchyme, pigment cell, NCC, otic, and muscle; 182 their respective fraction of the datasets were also calculated (Figure 1D-G; Figure 1-figure 183 supplement 2C,D; Figure 1-figure supplement 3H). Neuronal refers to cells predominantly 184 expressing neuron markers, such as elavl3/4, while neural cells are defined by a multipotent 185 state with potential towards fates of either glial or neuron identity, and marked by expression of 186 factors such as sox10, dla and/or ncamla.

187

188 Notably, mesenchyme tissue identity among clusters represented the largest proportion of the 189 datasets at $61 \%$ and $53 \%$ of the cells at 48-50 and 68-70 hpf, respectively (Figure 1-figure 190 supplement 3H). Mesenchyme clusters were identified by a combination of mesenchymal gene 191 markers, including: snaila/b, twistla/b, prrxla/b, meoxl, foxcla/b, cdh11, sparc, colec12, 
192 and/or pdgfra, as recently described in amniotes (Soldatov et al., 2019). Pigment cell 193 development markers tyrpla/b, dct, and mitfa were expressed in 5\% of the 48-50 hpf dataset 194 and increased to 14\% at 68-70 hpf (Figure 1-figure supplement 3H), during which time the 195 pigment cells diverged and expanded into distinct chromatophore lineages, as discussed further 196 in Figure 2. A NCC cluster, Cluster 5 at 48-50 hpf, which we also discuss further in Figure 4, 197 was identified by the combined expression of sox10, crestin, foxd3, ngfrb, and tfap2a. Cells 198 with an otic vesicle and muscle signature were also detected (Figure 1D-G; Figure 1-figure 199 supplement 3H; Figure 1-figure supplement 5), as has previously been described in the 200 sox10:GFP line (Carney et al., 2006; Rajan et al., 2018; Rodrigues et al., 2012; Kwak et al., 201 2013). Overall, major cell type cluster identities and top signature marker genes are 202 summarized in a table in Figure 1-figure supplement 4.

203

\section{Annotation of posterior sox10:GFP cell subtypes}

205 Analysis of the 42 cluster gene signatures among the two time points revealed distinct 206 subpopulations of posterior sox 10: $\mathrm{GFP}^{+}$cells and their transcriptomes in the developing 207 zebrafish. Indeed, we identified previously described sox10-derived cell subtypes. The 208 sox 10:GFP line has been shown to transiently label sensory dorsal root ganglion (DRG) 209 progenitors between the $1^{\text {st }}$ and $2^{\text {nd }}$ day of development (McGraw et al., 2008; Rajan et al., 210 2018). We observed sensory neuronal/DRG gene expression in Cluster 17 at 48-50 hpf (Figure 211 1-figure supplement 4; Figure1-figure supplement 6) by the markers neurod1, neurod4, 212 neurog1, sixla/b, elavl4 (Carney et al 2006; Delfino-Machín et al., 2017). In addition, the 213 scRNA-seq transcriptome datasets at both time points exhibited gene expression indicative of 214 previously described NCC-derived lineages (summarized in Hutchins et al., 2018) including 215 mesenchymal cells (Le Lievre and Le Douarin, 1975; Kague et al., 2012; Soldatov et al., 2019; 216 Ling and Sauka-Spengler, 2019), pigment cells (Reedy et al., 1998; Higdon et al., 2013), and 217 enteric neurons (Kelsh and Eisen, 2000; Kuo and Erickson, 2011; Lasrado et al., 2017), which 218 we describe in further detail for both time points in Figures 2-5.

\section{Identification of pigment cell chromatophore lineages}

221 With robust genetic lineage details published on pigment cell differentiation in zebrafish 222 (Kelsh, 2004; Lister, 2002; Quigley and Parichy, 2002), we sought to validate our scRNA-seq 223 analysis by assessing if we could resolve pigment cell gene expression states. Pigment cell 224 development has been broadly studied in the developing zebrafish, where NCCs give rise to 
225 three distinct chromatophore populations: melanophores, xanthophores, and iridophores

226 (Figure 2A). Melanophores, the best characterized population, express a combination of

227 markers throughout their development including mitfa, dct, tyrpla/b, and pmela (Du et al.,

228 2003; Lister et al., 1999; Ludwig et al., 2004; Quigley and Parichy, 2002). Similarly, the genes

229 pnp4a, tfec, gpnmb, and atic are all enriched in iridophores and are critical for their maturation

230 (Higdon et al., 2013; Lister et al., 2011; Petratou et al., 2018, 2019). Finally, differentiating

231 xanthophores express gch2, pax7a/b, xdh, mitfa, and aox5 (Nord et al., 2016; Parichy et al.,

232 2000; Saunders et al., 2019; Minchin and Hughes, 2008; Lister et al., 1999).

233

234 Our cluster analysis of sox 10:GFP ${ }^{+}$single cell datasets revealed the robust presence of pigment

235 cell lineages (Figure 2B-J; Figure 1-figure supplement 2). At 48-50 hpf, melanophores were

236 detected in Cluster 8 based on expression of mitfa, dct, tyrplb, and pmela (Figure 1F; Figure

237 2A), reflected by the dot and tSNE plots (Figure 2B,C). At 68-70 hpf, we resolved discrete

238 pigment cell populations that included xanthophore, iridophore, and two distinct melanophore

239 clusters (Figure 2D-G, Figure 1-figure supplement 4). The xanthophores mapped to Cluster

24015 and were enriched with $x d h$, aox5, pax7b, mitfa, and gch2 (Figure 2A,D,F). Cluster 16 was

241 identified as iridophores, which presented the well characterized markers: tfec, pnp4a, gpnmb,

242 and atic (Figure 2A,D,G; Figure 1-figure supplement 4).

243

244 The use of cell cycle markers revealed that two different melanophore clusters at 68-70 hpf

245 (Clusters 4 and 18) were present in different proliferative states. While the majority of cells in

246 Cluster 4 were in G1, Cluster 18 contained the presence of S and G2/M markers, such as pcna

247 and $a u r k b$, suggesting that this population is proliferating melanophores (Figure 1-figure

248 supplement 3B,E,F; Figure 2-source data 1). These data corroborate and extend previous

249 observations where melanophores in distinct proliferative and differentiating states have been

250 described during the larval stage at 5 days post fertilization (dpf) (Saunders et al., 251 2019). Overall, genes shared between Cluster 4 and Cluster 18, as well as their unique genes,

252 are summarized in Figure 2-source data 1.

253

254 At 68-70 hpf, we were able to identify a pigment progenitor population, where iridophore and 255 melanophore markers were co-expressed in Cluster 13: an irido-melano progenitor (Figure 256 2A,D). These undifferentiated pigment progenitor cells express $t f e c$ in combination with mitfa 257 and have been described recently at 24, 30, and $48 \mathrm{hpf}$ (Petratou et al. 2018). Additionally, 
258 Cluster 13 expressed tfap2e, gpx3, and trpm1b (Figure 1-figure supplement 4) whose 259 expression patterns have been previously reported in pigment progenitors (Saunders et al., 260 2019). Finally, a population of pigmented muscle (Cluster 9) was also found with a weak 261 melanophore signature coupled with expression of the muscle markers $c k m b$, tpma, tnnc2 and 262 tnnt3b (Figure 1-figure supplement 4; Figure 1-figure supplement 5).

264 We next performed whole mount HCR to assess the spatial expression of mitfa, tfec and $x d h$, 265 and to validate the sox10:GFP datasets. When examining mitfa and tfec at 48-50 hpf (Figure $266 \mathbf{2 H}$ ), we detected $\mathrm{GFP}^{+}$cells that expressed mitfa, identifying the melanophores (Figure 2H; 267 white arrowhead), and cells that expressed both mitfa and tfec, defining the pigment progenitors 268 (Figure 2H; red arrowhead). At 68-70 hpf, we confirmed the four distinct pigment populations 269 we identified through Seurat (Figure 2B-G): GFP $^{+}$melanophores expressing mitfa only 270 (Figure 2I; white arrowhead), iridophores only expressing tfec (Figure 2I; blue arrowhead), 271 and pigment progenitors expressing both mitfa and tfec (Figure 2I; red arrowhead) were 272 detected. When examining $x d h$ and mitfa expression patterns, $\mathrm{GFP}^{+}$xanthophores were found to 273 be expressing both markers (Figure 2J; orange arrowhead).

274 Taken together, these results show that the scRNA-seq datasets effectively identify discrete 275 subpopulations, and coupled with our HCR analysis, effectively shows we are able to validate 276 these cell populations in vivo.

\section{Mesenchyme in the posterior embryo and larvae exists in various subpopulations}

279 Heatmap analysis of gene expression groups depicted that mesenchyme cells clustered together 280 globally within the datasets (Figure 1-figure supplement 2C,D; Figure 3A,B), with twistla 281 expression broadly labeling all mesenchyme cells (Figure 1-figure supplement 2E,F). In 282 addition to twistla, mesenchyme cells also expressed prrxla/b, twistlb, foxcla/b, snaila/b, 283 cdh11, sparc, colec12, meoxl, pdgfra (Figure 3A,B), and other known mesenchymal markers 284 such as mmp2 (Figure 1-figure supplement 4) (Janssens et al., 2013; Theodore et al., 2017). In 285 whole mount embryos at $48 \mathrm{hpf}$, we observed broad expression of foxcla and mmp2 along the 286 posterior pharyngeal arches and ventral regions of the embryo via in situ hybridization (Figure 287 3-figure supplement 1C,D; arrowheads), confirming their expression territories within 288 posterior-ventral mesenchymal tissues. 
290 Analysis of the mesenchyme clusters revealed various subtypes were present in the scRNA-seq

291 datasets. Among these, we detected 9 chondrogenic cell subtypes-identified by expression of

292 mesenchymal signature genes, as well as the chondrogenic markers barxl and/or $d l x 2 a$ (Sperber

293 et al., 2008; Sperber and Dawid, 2008) (Figure 3C,D). All chondrogenic clusters expressed

294 barxl, regardless of the time point, which is expressed in developing mesenchymal tissues and

295 required for development of osteochondral progenitor cells and their tissue condensation therein

296 (Sperber et al., 2008; Sperber and Dawid, 2008; Ding et al., 2013; Barske et al., 2016). Within

297 the 9 chondrogenic subtypes, we discovered genes indicative of heterogeneous cell states;

298 ranging from proliferative, progenitor/stem-like, migratory to differentiating signatures (Figure

299 1-figure supplement 4).

300

301 All other mesenchyme subtypes were classified into various progenitor and differentiation

302 categories. Among these categories, 7 clusters expressed either proliferative progenitor markers,

303 differentiation signatures, or general migratory mesenchymal markers (Figure 1-figure

304 supplement 4). Additionally, Cluster 14 at $48 \mathrm{hpf}$ and Clusters 1 and 7 at 68-70 hpf exhibited a 305 general mesenchymal signature, but also expressed fin bud marker genes (hand2, tbx5a, 306 hoxd13a, prrxla) (Figure 1-figure supplement 6) (Yelon et al., 2000; Lu et al., 2019, 307 Nakamura et al., 2016; Feregrino et al., 2019). The fin bud cells formed distinct groupings, as 308 depicted in tSNE analysis (Figure 1-figure supplement 6).

310 Visualization of clusters with general mesenchyme and chondrogenic identities using a cluster 311 tree further highlighted potential similar subtypes between the time points (Figure 3C). For 312 example, the cluster tree showed proximal location of Cluster 8 at 68-70 hpf and Cluster 2 at 313 48-50 hpf, which we noted contained clear proliferative chondrogenic gene signatures (Figure 314 3D; Figure 1-figure supplement 4). Further, the tree depicted the closeness of Cluster 1 and 6 315 at 48-50 hpf with Cluster 2 at 68-70 hpf. These clusters present with varying 316 proliferative/migratory/differentiation states, suggesting that transcriptionally-related 317 mesenchymal cells captured in our datasets were in various stages of dynamic differentiation, 318 proliferation, and migration.

319

320 Feature plot exports confirmed that a sub-population of chondrogenic cells $\left(\right.$ barx $\left.I^{+}\right)$were 321 present in relation to all other mesenchyme $\left(\right.$ prrx $1 b^{+}$, twist $\left.1 a^{+}\right)$cells in the datasets (Figure 322 3E,L). To confirm the spatial co-expression of prrxlb, twistla, and barxl at 48-50 hpf and 68- 
32370 hpf, we utilized HCR analysis (Figure 3F-K,M-R). The expression of prrxlb, twistla, and

324 barxl was seen within sox10:GFP cells along the posterior pharyngeal arches (white 325 arrowheads) and fin bud mesenchyme (yellow arrowheads) at both time points (Figure 3F-

326 K,M-R). While prrxlb and twistla labeled the arches and fin buds (Figure 3F,H,M,O), barxl 327 was observed in the arches, but not the fin buds (Figure 3I,G,P,N).

328

329 Overall, these analyses reveal great diversity among the mesenchyme and suggest that 330 mesenchymal cells in the posterior zebrafish exist in various subpopulations and exhibit 331 dynamic transcriptional states during their development. Furthermore, these results show that 332 our dataset analysis can pinpoint previously unknown discrete sox10 subpopulations.

334 sox10-derived cells during the embryonic to early larval transition reveal enteric progenitor 335 to enteric neuron progression

336 At 48-50 hpf, cells with NCC identity gene signatures were notably detected in Cluster 5, 337 defined by expression of the core markers sox10, foxd3, crestin, and tfap2a (Figure 1F; Figure 338 4A, Figure 1-figure supplement 4) (Dutton et al., 2001; Luo et al., 2001; Knight et al., 2003; 339 Stewart et. al., 2006). In addition to the core genes, Cluster 5 cells also contained genes 340 previously shown to be expressed in zebrafish NCCs; including vim, snailb, sox9b, zeb2a, 341 mych, and mmp17b (Figure 4D) (Cerdà et al., 1998; Heffer et al., 2017; Hong et al., 2008; 342 Leigh et al., 2013; van Otterloo et al., 2012; Wang et al., 2011; Rocha et al., 2020). We 343 reasoned that many of the NCCs had started their respective differentiation programs and were

344 beginning to assume specified genetic profiles. Therefore, we sought to determine if the NCC 345 cluster also contained gene expression profiles of known differentiating NCC types along the 346 posterior body, such as enteric progenitors, also known as enteric neural crest cells (ENCCs).

348 During NCC diversification, ENCCs fated to give rise to the enteric nervous system (ENS) 349 express a combination of NCC and enteric progenitor marker genes over developmental time 350 (reviewed in Nagy and Goldstein, 2017; Rao and Gershon, 2018), which occurs between 32 to $35172 \mathrm{hpf}$ in zebrafish (reviewed in Ganz, 2018). Enteric markers in zebrafish include sox10, 352 phox2bb, ret, gfrala, meis3, and zeb2a (Dutton et al., 2001; Shepherd et al., 2004; Elworthy et 353 al., 2005; Delalande et al., 2008; Heanue and Pachnis, 2008; Uribe and Bronner, 2015). Given 354 the developmental timing of early ENS formation in zebrafish as occurring between 32 to 72 355 hpf, we expected to capture a population of ENCCs within our 48-50 hpf dataset. Indeed, within 
356 Cluster 5 we observed expression of the enteric markers phox $2 b b$, ret, gfrala, meis3, sox 10, and 357 zeb2a (Figure 4B-D). Using whole mount in situ hybridization, we confirmed the expression of 358 sox 10 and phox $2 b b$ within ENCCs along the foregut at $48 \mathrm{hpf}$ (Figure 3-figure supplement 359 1A,A',B,B'; arrowheads). Furthermore, gene orthologs known to be expressed in ENCC in 360 amniotes were detected within Cluster 5, such as ngfrb (orthologue to p75) (Anderson et al., 361 2006; Wilson et al., 2004) and hoxb5b (orthologous to Hoxb5) (Kam and Lui, 2015) (Figure 362 4B-D).

363

364 HCR analysis of $48 \mathrm{hpf}$ embryos validated the co-expression profiles of several ENCC markers 365 along the foregut (Figure 4E-F; foregut in grey box). Co-expression analysis demonstrated that 366 a chain of crestin $^{+}$cells localized in the foregut contained a subpopulation of cells expressing $367 n g f r b$, phox $2 b b$, and gfrala (Figure 4E; white arrowheads), or expressing foxd3, ngfrb, and 368 gfrala (Figure 4F; white arrowheads). Together, these HCR data reveal a subpopulation of 369 ENCCs within the zebrafish gut, confirming ENCC markers are co-expressed.

371 We next asked if we could resolve discrete differentiating enteric neurons over time. In 372 zebrafish, by $72 \mathrm{hpf}$ ENCCs have migrated throughout the length of the gut and begun early 373 neuron differentiation and neural patterning (Elworthy et al., 2005; Olden et al., 2008; Harrison 374 et al., 2014; Uribe and Bronner, 2015; Taylor et al., 2016). During early neuronal 375 differentiation, ENCCs display differential enteric progenitor gene expression patterns (Taylor 376 et al., 2016) and neurochemical signatures representative of varying stages of neuronal 377 differentiation and subtype diversification (Poon et al., 2003; Holmqvist et al., 2004; 378 Uyttebroek et al., 2010). Zebrafish early differentiating enteric neurons have been characterized 379 by the RNA expression of sox 10 , phox $2 b b$, gfrala, fgfl3b, and ret, as well as the 380 immunoreactivity of Elav13/4 (Shepherd et al., 2004; Heanue and Pachnis, 2008; Uyttebroek et 381 al., 2010; Taylor et al., 2016). In addition, at this time, enteric neurons express multiple 382 neurochemical markers, with Nos1 being most prominent (Olden et al., 2008; Uyttebroek et al., 383 2010), a finding consistent with studies performed within the amniote ENS (Hao and Young, 384 2009; Matini et al., 1995; Qu et al., 2008; Heanue et al., 2016). In light of these previous 385 observations, our 68-70 hpf dataset was expected to contain the transcriptomes of ENCCs 386 captured at various stages of their progressive differentiation into the diverse subtypes of the 387 ENS. 
389 tSNE analyses identified differentiating enteric neurons within the 68-70 hpf dataset based off 390 of the combinatorial expression of elavl3, phox 2bb, ret, and gfrala (Figure 4G), which mapped 391 to the neural/neuronal major cell type regions of the dataset (Figure 1E), comprising Clusters 5 392 and 12 (Figure 1E). Transcripts that encode for the neurochemical marker nosl, and the 393 neuropeptides vip and viph, a paralogue to vip (Gaudet et al., 2011), were found in a 394 subpopulation of enteric neurons localized to a distal group of the neuronal cluster, likely 395 indicative of a differentiating enteric neuron subtype (Figure 4G; red arrows). We then queried 396 for the presence of a combination of pan-neuronal and enteric neuron markers (Figure 4H). The 397 pan-neuronal markers tuba2, elavl3, stxlb, and gng2/3, as well as the autonomic neuron 398 markers, phox2a and phox2bb (Gou et al., 2018; Hans et al., 2013), were present in both 399 Clusters 5 and 12 (Figure 4H). However, the enteric neuron markers, gfrala, ret, hoxb5b, 400 ngfrb, fgfl3b, nosl, vipb, and vip were mostly confined to Cluster 12, suggesting that this 401 cluster contained differentiating enteric neurons (Figure 4H). Indeed, whole mount HCR 402 analysis validated the spatiotemporal expression of phox $2 b b$, nos 1 , vipb, and elavl3 transcripts 403 throughout the foregut of the zebrafish embryo by $69 \mathrm{hpf}$ (Figure 4I; yellow arrowheads). 404 These results suggest that elavl3 $3^{+}$phox $2 b b^{+}$early differentiating enteric neurons in the foregut 405 display an inhibitory neurochemical signature, consistent with prior observations in zebrafish 406 and mammalian ENS (Olden et al., 2008; Hao and Young, 2009).

407

408 In an effort to examine the enteric neuron populations with finer resolution, Clusters 5 and 12 409 were subset from the main dataset in Seurat, re-clustered and visualized using a tSNE plot, 410 producing 5 new clusters (Figure 5A). The gene markers from each new Sub-Cluster are 411 provided in Figure 5-source data 1. Following this, the previously mentioned enteric neuron 412 markers, with the addition of etvl, a recently identified marker of enteric intrinsic primary 413 afferent neurons (IPANs) in mouse (Morarach et al., 2020), were queried and visualized using 414 dot and feature plots allowing the identification of Sub-Cluster 3 as a differentiated enteric 415 neuron cluster (Figure 5A-C). nos1, vipb and vipb were enriched in Sub-Cluster 3 (Figure 416 5B,C; Figure 5-figure supplement 1). Interestingly, while expressed at lower average levels 417 than in Sub-Cluster 3, the enteric combination markers were also present in Sub-Cluster 1 418 (Figure 5B-C). Sub-Cluster 1 formed a central point from which Sub-Cluster 3 could be seen 419 emanating as a distal population (Figure 5A). Given the developmental timing, this is likely 
420 depicting enteric neurons captured at different stages along their progressive differentiation,

421 which would suggest that the distal most population represents the more mature enteric neurons.

422

423 Given our hypothesis that the enteric neurons further along a differentiation program were

424 localized to the distal tip of Sub-Cluster 3, we asked whether this population of cells contained

425 additional neurochemical or neuron subtype specific differentiation genes. As expected, a small

426 pocket of these cells was found to contain the two acetylcholine associated genes, acetylcholine

427 esterase (ache) (Bertrand et al., 2001; Huang et al., 2019) and vesicular acetylcholine

428 transferase (slc18a3a) (Hong et al., 2013; Zoli, 2000) (Figure 5E; red arrowheads). Within

429 Sub-Cluster 3, we detected the expression of calb2a and $p b x 3 b$ (Figure 5D-E; Figure 5-figure

430 supplement 1), two genes that have previously been shown to denote myenteric IPANs in

431 mammals (Furness et al., 2004; Memic et al., 2018). Corroborating our single-cell findings,

$432 \mathrm{HCR}$ analysis revealed the co-expression of $p b x 3 b$, calb2a, vipb, nos1, and slc18a3a in discrete

433 differentiating enteric neurons within the foregut region of the zebrafish gut at 68 hpf (Figure

434 5G). In particular, calb2a, vipb, nos1, and slc18a3a were all found to be co-expressed (Figure

435 5G; yellow arrowheads). While $p b x 3 b$ expression was found in combination with calb2a, vipb,

436 and nos1 (Figure 5G; white arrowheads), we were unable to observe detectable levels of

437 slc18a3a within the $p b x 3 b$ expressing cells. Taken together, these results regarding enteric

438 neuron subpopulation gene expression patterns suggest a model (Figure 5F), whereby nos 1 ,

$439 v i p b$, calb2a, and $p b x 3 b$ are co-expressed within early enteric neurons, and that through lineage-

440 restricted gene expression, $p b x 3 b$ expression may promote the assumption of an IPAN signature

441 characterized by the presence of $c a l b 2 a$, ache, and slc18a3a and the loss of inhibitor markers

442 nos1 and vipb. Therefore, our single-cell analysis in zebrafish suggests that the transcriptional

443 emergence of specific enteric neuron subtypes may be conserved between vertebrate species.

445 In order to identify the presence of novel gene pathways within the developing enteric neuron 446 population, the significantly enriched gene list from Sub-Cluster 3 was processed using gene 447 ontology (GO) pathway enrichment analysis. We found that three opioid signaling pathways 448 were among the top 10 highest fold enriched pathways (Figure 5-source data 2) (Mi et al., 449 2019). Further investigation into these pathways led to the identification of G-protein-coupled 450 receptors, oprl1 and oprd1b, respectively representing nociception/orphan FQ (N/OFQ) peptide 451 (NOP)-receptor and delta-opioid receptor (DOR) subtype members within the opioid receptor 452 superfamily (Figure 5H) (Donica et al., 2013; Sobczak et al., 2014). Specifically, feature plots 
453 showed that the expression of the opioid receptors was tightly confined within the pocket of 454 enteric neuron progenitors we identified as undergoing sensory lineage-specification, 455 suggesting the expression of opioid receptor genes within both excitatory and inhibitory 456 neurons at the early stages of enteric neuron differentiation within the zebrafish ENS (Figure 457 5E and H). Confirming this suggestion using HCR analysis, we observed the combinatorial 458 expression of oprl1, vipb and phox $2 b b$ within migrating enteric neuron progenitors at 68 hpf 459 along the foregut (Figure 5I-N). The presence of opioid receptors within immature enteric 460 neurons undergoing lineage-specification helps us to better understand the complexity of early 461 ENS signaling and highlights an area that requires further investigation.

462

463 Based on our observation that the enteric neuron population that comprised Sub-Cluster 3 only 464 made up one of five phox $2 b b^{+}$Sub-Clusters (Figure 5A-C), we suspected that the remaining 465 Sub-Clusters were made up of closely related autonomic neurons. In order to better visualize 466 specific differences between the Sub-Clusters, we viewed them using UMAP (Becht et al., 467 2019; Mcinnes et al., 2018) (Figure 5-figure supplement 2). While the identity of the previous 468 tSNE Sub-Clusters were maintained, UMAP analysis allowed us to better visualize the 469 separation between the Sub-Clusters, which we were able to broadly classify as autonomic 470 neurons based on their shared expression of asclla, hand2, phox $2 a$ and phox $2 b b$ (Figure 5-

471 figure supplement $\mathbf{2 A , B}, \mathbf{D})$. Within the population of autonomic neurons, we were able to 472 distinguish a population of sympathetic neurons within Sub-Cluster 2 based on their 473 combinatorial expression of $t h$, $d b h$, lmol and insmla (Figure 5-figure supplement 2B,E), 474 which could be clearly distinguished from the enteric neuron Sub-Cluster 3 (Figure 5-figure 475 supplement $\mathbf{2 B}, \mathbf{F})$. Using a cluster tree, we were able to confirm the distinction between enteric 476 neuron Sub-Cluster 3 and sympathetic neuron Sub-Cluster 2 (Figure 5-figure supplement 2C).

477 Overall, these results suggest that Sub-Cluster 0 cells may represent a pool of immature 478 sympatho-enteric neurons, and that Sub-Clusters 1 and 4 both represent better resolved, yet still 479 immature, pools of enteric and sympathetic neurons.

480

481 Atlas of sox10:GFP ${ }^{+}$cell types encompassing the embryonic-to-larval transition

482 To describe the dynamic relationship between sox 10: $\mathrm{GFP}^{+}$cells across both time points, we 483 merged the 48-50 hpf and 68-70 hpf datasets using Seurat's dataset and Integration and Label 484 Transfer utility (Stuart et al., 2019). The merged datasets were visualized via UMAP, which 485 allowed us to describe the transition between cell types by making both inter- and intra-cluster 
486 comparisons. From the merged datasets, we detected 27 clusters (Figure 6-figure supplement

487 1A). We observed that every cluster identified in the 48-50 hpf dataset mapped proximally to 488 clusters at 68-70 hpf (Figure 6-figure supplement 2A). We labeled each cell using the major 489 cell type categories: neural, neuronal, glial, NCC, pigment, mesenchyme, otic, and muscle, 490 forming a major cell type atlas (Figure 6-figure supplement 1B). Further refinement of the cell 491 identities based on our previous curation (Figure 1-figure supplement 2) allowed us to form a 492 higher resolution atlas for each cell type (Figure 6A). The genes for each major cell type 493 category in the atlas is provided in Figure 6-source data 1.

494

495 The overall architecture of the UMAP revealed that the cells of each major cell type 496 congregated together, strongly supporting that our formerly described characterizations of each 497 time point are accurate and predictive. For example, cells with mesenchyme identity 498 constellated together, forming three large mesenchyme regions in the atlas: general, 499 chondrogenic, and fin bud (Figure 6A,B). NCCs mapped precisely to the top end of a 500 neural/neuronal region of the atlas, while differentiating neurons positioned at the base (Figure 501 6A,D). Additionally, pigment cell types aligned adjacent to one another in the atlas (Figure 502 6А,C).

503

504 Comparison of individual subsets of clusters provided deeper analysis of each cell type, with 505 respect to changing cell states across time. We examined three of the largest regions of the atlas 506 in detail: mesenchyme, pigment, and neural/neuronal cell types. We observed consistency 507 across the larger mesenchyme population, which excluded the fin bud mesenchyme, in both the 508 cluster identity shown in the UMAP and gene expression profiles. For example, 48h-Cluster 2 509 and 68h-Cluster 8 both showed a very high degree of similarity, as well as consistent barxl, $510 d l x 2 a$, and twistla expression (Figure 6B), consistent with our prior analysis (Figure 511 3C,D). The central node of the pigment region within the atlas was marked by the 48 h-Cluster 512 8, which resolved into respective pigment chromatophore clusters at 68-70 hpf (Figure 6C). 513 We were able to globally discern that pigment cell types displayed expression of sox10, 514 regardless of time point. As expected from our previous analysis, we observed the early 515 specified melanophore population at 48h-Cluster 8 branched into later stage melanophore 516 populations (68h-Clusters 4 and 18), both of which expressed mitfa and $d c t$. Further, we 517 observed that the common bi-potent pigment progenitor population (68h-Cluster 13) bridged 518 both melanophore clusters and the iridophore $68 \mathrm{~h}-$ Cluster 16 . This nested positioning of $68 \mathrm{~h}-$ 
519 Cluster 13 supports its dual progenitor identity. Xanthophores, marked by $x d h$, segregated

520 tightly away from the remaining pigment populations, reflective of their earlier and distinct

521 lineage (Figure 2A).

522

523 Cells within the neural/neuronal clusters of the atlas assembled such that progenitor cells

524 bridged into differentiating neurons spatially from the top to the bottom of the neural/neuronal 525 region of the atlas (Figure 6D). 6 clusters (Clusters 0, 5, 7, 13, 15, 17) were represented from 526 48-50 hpf, and 5 clusters (Clusters 3, 5, 10, 12, 14) from 68-70 hpf. The 68-70 hpf neural 527 progenitor populations (Clusters 3 and 10) shared common gene expression with the 48-50 hpf 528 NCC population (48h-Cluster 5), reflected largely by their co-expression of sox10, notchla, dla, 529 and foxd3 (Figure 6D; Figure 6-figure supplement 1D). We confirmed the spatiotemporal 530 expression domains of notchla and dla along the hindbrain, spinal cord, and in NCC 531 populations along the post-otic vagal domain at $48 \mathrm{hpf}$ (Figure 3-figure supplement 1E,F; 532 arrowheads), in particular with $d l a$ in the ENCCs along the foregut (Figure 3-figure 533 supplement 1F; arrow), a pattern similar to the ENCC makers sox10 and phox2bb (Figure 3534 figure supplement $\mathbf{1 A , B}$ ). Delineated from the neural progenitor cells, we observed a 535 bifurcation in cell states; with one moving towards a Schwann/glial cell fate, while the other 536 branched towards neuronal. The glial arm followed a temporal progression of earlier cell fates 537 at $48-50 \mathrm{hpf}$ (48h-Cluster 15) toward the more mature fates at 68-70 hpf (68h-Cluster 14), both 538 denoted by expression of olig2 and pou3f1, respectively (Figure 6D). From 48h-Cluster 13, we 539 observed the beginning of the neuronal populations, namely $48 \mathrm{~h}$-Clusters $0,7,13$, and 17 and 540 68h-Clusters 5 and 12. Cells in these clusters patterned in the atlas UMAP such that the 541 progenitor clusters (48h-Clusters 0, 13, and 17; 68h-Cluster 5) formed a spectrum of cell states 542 leading toward the neuronal populations (48h-Cluster 7; 68h-Cluster 12). Among the neuronal 543 populations, we observed a clear autonomic signature, indicated by phox $2 a$ and phox $2 b b$ 544 (Figure 6D; Figure 6-figure supplement 1D). We also detected a large fraction of enteric 545 progenitors, indicated by $r e t$, $n g f r b$, and $h o x b 5 b$ expression, (Figure 6D; Figure 6-figure 546 supplement 1D) supporting our previous observations (Figure 4,5). The enteric progenitors 547 culminated into a pool of enteric neurons, with the specific neural signature: vipb, nosl, gfrala, $548 f g f 13 b$, and $e t v 1$ (Figure 6D; Figure 6-figure supplement 1D).

550 Closer inspection of the pigment, mesenchymal, and neural/neuronal clusters separated by 551 time highlighted both predicted and novel changes in gene expression patterns (Figure 6 - 
552 figure supplement 2). Analysis of each of these sub-setted cell type lineages revealed temporal 553 differences between the two stages, as clearly exemplified in the pigment subcluster (Figure 6 -

554 figure supplement 2B). For example, the xanthophore differentiation marker $x d h$ demonstrated 555 restricted expression to 68-70hpf. Further, we identified genes with no known roles in pigment 556 cell development differentially expressed between the two sages, such as rgs 16 and SMIM18.

557 Within the mesenchyme lineages, both barxl and snailb followed expected temporal 558 expression trends, while abracl and idl both demonstrated novel differential gene expression 559 profiles within the mesenchyme (Figure 6 - figure supplement 2C). Lastly, the 560 neural/neuronal lineage showed expected differential gene expression of genes such as etvl and 561 vipb, while revealing novel expression of nova2 and zgc:162730, which have previously 562 uncharacterized roles in sox10-derived cells (Figure 6 - figure supplement 2D). Together, 563 these findings demonstrate the power of the sox10 atlas not only at cataloguing lineages, but 564 also at characterizing novel gene expression changes across developmental stages.

565

566 A hox gene signature within sox10-derived cells in the posterior zebrafish

567 A common theme examined by many recent and insightful single cell profile studies of the 568 NCC (Dash and Trainor, 2020; Soldatov et al., 2019) is that patterns of Homeobox transcription 569 factors, known as hox genes, display discrete expression between various cell lineages, such as 570 in the cranial NCC. We wondered whether specific hox signatures were expressed within 571 posterior NCC and their recent derivatives. To analyze if we could detect hox gene patterns 572 within the atlas, we queried all the known canonical hox genes within zebrafish as listed on 573 zfin.org (Ruzicka et al., 2019). We detected broad expression of 45 of the 49 zebrafish hox 574 genes across the atlas, with $85 \%$ of the cells in the atlas expressing at least one hox gene 575 (Figure 7-figure supplement 1A,J). The four undetected hox genes (hoxcla, hoxcl2b, 576 hoxalla, and hoxa3a) were not examined further.

577

578 A dot plot revealed that specific hox gene expression patterns demarcated distinct tissues, with 579 specific robustness in the neural fated cells (Figure 7A). Common to the neural lineages, we 580 observed a core hox profile which included hoxb1b, hoxcla, hoxb2a, hoxb3a, hoxc $3 a$, hoxd3a, 581 hoxa4a, hoxd4a, hoxb5a, hoxb5b, hoxc5a, hoxb6a, hoxb6b, and hoxb8a (Figure 7A). One of 582 the top expressed constituents of the core signature, hoxa4a, was also widely expressed in 583 several other lineages (Figure 7A; Figure 7 - figure supplement 10). The hox signature 584 applied to the NCC, neural progenitor, enteric progenitor, enteric neuron, glial progenitor, 
585 autonomic neuronal progenitor, and CNS lineages described in the atlas. Clustering of all the 586 atlas lineages relying only on hox gene expression highlighted the robustness of the core hox

587 signature to distinguish the neural lineage fates, grouping the differentiating (autonomic 588 neuronal progenitors, enteric neurons, and enteric progenitors, and CNS neurons) and 589 progenitor (neural progenitors and glial progenitors) lineages into neighboring clades (Figure 590 7B). Building on the core neural signature unifying the neural fates, slight variations in hox 591 expression between autonomic and enteric lineages distinguished them from one another, which 592 are summarized in Figure 7E. Most notably, considering the lineages in increasing specificity 593 of cell fate, there was a detectable shift in hox expression among the autonomic neural 594 progenitors to the enteric neuronal lineage, demarcated by the increase in hoxb $2 a$, hoxd4a, 595 hoxa $5 a$, hoxb5a, and hoxb5b, accompanied by diminished expression of hoxc $3 a$, hoxc $5 a$, 596 hoxb6a and hoxb8a, which formed a distinctive enteric hox signature (Figure 7 - figure 597 supplement 1 A, K-N).

598

599 In order to better understand the complexities of hox codes within specific lineages, we 600 performed a pairwise comparison of each hox gene for autonomic and enteric lineages, counting 601 the number of cells which coexpressed each hox pair. Examining the autonomic neuronal 602 progenitors (Figure 7C) and the enteric neuron populations (Figure 7D), both lineages 603 demonstrated pervasive fractions of co-positive cells for combinations of the core hox signature. 604 For example, autonomic neuronal cells were enriched with a high fraction of pairwise 605 combinations for hoxcla, hoxa4a, hoxb3a, and/or hoxb5b (Figure 7C). The enteric signature 606 was highly enriched in the unique expression of hoxa $5 a$, with co-expression for hoxb5a (36\%) 607 and hoxb5b (36\%), as well as strong co-expression of hoxd4a or hoxb5a with hoxb5b (Figure 608 7D).

609

610 To confirm that hox core genes were co-expressed within enteric neurons, we sought to validate 611 their co-expression patterns using HCR probes. As previously described, hoxd4a, hoxa5a, $612 h o x b 5 a$, and hoxb5b all exhibited strong hindbrain expression (Figure 7 - figure supplement 1

613 B-I) (Barsh et al., 2017), confirming the specificity of our probes. At 70-72 hpf, as predicted by 614 our analysis, enteric neurons along the level of the midgut, marked by phox $2 b b$ expression 615 (Figure 7 F,J), were hoxb5a $a^{+} / \operatorname{hoxb}^{+} b^{+}$(Figure 7 G-I) and hoxd $4 a^{+} / h o x a 5 a^{+}$(Figure 7 K-M).

616 These data confirm that enteric neurons co-express enteric hox code genes during their early 617 development. 
619 With respect to the remaining cluster identities (Figure 7A), many of the populations showed

620 varied hox expression profiles. Both the chondrogenic and general mesenchyme clusters

621 demonstrated hoxa2b expression, as well as weak expression for hoxb2a, hoxb3a, and hoxd4a.

622 Our detection of these hox expression profiles was consistent with prior reports that they are

623 expressed within NCC targets toward the posterior pharyngeal arches, as well as migrating 624 NCC (Minoux and Rijli, 2010; Parker et al., 2018, 2019). We detected the distinct identity of 625 the fin bud mesenchyme (Ahn and Ho, 2008; Nakamura et al., 2016 ) through the expression of 626 hoxa9b, hoxal0b, hoxal1b, hoxa13b, hoxd9a, and hoxd12a (Figure 7A; Figure 7 - figure 627 supplement 1 P-Q). The pigment populations, including the pigment progenitors, 628 melanophores, iridophores, and xanthophores, contained generally low levels of hox gene 629 expression. Despite this, we still observed a slight variation of hox expression among the 630 pigment populations. For example, low levels of hoxa $4 a$, hoxb7a, hoxb8a, hoxc $3 a$, and hoxd $4 a$ 631 were detected among the iridophore population, while only hoxb7a was detected within a high 632 fraction of xanthophores (Figure 7 - figure supplement 1A). Interestingly, these expression 633 profiles are not shared by the melanophore population, which displayed uniformly very low 634 levels of detectable hox expression. Lastly, the muscle, otic, and unidentified cells showed 635 almost no hox expression profile, which serves a foil for the specificity of the signatures 636 outlined. We noted that the "pigmented muscle" cluster weakly mirrored the general neural hox 637 signature, likely a shared signature more reflective of the axial position of the muscle cells 638 rather than a shared genetic profile, as corroborated by their distinct separation of the clusters 639 on the atlas UMAP (Figure 6A).

640

641 Overall, these above described hox signatures detected within our scRNA-seq atlas indicates 642 that distinct cell types express unique hox combinations during their delineation. Description of 643 the hox signatures within the sox10 atlas provides further tools to identify these discrete cell 644 populations, as well as exciting new avenues for further mechanistic investigation.

\section{DISCUSSION}

647 We present a single cell transcriptomic atlas resource capturing diversity of posterior-residing 648 sox 10-derived cells during the embryonic (48-50 hpf) to early larval transition (68-70 hpf) in 649 zebrafish. From our analysis, we identified a large number of cell types; including pigment 650 progenitor cells delineating into distinct chromatophores, as well as NCC, glial, neural, 
651 neuronal, and mesenchymal cells, extending prior whole embryo-based zebrafish single cell 652 studies (Farnsworth et al., 2020) and expanding the resolution at which these cells have been 653 described to date. We discovered that distinct hox transcriptional codes demarcate 654 differentiating neural and neuronal populations, highlighting their potential roles during cell 655 subtype specification. We also uncovered evolutionarily-conserved and novel transcriptional 656 signatures of differentiating enteric neuron cell types, thereby expanding our knowledge of ENS 657 development. Corroborating our transcriptomic characterizations, we validated the 658 spatiotemporal expression of several key cell type markers using HCR. Furthermore, our 659 datasets captured otic vesicle and muscle cells, populations which the sox 10:GFP line has been 660 characterized as marking, and may be useful for investigating these cell types in the future.

661 Collectively, this comprehensive cell type atlas can be used by the wider scientific community 662 as a valuable resource for further mechanistic and evolutionary investigation of posterior sox10663 expressing and NCC-derived cells during development and the ontogenesis of 664 neurocristopathies. The atlas is available via an interactive cell browser (https://zebrafish665 neural-crest-atlas.cells.ucsc.edu/).

666

667 The study of NCC-derived posterior cell types has recently gained increased attention due to 668 their complex and essential roles in vertebrate development (Gandhi et al., 2020; Hutchins et 669 al., 2018; Soldatov et al., 2019; Ling and Sauka-Spengler, 2019). Characterizing the 670 differentiation of NCC-derived cells is important to understand as it will enhance our concept of 671 human health, especially to fields such as stem cell therapeutics and regenerative medicine.

672 Prior studies provide incredible insight into their own respective research systems. Our paper is 673 the first single-cell transcriptomic analysis covering detailed description of the early 674 development of ENS in zebrafish, in addition to analysis of the $\operatorname{sox} 10^{+}$mesenchyme and 675 pigment cells present during the late embryonic to larval phase. The developmental window we 676 examined, the embryonic to larval transition, is regarded as an ephemeral phase (Singleman and 677 Holtzman, 2014) and as such is expected to contain the dynamic cell differentiation states that 678 we observed within our atlas.

679

680 Analysis of pigment populations demonstrated the accuracy and specificity of our transcriptome 681 datasets and identified distinct NCC-derived differentiating chromatophore lineages during the 682 embryonic to larval transition, extending on previous descriptions of pigment cell lineage 683 development performed in older larval and juvenile zebrafish at single cell resolution (Saunders 
684 et al., 2019). Specifically, melanophores were identified in the 48-50 hpf dataset (Figure 2B,C), 685 while at 68-70 hpf we identified iridophore, xanthophore, pigment progenitor, and two distinct 686 melanophore populations (Figure 2D-G). We employed the robust characterization of these 687 pigment populations to validate technical aspects of integrating both time points into a single, 688 cohesive atlas (Figure 6A). The atlas shows a common progenitor population branching into 689 both the iridophores and the melanophores, which are composed of the melanophore progenitor 690 cluster from 48-50 hpf and the two melanophore clusters at 68-70 hpf (Figure 6C). We 691 validated the results regarding pigment population gene signatures using whole mount HCR on 692 48-50 hpf and 68-70 hpf embryos (Figure 2H-J). Thus, our validation of pigment populations 693 highlights that the sox10 atlas can be used to identify cell lineages and discover new 694 information regarding their development in zebrafish.

695

696 Our datasets captured the transition from enteric neural progenitor to differentiating enteric 697 neuron subtype (Figure 4,5,6). We found that in both 48-50 and 68-70 hpf datasets, the 698 expression of elavl3, phox $2 b b$, ret, and gfrala transcripts were present (Figure 4,5); however, 699 enteric progenitor populations at 48-50 hpf still retained a NCC signature, marked by crestin 700 and foxd3, among others (Figure 4). The combined atlas revealed broad transcriptional states 701 captured within enteric neural progenitors and enteric neurons (Figure 6D), whereby elavl3, 702 phox $2 b b$, ret, $n g f r b$, and gfrala could be seen extending throughout the neural/neuronal regions 703 of the atlas. A similar enteric progenitor population consisting of Sox10, Ret, Phox $2 b$, and 704 Elavl4 was identified by scRNA-seq in the mouse (Lasrado et al., 2017), indicating zebrafish 705 express conserved enteric programs. Notably, genes that encode for neurochemicals within 706 enteric neurons were detected in the enteric clusters, with nos 1 and vipb being most prominent 707 (Figure 6D) and co-expressed in a subset of cells among the enteric neuron population along 708 the foregut (Fig 5A-C). Collectively, these results regarding enteric populations suggest that the 709 atlas likely reflects cells captured across a spectrum of differentiation states, with immature 710 neurons reflecting the onset of elavl3 expression, while others, such as the nos $1^{+} / v i p b^{+}$ 711 subpopulation, representing cells further along a differentiation trajectory.

712

713 A recent scRNA-seq study performed using E15.5 mice, a time point further along in ENS 714 development when compared to our zebrafish study described here, suggests that $\mathrm{NosI}^{+} / \mathrm{Vip}^{+}$ 715 cells represent a post-mitotic immature neuron population capable of branching into excitatory 716 and inhibitory neurons via subsequent differentiation mediated by lineage-restricted gene 
717 expression (Morarach et al., 2020). Their model posits that $\mathrm{Nos}^{+} / \mathrm{Vip}^{+} / \mathrm{Gal}^{+}$enteric neurons are

718 capable of assuming an intrinsic primary afferents neuron (IPAN) signature, characterized by

719 the loss of Vip and Nosl, and the gain of Calb, Slc18a2/3, and Ntng1; a process regulated by

720 transcription factors, $P b x 3$ and Etv1. This model of IPAN formation appears congruent with a

721 previous birth dating study performed in mice, where researchers demonstrated the transient

722 expression of Nos 1 in enteric neurons (Bergner et al., 2014). We wondered if the IPAN gene

723 expression signature was evolutionarily conserved in zebrafish. Testing this spatiotemporal

724 gene signature model in our own datasets, we asked if the nos $1^{+} / v i p b^{+}$population represented a

725 snapshot of immature enteric neurons. We found that $p b x 3 b$, etv1, calb2a, slc18a3a, ache, vipb,

726 and nos 1 were all expressed in differentiating enteric neuron clusters (Figure 5D-E; Figure 5-

727 figure supplement 1A), likely reflecting their transition to an IPAN fate in our 68-70 hpf

728 dataset. Intriguingly, we discovered that the markers tightly mapped to a subpopulation of cells

729 in an enteric neuron sub-cluster (Figure 7E, red arrows) and that nos 1 was either absent or

730 expressed at lower levels than other enteric subpopulations (Figure 5C; Figure 5-figure

731 supplement 1), a finding that corroborates the proposed mammalian model. Our observations

732 in zebrafish suggest that we captured a transitional time point where subsequent differentiation

733 is just being initiated and suggests an evolutionarily-conserved mechanism of ENS formation

734 across vertebrate species.

735

736 Within the enteric neuron subpopulation in our dataset, we discovered the enrichment of opioid 737 pathway members. Opioids have been known effectors of gastrointestinal function for centuries

738 based on their use as an anti-diarrheal medicine (De Luca and Coupart, 1996). Modern research

739 has allowed us to understand the mechanism by which opioids exert their effect on gut function,

740 namely, through the signaling mediated by the superfamily of G-protein coupled opioid

741 receptors that serve to regulate neurotransmission within the adult ENS (Holzer, 2004; De Luca

742 and Coupart, 1996; Wood and Galligan, 2004). This superfamily of opioid receptors is

743 comprised of mu- (MOR), delta- (DOR), kappa- (KOR), and nociception/orphan FQ (N/OFQ)

744 peptide (NOP)-receptors (Donica et al., 2013; Holzer, 2004). The expression of opioid

745 receptors has previously been shown in inhibitory interneurons found within the adult ENS and

746 are believed to inhibit gut peristalsis and secretion by inducing hyperpolarization of inhibitory

747 neurons, resulting in the deregulation of the excitatory circuits that drive smooth muscle

748 contraction within the gut (DiCello et al., 2020; Lay et al., 2016; Wood and Galligan, 2004). 
749 According to the CDC, licit and illicit opioid abuse has risen $400 \%$ in pregnant women between 750 1999-2014, which has in turn led to a $400 \%$ increase in the number of infants born with

751 neonatal abstinence syndrome (NAS), a multisystemic clinical condition characterized by a 752 wide array of symptoms including autonomic nervous system and gastrointestinal dysfunction 753 (Raffaeli et al., 2017).

754

755 While the presence and inhibitory effect of opioid receptors is well characterized within the 756 adult ENS, the role of opioid signaling during the earliest stages of enteric neuron maturation 757 and ENS formation has yet to be investigated. Indeed, a recent study performed in zebrafish 758 found that the NOP-receptor, oprl1 was expressed within $7 \mathrm{dpf}$ enteric neurons following bulk 759 RNA sequencing (Roy-Carson et al., 2017). However, this data represents a developmental 760 stage where zebrafish are characterized as free swimming larva that display feeding behavior 761 and digestive capability representative of a functioning and more mature ENS (Cassar et al., 762 2018). As such, our 68-70 hpf dataset, in which we detected the expression of the two receptors, 763 oprl1 and oprd1b, respectively representing (NOP) and (DOR) class opioid receptors (Figure $764 \mathbf{5 H}$ ), represents the earliest stage in which these opioid receptors have been shown to be 765 expressed within the early developing ENS. The presence of opioid receptors within the ENS at 766 68-70 hpf, a time when immature enteric neurons are continuing to migrate and pattern within 767 the developing embryo, highlights an important area of research focusing on the interplay 768 between opioid use and fetal ENS development, a reality that has been on the rise in recent 769 decades as opioid abuse continues to increase.

771 Finally, we have elucidated a comprehensive, combinatorial code of Hox transcription factor 772 expression which define specific cell lineages within the context of the sox10 atlas. The fin bud 773 mesenchyme, pigment populations, and neural fates presented the most specific hox codes 774 (Figure 7). The previously well characterized signature identified in the fin bud served as 775 validation of our dataset's curation for further analysis of the hox signatures. Among the neural 776 lineages, we identified a previously undescribed hox signature demarcating the developing 777 enteric neuron population in zebrafish: high relative expression of hoxb2a, hoxa5a, hoxd4a, 778 hoxb5a and hoxb5b, while also exhibiting low expression of hoxc $3 a$, hoxc5a, hoxb6a and 779 hoxb8a (Figure 7). While previous bulk microarray studies of differentiating enteric neurons 780 from humans and mice have been shown to express orthologs to the former signature (Heanue 781 and Pachnis, 2006; Memic et al., 2018), our analysis extends knowledge to comprehensively 
782 show for the first time specific combinatorial hox expression at a single cell resolution, thereby

783 providing a heretofore unknown readout of hox heterogeneity among nascent enteric cells. The

784 conservation of an enteric hox signature between zebrafish and other systems point toward

785 larger conservation of function, which may facilitate translation of future findings between

786 models. These findings imply interesting potential models wherein combinations of hox codes

787 may represent a molecular address designating the axial site of origination for migrating NCC

788 or indicate dynamic expression profiles which are modified during the NCC to enteric neuron

789 developmental course. Further work is required to test these possible models as well as the

790 functional requirement of the constituent members of the hox code the developing zebrafish

791 ENS. Considered collectively, these data lend support to a model in which overlapping

792 expression domains of hox genes may facilitate enteric neural subtype differentiation, similar to

793 their function in hindbrain and spinal neurons (Philippidou and Dasen, 2013).

794

795 In summary, our study greatly increases our foundational understanding of NCC-derived cell

796 fates, as well as other $\operatorname{sox} 10^{+}$posterior cell types in zebrafish, thereby complementing ongoing

797 studies in mammalian models and expanding fundamental knowledge of how cells diversify in

798 developing organisms. The spatiotemporal information contained within our zebrafish atlas will

799 serve as a resource for the developmental biology, stem cell, evolutionary biology and

800 organogenesis communities.

801

802

803

804 METHODS \& MATERIALS

805 KEY RESOURCE TABLE

\begin{tabular}{|c|l|l|l|l|}
\hline $\begin{array}{c}\text { Reagent type } \\
\text { species) or resource }\end{array}$ & $\begin{array}{c}\text { pesignatio } \\
\mathbf{n}\end{array}$ & $\begin{array}{c}\text { Source or } \\
\text { reference }\end{array}$ & Identifiers & Additional information \\
\hline $\begin{array}{c}\text { recombinant DNA } \\
\text { reagent }\end{array}$ & phox $2 b b$ & $\begin{array}{c}\text { Uribe and } \\
\text { Bronner, 2015 }\end{array}$ & & \\
\hline recombinant DNA & sox10 & putton et al. 2001 & & \\
\hline
\end{tabular}




\begin{tabular}{|c|c|c|c|c|}
\hline reagent & & & & \\
\hline $\begin{array}{l}\text { recombinant DNA } \\
\text { reagent }\end{array}$ & mmp2 & $\begin{array}{c}\text { Strausberg et al., } \\
2002\end{array}$ & & \\
\hline $\begin{array}{l}\text { sequence-based } \\
\text { reagent }\end{array}$ & notchla & Uribe Lab & & $\begin{array}{c}\text { Forward 5'- } \\
\text { CAGTGGACTCAGCAGCAT } \\
\text { C-3' Reverse 5'- } \\
\text { CCTTCCGACCAATCAGAC } \\
\text { AAG-3' }\end{array}$ \\
\hline $\begin{array}{l}\text { sequence-based } \\
\text { reagent }\end{array}$ & dla & Uribe Lab & & \begin{tabular}{|} 
Forward 5'- \\
AAGCCAAGTTGCTCAGAG- \\
3' Reverse 5'- \\
TTACAGAGAACCAGCTCA \\
TC-3'
\end{tabular} \\
\hline $\begin{array}{l}\text { sequence-based } \\
\text { reagent }\end{array}$ & foxcla & Uribe Lab & & \begin{tabular}{|c} 
Forward 5'- \\
ATACGGTGGACTCTGTGG- \\
3' Reverse 5'- \\
'AGCGTCTGTCAGTATCG- \\
3'
\end{tabular} \\
\hline $\begin{array}{l}\text { Genetic reagent } \\
\text { (Danio rerio) }\end{array}$ & $\mathrm{AB}$ & Zirc & & Wild-type zebrafish \\
\hline $\begin{array}{l}\text { Genetic reagent } \\
\text { (Danio rerio) }\end{array}$ & $\begin{array}{c}\mathrm{Tg}(- \\
\text { 4.9sox10:e } \\
\text { gfp)ba2Tg }\end{array}$ & Earney et al., 2006 & & $\begin{array}{l}\text { GFP Labeled Neural Crest } \\
\text { Cells }\end{array}$ \\
\hline $\begin{array}{l}\text { peptide, recombinant } \\
\text { protein }\end{array}$ & mitfa & $\begin{array}{l}\text { Molecular } \\
\text { Instruments }\end{array}$ & NM_130923.2 & \\
\hline commercial assay, kit & tfec & $\begin{array}{l}\text { Molecular } \\
\text { Instruments }\end{array}$ & JM_001030105.2 & \\
\hline commercial assay, kit & $x d h$ & $\begin{array}{l}\text { Molecular } \\
\text { Instruments }\end{array}$ & XM_683891.7 & \\
\hline commercial assay, kit & phox $2 b b$ & $\begin{array}{l}\text { Molecular } \\
\text { Instruments }\end{array}$ & NM_001014818.1 & \\
\hline
\end{tabular}




\begin{tabular}{|c|c|c|c|c|}
\hline commercial assay, kit & $n g f r b$ & $\begin{array}{l}\text { Molecular } \\
\text { Instruments }\end{array}$ & NM_001198660.1 & \\
\hline commercial assay, kit & gfrala & $\begin{array}{l}\text { Molecular } \\
\text { Instruments }\end{array}$ & NM_131730.1 & \\
\hline commercial assay, kit & crestin & $\begin{array}{l}\text { Molecular } \\
\text { Instruments }\end{array}$ & AF195881.1 & \\
\hline commercial assay, kit & foxd3 & $\begin{array}{l}\text { Molecular } \\
\text { Instruments }\end{array}$ & NM_131290.2 & \\
\hline commercial assay, kit & vipb & $\begin{array}{l}\text { Molecular } \\
\text { Instruments }\end{array}$ & NM_001114555.1 & \\
\hline commercial assay, kit & elavl3 & $\begin{array}{l}\text { Molecular } \\
\text { Instruments }\end{array}$ & NM_131449 & \\
\hline commercial assay, kit & oprll & $\begin{array}{l}\text { Molecular } \\
\text { Instruments }\end{array}$ & NM_205589.2 & \\
\hline commercial assay, kit & barxl & $\begin{array}{l}\text { Molecular } \\
\text { Instruments }\end{array}$ & NM_001024949.1 & \\
\hline commercial assay, kit & $p b \times 3 b$ & $\begin{array}{l}\text { Molecular } \\
\text { Instruments }\end{array}$ & BC131865.1 & \\
\hline commercial assay, kit & prrxlb & $\begin{array}{l}\text { Molecular } \\
\text { Instruments }\end{array}$ & NM_200050.1 & \\
\hline commercial assay, kit & slc18a3a & $\begin{array}{l}\text { Molecular } \\
\text { Instruments }\end{array}$ & $\begin{array}{c}\text { MM_0010775550. } \\
1\end{array}$ & \\
\hline commercial assay, kit & hoxb5a & $\begin{array}{l}\text { Molecular } \\
\text { Instruments }\end{array}$ & NM_131101.2 & \\
\hline commercial assay, kit & hoxb5b & $\begin{array}{l}\text { Molecular } \\
\text { Instruments }\end{array}$ & bc078285.1 & \\
\hline
\end{tabular}




\begin{tabular}{|c|c|c|c|c|}
\hline commercial assay, kit & hoxd $4 a$ & $\begin{array}{l}\text { Molecular } \\
\text { Instruments }\end{array}$ & NM_001126445 & \\
\hline commercial assay, kit & hoxa $5 a$ & $\begin{array}{l}\text { Molecular } \\
\text { Instruments }\end{array}$ & NM_131540.1 & \\
\hline commercial assay, kit & twistla & $\begin{array}{l}\text { Molecular } \\
\text { Instruments }\end{array}$ & NM_130984.2 & \\
\hline commercial assay, kit & $\begin{array}{l}\text { Pingle Cell } \\
3^{\prime} \text { v2 } \\
\text { Chemistry } \\
\text { Kit for } \\
10,000 \\
\text { cells }\end{array}$ & 10x Genomics & CG00052 & $\begin{array}{l}\text { tttps://support.10xgenomics.co } \\
\text { m/single-cell-gene- } \\
\text { expression/library- } \\
\text { rep/doc/user-guide-chromium- } \\
\text { ingle-cell-3-reagent-kits-user- } \\
\text { guide-v2-chemistry }\end{array}$ \\
\hline commercial assay, kit & $\begin{array}{l}\text { NextSeq } \\
500 / 550 \\
\text { Mid Output } \\
\text { Kit v2.5 } \\
\text { (150 } \\
\text { Cycles) }\end{array}$ & illumina & 20024904 & $\begin{array}{l}\text { tttps://www.illumina.com/prod } \\
\begin{array}{c}\text { ucts/by-type/sequencing- } \\
\text { kits/cluster-gen-sequencing- }\end{array} \\
\text { eagents/nextseq-series-kits-v2- } \\
\underline{5 . h t m l}\end{array}$ \\
\hline $\begin{array}{c}\text { chemical compound, } \\
\text { drug }\end{array}$ & $\begin{array}{l}\text {-phenyl 2- } \\
\text { thiourea } \\
\text { (PTU)/E3 } \\
\text { solution }\end{array}$ & $\begin{array}{l}\text { Karlsson } 741 \text { et } \\
\text { al., } 2001\end{array}$ & Sigma-Aldrich & P7629 \\
\hline $\begin{array}{c}\text { chemical compound, } \\
\text { drug }\end{array}$ & Tricaine & A5040 & Sigma & \\
\hline $\begin{array}{c}\text { chemical compound, } \\
\text { drug }\end{array}$ & $\begin{array}{c}\text { Accumax } \\
\text { buffer }\end{array}$ & A7089 & Sigma-Aldrich & \\
\hline $\begin{array}{c}\text { chemical compound, } \\
\text { drug }\end{array}$ & $\begin{array}{l}\text { Hank's } \\
\text { Buffer }\end{array}$ & $55021 \mathrm{C}$ & Sigma-Aldrich & \\
\hline $\begin{array}{c}\text { chemical compound, } \\
\text { drug }\end{array}$ & $\begin{array}{c}\text { Phusion- } \\
\text { HF }\end{array}$ & M0530S & $\begin{array}{c}\text { New England } \\
\text { Biolabs }\end{array}$ & \\
\hline $\begin{array}{c}\text { chemical compound, } \\
\text { drug }\end{array}$ & $\begin{array}{c}\text { Zero } \\
\text { Blunt }\end{array}$ & 451245 & Invitrogen & \\
\hline
\end{tabular}




\begin{tabular}{|c|c|c|c|c|}
\hline & $\begin{array}{l}\text { TOPO } \\
\text { PCR } \\
\text { lloning Kit }\end{array}$ & & & \\
\hline Software, algorithm & R v3.6.3 & R-project & $\begin{array}{c}\text { RRID:SCR_0019 } \\
05\end{array}$ & https://www.r-project.org/ \\
\hline Software, algorithm & $\begin{array}{l}\text { Seurat } \\
\text { v3.1.1 }\end{array}$ & Satija Lab & $\begin{array}{c}\text { RRID:SCR_0073 } \\
22\end{array}$ & $\begin{array}{c}\text { ttps://github.com/satijalab/seur } \\
\text { at }\end{array}$ \\
\hline Software, algorithm & Fiji & PMID: 22743772 & $\frac{\text { RRID:SCR_0022 }}{\underline{85}}$ & $\underline{\text { https://imagej.net/Fiji }}$ \\
\hline Software, algorithm & $\begin{array}{l}\text { IMARIS } \\
\text { v9.2 }\end{array}$ & Bitplane & $\frac{\text { RRID:SCR_0073 }}{7 \underline{70}}$ & $\underline{\text { Bitplane.com }}$ \\
\hline Software, algorithm & PANTHER & $\begin{array}{l}\text { JENEONTOLOG } \\
\text { Y Unifying } \\
\text { Biology }\end{array}$ & $\begin{array}{c}\text { RRID:SCR_0048 } \\
69\end{array}$ & http://pantherdb.org \\
\hline Software, algorithm & $\begin{array}{c}\text { Cell } \\
\text { Ranger } \\
\text { v2.1.0 }\end{array}$ & 10x Genomics & $\begin{array}{c}\text { RRID:SCR_0173 } \\
44\end{array}$ & $\begin{array}{c}\text { Zheng et al., 2017, } \\
\text { tttps://support.10xgenomics.co } \\
\text { m/single-cell-gene- } \\
\text { xpression/software/pipelines/la } \\
\text { test/what-is-cell-ranger }\end{array}$ \\
\hline
\end{tabular}

\section{Animal Husbandry, Care, \& Synchronous Embryo Collection}

809 Groups of at least 15 adult $\mathrm{Tg}\left(-4.9\right.$ sox 10:GFP) ${ }^{\text {ba2Tg }}$ (Carney et al., 2006) zebrafish (Danio rerio)

810 males and 15 females from different tank stocks were bred to generate synchronously staged

811 embryos across several clutches. All embryos were cultured in standard E3 media until 24 hours

812 post fertilization (hpf), then transferred to $.003 \%$ 1-phenyl 2-thiourea (PTU)/E3 solution

813 (Karlsson et al., 2001), to arrest melanin formation and enable ease of GFP sorting. While it has

814 been suggested that high concentration (.03\%) PTU incubation prior to 22 hpf may cause

815 organism-wide effects, .003\% PTU application after $22 \mathrm{hpf}$ has been shown to have no major

816 effects on NCC survival or pigment cell formation, as described (Bohnsack et al., 2011).

817 Embryos were manually sorted for GFP expression and synchronously staged at 24 hpf. Care

818 was taken such that embryos which exhibited developmental delay or other defects were 
819 removed prior to collection. All work was performed under protocols approved by, and in

820 accordance with, the Rice University Institutional Animal Care and Use Committee (IACUC).

821

\section{Isolation of Tissue \& Preparation of Single Cell Suspension}

823100 embryos between 48-50 hpf and 100 larvae between 68-70 hpf were dechorionated

824 manually and then transferred to $1 \mathrm{X}$ sterile filtered PBS, supplemented with $0.4 \%$ Tricane

825 (Sigma, A5040) to anesthetize. Tissue anterior to the otic vesicle and tissue immediately

826 posterior to the anal vent was manually removed using fine forceps in 48-50 hpf embryos, while

827 tissue anterior to the otic vesicle was removed from 68-70 hpf larvae, as schematized in Figure

828 1. This was to capture as many posterior sox $10: \mathrm{GFP}^{+}$cells in the later time point as possible.

829 Remaining tissue segments were separated into nuclease-free tubes and kept on ice immediately

830 following dissection. Dissections proceeded over the course of 1 hour. To serve as control for

831 subsequent steps, similarly staged AB WT embryos were euthanized in tricaine and then

832 transferred to sterile $1 \mathrm{X}$ PBS. All following steps were conducted rapidly in parallel to

833 minimize damage to cells: Excess PBS was removed and tissue was digested in $37^{\circ} \mathrm{C} 1 \mathrm{X}$

834 Accumax buffer (Sigma-Aldrich, A7089) for 30-45 minutes to generate a single cell suspension

835 for each sample. At 10 minute intervals, tissue was gently manually disrupted with a sterile

836 pipette tip. As soon as the tissue was fully suspended, the cell solutions were then transferred to

837 a fresh chilled sterile conical tube and diluted 1:5 in ice cold Hank's Buffer (1x HBSS; 2.5

$838 \mathrm{mg} / \mathrm{mL}$ BSA; $10 \mu \mathrm{M}$ pH8 HEPES) to arrest the digestion. Cells were concentrated by

839 centrifugation at $200 \mathrm{rcf}$ for 10 minutes at $4^{\circ} \mathrm{C}$. Supernatant was discarded carefully and cell

840 pellets were resuspended in Hank's Buffer. Cell solution was passed through a $40 \mu \mathrm{m}$ sterile

841 cell strainer to remove any remaining undigested tissue and then centrifuged as above.

842 Concentrated cells were resuspended in ice cold sterile 1X PBS and transferred to a tube

843 suitable for FACS kept on ice. The 48-50 hpf and 68-70 hpf experiments were performed on

844 completely separate dates and times using the above described procedures.

845

846 Fluorescent Cell Sorting, \& Single Cell Sequencing

847 Fluorescent Assisted Cell Sorting (FACS) was performed under the guidance of the Cytometry 848 and Cell Sorting Core at Baylor College of Medicine (Houston, TX) using a BD FACSAria II 849 (BD Biosciences). Zebrafish cells sorted via GFP fluorescence excited by a $488 \mathrm{~nm}$ laser, 850 relying on an $85 \mu \mathrm{m}$ nozzle for cell selection. Detection of $\mathrm{GFP}^{+}$cells was calibrated against $851 \mathrm{GFP}^{-}$cells collected from AB wildtype embryos, as well as $\mathrm{GFP}^{+}$cells collected from the 
852 anterior portions of the sox10:GFP embryos. Optimal conditions for dissociated tissue inputs

853 (number of embryos needed, etc.) and FACS gating was determined via pilot experiments prior

854 to collection for subsequent scRNA-seq experiments. Sample preparation for scRNA-seq was 855 performed by Advanced Technology Genomics Core (ATGC) at MD Anderson (Houston, TX).

8564905 and 4669 FACS-isolated cells for the 48-50 and 68-70 hpf datasets were prepared on a

857 10X Genomics Chromium platform using 10X Single Cell 3' V2 chemistry kit for 10,000 cells.

858 cDNA libraries were amplified and prepared according to the 10X Genomics recommended

859 protocol, with details provided in Figure 1-figure supplement 1C. A 150 cycle Mid-Output

860 flow cell was used for sequencing on an Illumina NextSeq500. Sequencing was aligned at MD

861 Anderson ATGC to the DanioGRCz10 version of the zebrafish genome using the 10X

862 Genomics Cell Ranger software (v2.1.0) (Zheng et al., 2017). Gene reads per cell were stored in

863 a matrix format for further analysis.

864

865 Data Processing \& Analysis

866 The 10x genomics sequencing data was then analyzed using Seurat (Satija et al., 2015, Stuart et 867 al. 2019, Butler et al., 2018) v3.1.1 software package for R, v3.6.3 (R Core Team, 2020). The 868 standard recommended workflow was followed for data processing. Briefly, for both the 48-50 869 hpf and 68-70 hpf datasets, cells which contained low $(<200)$ or high $(>2500)$ genes were 870 removed from analysis. Gene expression was normalized using the NormilizeData command, 871 opting for the LogNormalize method (Scale factor set at 10,000) and further centered using the 872 ScaleData command. Variable features of the dataset were calculated with respect to groups of 8732,000 genes at a time. Both datasets were evaluated considering the first 20 principle 874 components (PC) as determined by the RunPCA command with a resolution of 1.2 for PCA, 875 tSNE, and UMAP analyses. The appropriate PCs were selected based on a Jack Straw analysis 876 with a significance of $\mathrm{P}<0.01$, as generated by the JackStraw command.

877

878 Clustering was performed using FindNeighbors and FindClusters in series. We identified 19 879 clusters in the $48-50 \mathrm{hpf}$ dataset and 23 clusters in the 68-70 hpf dataset. Significant genes for 880 each cluster were determined via a Wilcoxon Rank Sum test implemented by the 881 FindAllMarkers command. From these expressed gene lists within each cluster, all cluster 882 identities were manually curated via combinatorial expression analysis of published marker 
883 genes in the literature, zfin.org and/or bioinformatics GO term analysis via the Panther

884 Database.

885

886 Generation of the merged atlas was performed via the FindIntegrationAnchors workflow 887 provided in the Standard Workflow found on the Seurat Integration and Label Transfer vignette.

888 Clustering was performed for the atlas based on the first $20 \mathrm{PCs}$, consistent with the original 889 datasets. Subsets of the atlas discounted any spuriously sorted cells for clarity. All features plots 890 represent expression values derived from the RNA assay. Sub-clustering of the enteric clusters 891 was performed by sub-setting clusters 5 and 12 from the 68-70 hpf dataset and reinitializing the 892 Seurat workflow, as described above. Clusters were identified based on the first 6 PCs. 893 Detection of cell cycle phase was conducted following the Cell cycle and scoring vignette. 894 Genes used for identification of cell cycle phases can be found in the supplementary table 895 (Figure 1-figure supplement 3). Pairwise hox analysis was conducted using tools from the 896 Seurat package in $\mathrm{R}$ by assessing the number of cells which had expression for hox gene pairs 897 queried with a $\log 2$ fold change greater than 0. Dendrogram Cluster trees were generated using 898 Seurat's BuildClusterTree function.

899

\section{Whole mount in situ Hybridization}

901 cDNAs for foxcla, notchla, and dla were amplified via high fidelity Phusion-HF PCR (NEB) 902 from $48 \mathrm{hpf}$ AB WT cDNA libraries using primers in the Key resources table. PCR products 903 were cloned using the Zero Blunt ${ }^{\mathrm{TM}}$ TOPO $^{\mathrm{TM}}$ PCR Cloning Kit (Invitrogen), as per 904 manufacturer protocols, and sequenced validated. Plasmids encoding phox $2 b b$, sox 10, mmp2 905 were generously sourced as listed in the key resources table. Antisense digoxigenin (DIG)906 labeled riboprobes were produced from cDNA templates of each gene. AB wild type embryos 907 were treated and stained to visualize expression as previously described in (Jowett and Lettice, 908 1994). Following in situ reactions, embryos were post-fixed in 4\% Paraformaldehyde (PFA) 909 and mounted in 75\% Glycerol for imaging. A Nikon Ni-Eclipse Motorized Fluorescent upright 910 compound microscope with a $4 \mathrm{X}$ objective was used in combination with a DS-Fi3 color 911 camera. Images were exported via Nikon Elements Image Analysis software.

912

\section{Whole mount Hybridization Chain Reaction}

914 HCR probes were purchased commercially (Molecular Instruments Inc., CA) and were targeted 915 to specific genes based on their RefSeq ID (Key resources table). Whole mount HCR was 
916 performed according to the manufacturer's instructions (v3.0, Choi et al., 2016, 2018) on

917 sox 10: $\mathrm{GFP}^{+}$or $\mathrm{AB}$ embryos previously fixed at the appropriate stage in $4 \%$ PFA.

918

\section{Confocal Imaging \& Image Processing}

920 Prior to imaging, embryos were embedded in 1\% low melt agarose (Sigma) and were then

921 imaged using an Olympus FV3000 Laser Scanning Confocal, with a UCPlanFLN 20×/0.70NA

922 objective. Confocal images were acquired using lambda scanning to separate the Alexafluor

923 488/Alexafluor 514 or the Alexafluor 546/Alexafluor 594 channels. Final images were

924 combined in the FlowView software and exported for analysis in either Fiji (Rueden et al.,

925 2017; Schneider et al., 2012; Schindelin et al., 2012) or IMARIS image analysis software

926 (Bitplane). Figures were prepared in Adobe Photoshop and Illustrator software programs, with

927 some cartoons created via BioRender.com.

928

929 Data Availability

930 The raw sequence read files and processed cellular barcode, gene, and matrix files produced by

931 CellRanger are available in the National Center for Biotechnology Information's (NCBI) Gene

932 Expression Omnibus (GEO) database (https://www.ncbi.nlm.nih.gov/geo/), accession number:

933 GSE152906. The atlas/associated processed Seurat objects are available on the University of

934 California, Santa Cruz (UCSC) Cell Browser (https://zebrafish-neural-crest-

935 atlas.cells.ucsc.edu/). Code written for Seurat data analysis is available on GitHub

936 (https://github.com/UribeLabRice).

937

\section{ACKNOWLEDGEMENTS}

939 Funding for this project was provided by Rice University, Cancer Prevention \& Research 940 Institute of Texas (CPRIT) Recruitment of First-Time Tenure Track Faculty Members (CPRIT941 RR170062) and the NSF CAREER Award (1942019) awarded to R.A.U., a Houston Livestock

942 Show \& Rodeo Research Award to J.A.M. and P.A.B., and a SDB Choose Development! 943 Fellowship award to J.L.W. We acknowledge the Cytometry and Cell Sorting Core at Baylor 944 College of Medicine, which is funded from the CPRIT Core Facility Support Award (CPRIT945 RP180672), the NIH (P30 CA125123 and S10 RR024574), and the expert assistance of Joel M.

946 Sederstrom for assistance with flow cytometry. Single cell library preparation, Illumina 947 sequencing, and Cell Ranger alignment was facilitated by Advanced Technology Genomics 948 Core at MD Anderson Cancer Research Center funded by CA016672(ATGC). IMARIS image 949 analysis was performed using Rice University's Shared Equipment Authority (SEA) IMARIS 950 workstation. We thank George Eisenhoffer and Oscar Ruiz (MD Anderson) for advice 951 regarding flow cytometry and single-cell RNA-seq methodology. We thank Sarah Kucenas 
952 (University of Virginia) for helpful advice on glial populations. We thank Robert Naja and 953 Robyn Fenty for technical assistance.

954

955 Competing Interests: The authors claim no competing interests.

956

957

958

959 Citations

960 Ahn, D., and Ho, R.K. (2008). Tri-phasic expression of posterior Hox genes during 961 development of pectoral fins in zebrafish: Implications for the evolution of vertebrate paired 962 appendages. Dev. Biol. 322, 220-233.

963 Anderson, R.B., Stewart, A.L., and Young, H.M. (2006). Phenotypes of neural-crest-derived 964 cells in vagal and sacral pathways. Cell Tissue Res. 323, 11-25.

965 Barlow, A.J. (1984). Neural Crest Cells in Enteric Nervous System Development and Disease. 966 In Neural Crest Cells, (Elsevier Inc.), pp. 101-104.

967 Barsh, G.R., Isabella, A.J., and Moens, C.B. (2017). Vagus Motor Neuron Topographic Map 968 Determined by Parallel Mechanisms of hox5 Expression and Time of Axon Initiation. Curr. 969 Biol. 27, 3812-3825.

970 Barske, L., Askary, A., Zuniga, E., Balczerski, B., Bump, P., Nichols, J.T., and Crump, J.G. 971 (2016). Competition between Jagged-Notch and Endothelin1 Signaling Selectively Restricts 972 Cartilage Formation in the Zebrafish Upper Face. PLoS Genet. 12, e1005967.

973 Becht, E., McInnes, L., Healy, J., Dutertre, C.A., Kwok, I.W.H., Ng, L.G., Ginhoux, F., and 974 Newell, E.W. (2019). Dimensionality reduction for visualizing single-cell data using UMAP. 975 Nat. Biotechnol. 37, 38-47.

976 Bergner, A.J., Stamp, L.A., Gonsalvez, D.G., Allison, M.B., Olson, D.P., Myers, M.G., 977 Anderson, C.R., and Young, H.M. (2014). Birthdating of myenteric neuron subtypes in the 978 small intestine of the mouse. J. Comp. Neurol. 522, 514-527.

979 Bertrand, C., Chatonnet, A., Takke, C., Yan, Y.L., Postlethwait, J., Toutant, J.P., and Cousin, 980 X. (2001). Zebrafish acetylcholinesterase is encoded by a single gene localized on linkage 981 group 7. Gene structure and polymorphism; molecular forms and expression pattern during 982 development. J. Biol. Chem. 276, 464-474.

983 Bohnsack B.L., Gallina D., Kahana A. (2011). Phenothiourea Sensitizes Zebrafish Cranial 984 Neural Crest and Extraocular Muscle Development to Changes in Retinoic Acid and IGF 985 Signaling. PLoS ONE 6: e22991 
986 Bolande, R.P. (1997). Neurocristopathy: Its Growth and Development in 20 Years. Pediatr. 987 Pathol. Lab. Med. 17, 1-25.

988 Brosens, E., Burns, A.J., Brooks, A.S., Matera, I., Borrego, S., Ceccherini, I., Tam, P.K., 989 García-Barceló, M.M., Thapar, N., Benninga, M.A., et al. (2016). Genetics of enteric 990 neuropathies. Dev. Biol. 417, 198-208.

991 Butler, A., Hoffman, P., Smibert, P., Papalexi, E., and Satija, R. (2018). Integrating single-cell 992 transcriptomic data across different conditions, technologies, and species. Nat. Biotechnol. 36, 993 411-420.

994 Carney, T.J., Dutton, K.A., Greenhill, E., Delfino-Machin, M., Dufourcq, P., Blader, P., and 995 Kelsh, R.N. (2006). A direct role for Sox10 in specification of neural crest-derived sensory 996 neurons. Development 113, 4619-4630.

997 Cassar, S., Huang, X., and Cole, T. (2018). High-throughput Measurement of Gut Transit Time 998 Using Larval Zebrafish. J. Vis. Exp. 140, e58497.

999 Cerdà, J., Conrad, M., Markl, J., Brand, M., and Herrmann, H. (1998). Zebrafish vimentin: 1000 Molecular characterisation, assembly properties and developmental expression. Eur. J. Cell 1001 Biol. 77, 175-187.

1002 Choi, H.M.T., Calvert, C.R., Husain, N., Huss, D., Barsi, J.C., Deverman, B.E., Hunter, R.C., 1003 Kato, M., Lee, S.M., Abelin, A.C.T., et al. (2016). Mapping a multiplexed zoo of mRNA 1004 expression. Development 143, 3632-3637.

1005 Choi, H.M.T., Schwarzkopf, M., Fornace, M.E., Acharya, A., Artavanis, G., Stegmaier, J., 1006 Cunha, A., and Pierce, N.A. (2018). Third-generation in situ hybridization chain reaction: 1007 multiplexed, quantitative, sensitive, versatile, robust. Development 145, dev165753.

1008 Dash, S., and Trainor, P. (2020). The development, patterning and evolution of neural crest cell 1009 differentiation into cartilage and bone. Bone 137, 115409.

1010 Delalande, J.M., Guyote, M.E., Smith, C.M., and Shepherd, I.T. (2008). Zebrafish sip1a and 1011 sip1b are essential for normal axial and neural patterning. Dev. Dyn. 237, 1060-1069.

1012 Delfino-Machín, M., Madelaine, R., Busolin, G., Nikaido, M., Colanesi, S., Camargo-Sosa, K., 1013 Law, E.W.P., Toppo, S., Blader, P., Tiso, N., et al. (2017). Sox10 contributes to the balance of 1014 fate choice in dorsal root ganglion progenitors. PLoS One 12, e0172947.

1015 DiCello, J.J., Carbone, S.E., Saito, A., Rajasekhar, P., Ceredig, R.A., Pham, V., Valant, C., 1016 Christopoulos, A., Veldhuis, N.A., Canals, M., et al. (2020). Mu and Delta Opioid Receptors 1017 Are Coexpressed and Functionally Interact in the Enteric Nervous System of the Mouse Colon. 1018 CMGH 9, 465-483.

1019 Ding, H.L., Clouthier, D.E., and Artinger, K.B. (2013). Redundant roles of PRDM family 1020 members in zebrafish craniofacial development. Dev. Dyn. 242, 67-79. 
1021 Donica, C.L., Awwad, H.O., Thakker, D.R., and Standifer, K.M. (2013). Cellular mechanisms 1022 of nociceptin/orphanin FQ (N/OFQ) peptide (NOP) receptor regulation and heterologous 1023 regulation by N/OFQ. Mol. Pharmacol. 83, 907-918.

1024 Le Douarin, N., and Kalcheim, C. (1999). The Neural Crest (Cambridge University Press).

1025 Le Douarin, N.M., and Teillet, M.A.M. (1974). Experimental analysis of the migration and 1026 differentiation of neuroblasts of the autonomic nervous system and of neurectodermal 1027 mesenchymal derivatives, using a biological cell marking technique. Dev. Biol. 41, 162-184.

1028 De Luca, A., and Coupart, L.M. (1996). Insights into Opioid Action in the Intestinal Tract 1029 (Elsevier Science Inc).

1030 Du, J., Miller, A.J., Widlund, H.R., Horstmann, M.A., Ramaswamy, S., and Fisher, D.E. 1031 (2003). MLANA/MART1 and SILV/PMEL17/GP100 are transcriptionally regulated by MITF 1032 in melanocytes and melanoma. Am. J. Pathol. 163, 333-343.

1033 Dutton, K.A., Pauliny, A., Lopes, S.S., Elworthy, S., Carney, T.J., Rauch, J., Geisler, R., 1034 Haffter, P., and Kelsh, R.N. (2001). Zebrafish Colourless Encodes sox10 and Specifies Non1035 Ectomesenchymal Neural Crest Fates. Development 128, 4113-4125.

1036 Elworthy, S., Pinto, J.P., Pettifer, A., Cancela, M.L., and Kelsh, R.N. (2005). Phox2b function 1037 in the enteric nervous system is conserved in zebrafish and is sox10-dependent. Mech. Dev. 1038 122, 659-669.

1039 Epstein, M.L., Mikawa, T., Brown, A.M.C., and McFarlin, D.R. (1994). Mapping the origin of 1040 the avian enteric nervous system with a retroviral marker. Dev. Dyn. 201, 236-244.

1041 Escot, S., Blavet, C., Faure, E., Zaffran, S., Duband, J.L., and Fournier-Thibault, C. (2016). 1042 Disruption of CXCR4 signaling in pharyngeal neural crest cells causes DiGeorge syndrome-like 1043 malformations. Development 143, 582-588.

1044 Farnsworth, D.R., Saunders, L.M., and Miller, A.C. (2020). A single-cell transcriptome atlas for 1045 zebrafish development. Dev. Biol. 459, 100-108.

1046 Feregrino, C., Sacher, F., Parnas, O., and Tschopp, P. (2019). A single-cell transcriptomic atlas 1047 of the developing chicken limb. BMC Genomics 20, 401.

1048 Furness, J.B., Jones, C., Nurgali, K., and Clerc, N. (2004). Intrinsic primary afferent neurons 1049 and nerve circuits within the intestine. Prog. Neurobiol. 72, 143-164.

1050 Gandhi, S., Ezin, M., and Bronner, M.E. (2020). Reprogramming Axial Level Identity to 1051 Rescue Neural-Crest-Related Congenital Heart Defects. Dev. Cell 53, 300-315.e4.

1052 Ganz, J. (2018). Gut feelings: Studying enteric nervous system development, function, and 1053 disease in the zebrafish model system. Dev. Dyn. 247, 268-278.

1054 Gaudet, P., Livstone, M.S., Lewis, S.E., and Thomas, P.D. (2011). Phylogenetic-based 1055 propagation of functional annotations within the Gene Ontology consortium. Brief. Bioinform. 1056 12, 449-462. 
1057 Gou, Y., Guo, J., Maulding, K., and Riley, B.B. (2018). sox2 and sox3 cooperate to regulate 1058 otic/epibranchial placode induction in zebrafish. Dev. Biol. 435, 84-95.

1059 Graham, A., Begbie, J., and McGonnell, I. (2004). Significance of the Cranial Neural Crest. 1060 Dev. Dyn. 229, 5-13.

1061 Green, S.A., Simoes-costa, M., Bronner, M.E., and Engineering, B. (2016). Evolution of 1062 vertebrates: a view from the crest. Nature 520, 474-482.

1063 Hall, B.K., and Hörstadius, S. (1988). The Neural Crest (London, New York, Tokyo, Toronto: 1064 Oxford University Press).

1065 Hans, S., Irmscher, A., and Brand, M. (2013). Zebrafish Foxi1 provides a neuronal ground state 1066 during inner ear induction preceding the Dlx3b/4b-regulated sensory lineage. Development 140, 1067 1936-1945.

1068 Hao, M.M., and Young, H.M. (2009). Development of enteric neuron diversity. J. Cell. Mol. 1069 Med. 13, 1193-1210.

1070 Harrison, C., Wabbersen, T., and Shepherd, I.T. (2014). In vivo visualization of the 1071 development of the enteric nervous system using a $\operatorname{Tg}(-8.3$ bphox $2 b$ : Kaede) transgenic 1072 zebrafish. Genesis 52, 985-990.

1073 Heanue, T.A., and Pachnis, V. (2008). Ret isoform function and marker gene expression in the 1074 enteric nervous system is conserved across diverse vertebrate species. Mech. Dev. 125, 6871075699.

1076 Heanue, T.A., Shepherd, I.T., and Burns, A.J. (2016). Enteric nervous system development in 1077 avian and zebrafish models. Dev. Biol. 417, 129-138.

1078 Heffer, A., Marquart, G.D., Aquilina-Beck, A., Saleem, N., Burgess, H.A., and Dawid, I.B. 1079 (2017). Generation and characterization of Kctd15 mutations in zebrafish. PLoS One 12, $1080 \mathrm{e} 0189162$.

1081 Higdon, C.W., Mitra, R.D., and Johnson, S.L. (2013). Gene Expression Analysis of Zebrafish 1082 Melanocytes, Iridophores, and Retinal Pigmented Epithelium Reveals Indicators of Biological 1083 Function and Developmental Origin. PLoS One 8, e67801.

1084 Hockman, D., Chong-Morrison, V., Green, S.A., Gavriouchkina, D., Candido-Ferreira, I., Ling, 1085 I.T.C., Williams, R.M., Amemiya, C.T., Smith, J.J., Bronner, M.E., et al. (2019). A genome1086 wide assessment of the ancestral neural crest gene regulatory network. Nat. Commun. 10, 1087 e4689.

1088 Holmqvist, B., Ellingsen, B., Forsell, J., Zhdanova, I., and Alm, P. (2004). The early ontogeny 1089 of neuronal nitric oxide synthase systems in the zebrafish. J. Exp. Biol. 207, 923-935.

1090 Holzer, P. (2004). Opioids and opioid receptors in the enteric nervous system: From a problem 1091 in opioid analgesia to a possible new prokinetic therapy in humans. Neurosci. Lett. 361, 1921092195. 
1093 Hong, E., Santhakumar, K., Akitake, C.A., Ahn, S.J., Thisse, C., Thisse, B., Wyart, C., Mangin, 1094 J.M., and Halpern, M.E. (2013). Cholinergic left-right asymmetry in the habenulo1095 interpeduncular pathway. Proc. Natl. Acad. Sci. U. S. A. 110, 21171-21176.

1096 Hong, S.K., Tsang, M., and Dawid, I.B. (2008). The Mych gene is required for neural crest 1097 survival during zebrafish development. PLoS One 3, e2029.

1098 Huang, V., Butler, A.A., and Lubin, F.D. (2019). Telencephalon transcriptome analysis of 1099 chronically stressed adult zebrafish. Sci. Rep. 9, 1379.

1100 Hutchins, E.J., Kunttas, E., Piacentino, M.L., Howard, A.G.A., Bronner, M.E., and Uribe, R.A. 1101 (2018). Migration and diversification of the vagal neural crest. Dev. Biol. 444, S98-S109.

1102 Janssens, E., Gaublomme, D., de Groef, L., Darras, V.M., Arckens, L., Delorme, N., Claes, F., 1103 van Hove, I., and Moons, L. (2013). Matrix Metalloproteinase 14 in the Zebrafish: An Eye on 1104 Retinal and Retinotectal Development. PLoS One 8, e52915.

1105 Jarinova, O., Hatch, G., Poitras, L., Prudhomme, C., Grzyb, M., Aubin, J., Bérubé-Simard, F.1106 A., Jeannotte, L., and Ekker, M. (2008). Functional resolution of duplicated hoxb5 genes in 1107 teleosts. Development 135, 3543-3553.

1108 Jowett, T., and Lettice, L. (1994). Whole-mount in situ hybridizations on zebrafish embryos 1109 using a mixture of digoxigenin- and fluorescein- labelled probes. Trends Genet. 10, 73-74.

1110 Kague, E., Gallagher, M., Burke, S., Parsons, M., Franz-Odendaal, T., and Fisher, S. (2012). 1111 Skeletogenic Fate of Zebrafish Cranial and Trunk Neural Crest. PLoS One 7, e47394.

1112 Kam, M.K.M., and Lui, V.C.H. (2015). Roles of Hoxb5 in the development of vagal and trunk 1113 neural crest cells. Dev. Growth Differ. 57, 158-168.

1114 Kam, M.K.M., Cheung, M.C.H., Zhu, J.J., Cheng, W.W.C., Sat, E.W.Y., Tam, P.K.H., and Lui, 1115 V.C.H. (2014). Perturbation of Hoxb5 signaling in vagal and trunk neural crest cells causes 1116 apoptosis and neurocristopathies in mice. Cell Death Differ. 21, 278-289.

1117 Karlsson, J., Von Hofsten, J., and Olsson, P.E. (2001). Generating transparent zebrafish: A 1118 refined method to improve detection of gene expression during embryonic development. Mar. 1119 Biotechnol. 3, 522-527.

1120 Kelsh, R.N. (2004). Genetics and evolution of pigment patterns in fish. Pigment Cell Res. 17, $1121326-336$.

1122 Kelsh, R.N., and Eisen, J.S. (2000). The zebrafish colourless gene regulates development of 1123 non-ectomesenchymal neural crest derivatives. Development 127, 515-525.

1124 Knight, R.D., Nair, S., Nelson, S.S., Afshar, A., Javidan, Y., Geisler, R., Rauch, G.J., and 1125 Schilling, T.F. (2003). Lockjaw encodes a zebrafish tfap2a required for early neural crest 1126 development. Development 130, 5755-5768.

1127 Kuo, B.R., and Erickson, C.A. (2011). Vagal neural crest cell migratory behavior: A transition 1128 between the cranial and trunk crest. Dev. Dyn. 240, 2084-2100. 
1129 Kwak, J., Park, O.K., Jung, Y.J., Hwang, B.J., Kwon, S.H., and Kee, Y. (2013). Live image 1130 profiling of neural crest lineages in zebrafish transgenic lines. Mol. Cells 35, 255-260.

1131 Lasrado, R., Boesmans, W., Kleinjung, J., Pin, C., Bell, D., Bhaw, L., McCallum, S., Zong, H., 1132 Luo, L., Clevers, H., et al. (2017). Lineage-dependent Spatial and Functional Organization of 1133 the Mammalian Enteric Nervous System. Science (80-. ). 356, 722-726.

1134 Lay, J., Carbone, S.E., Dicello, J.J., Bunnett, N.W., Canals, M., and Poole, D.P. (2016). 1135 Distribution and trafficking of the-opioid receptor in enteric neurons of the guinea pig. Am J 1136 Physiol Gastrointest Liver Phy-Siol 311, 252-266.

1137 Leigh, N.R., Schupp, M.O., Li, K., Padmanabhan, V., Gastonguay, A., Wang, L., Chun, C.Z., 1138 Wilkinson, G.A., and Ramchandran, R. (2013). Mmp17b Is Essential for Proper Neural Crest 1139 Cell Migration In Vivo. PLoS One 8, e76484.

1140 Le Lievre, C.S., and Le Douarin, N.M. (1975). Mesenchymal derivatives of the neural crest: 1141 analysis of chimaeric quail and chick embryos. J. Embryol. Exp. Morphol. 34, 125-154.

1142 Ling, I.T.C., and Sauka-Spengler, T. (2019). Early chromatin shaping predetermines 1143 multipotent vagal neural crest into neural, neuronal and mesenchymal lineages. Nat. Cell Biol. $114421,1504-1517$.

1145 Lister, J.A. (2002). Development of pigment cells in the zebrafish embryo. Microsc. Res. Tech. $114658,435-441$.

1147 Lister, J.A., Robertson, C.P., Lepage, T., Johnson, S.L., and Raible, D.W. (1999). Nacre 1148 Encodes a Zebrafish Microphthalmia-Related Protein That Regulates Neural-Crest-Derived 1149 Pigment Cell Fate. Development 126, 3757-3767.

1150 Lister, J.A., Lane, B.M., Nguyen, A., and Lunney, K. (2011). Embryonic expression of 1151 zebrafish MiT family genes Tfe3b, Tfeb, and Tfec. Dev. Dyn. 240, 2529-2538.

1152 Lu, J.-K., Tsai, T.-C., Lee, H., Hsia, K., Lin, C.-H., and Lu, J.-H. (2019). Pectoral Fin 1153 Anomalies in tbx5a Knockdown Zebrafish Embryos Related to the Cascade Effect of N1154 Cadherin and Extracellular Matrix Formation. J. Dev. Biol. 7, 15.

1155 Ludwig, A., Rehberg, S., and Wegner, M. (2004). Melanocyte-specific expression of 1156 dopachrome tautomerase is dependent on synergistic gene activation by the Sox10 and Mitf 1157 transcription factors. FEBS Lett. 556, 236-244.

1158 Lumb, R., Buckberry, S., Secker, G., Lawrence, D., and Schwarz, Q. (2017). Transcriptome 1159 profiling reveals expression signatures of cranial neural crest cells arising from different axial 1160 levels. BMC Dev. Biol. 17, e5.

1161 Luo, R., An, M., Arduini, B.L., and Henion, P.D. (2001). Specific pan-neural crest expression 1162 of zebrafish crestin throughout embryonic development. Dev. Dyn. 220, 169-174.

1163 Martik, M.L., and Bronner, M.E. (2017). Regulatory Logic Underlying Diversification of the 1164 Neural Crest. Trends Genet. 33, 715-727. 
1165 Matini, P., Manneschi, L.I., Mayer, B., and Faussone-Pellegrini, M.S. (1995). Nitric oxide 1166 producing neurons in the human colon: an immunohistochemical and histoenzymatical study. 1167 Neurosci. Lett. 193, 17-20.

1168 McGraw, H.F., Nechiporuk, A., and Raible, D.W. (2008). Zebrafish Dorsal Root Ganglia 1169 Neural Precursor Cells Adopt a Glial Fate in the Absence of neurogenin1. J. Neurosci. 28, $117012558-12569$.

1171 Mcinnes, L., Healy, J., and Melville, J. (2018). UMAP: Uniform Manifold Approximation and 1172 Projection for Dimension Reduction. ArXiv 1802.03426v2.

1173 Memic, F., Knoflach, V., Morarach, K., Sadler, R., Laranjeira, C., Hjerling-Leffler, J., 1174 Sundström, E., Pachnis, V., and Marklund, U. (2018). Transcription and Signaling Regulators 1175 in Developing Neuronal Subtypes of Mouse and Human Enteric Nervous System. 1176 Gastroenterology 154, 624-636.

1177 Mi, H., Muruganujan, A., Huang, X., Ebert, D., Mills, C., Guo, X., and Thomas, P.D. (2019). 1178 Protocol Update for large-scale genome and gene function analysis with the PANTHER 1179 classification system (v.14.0). Nat. Protoc. 14, 703-721.

1180 Minchin, J.E.N., and Hughes, S.M. (2008). Sequential actions of Pax3 and Pax7 drive 1181 xanthophore development in zebrafish neural crest. Dev. Biol. 317, 508-522.

1182 Minoux, M., and Rijli, F.M. (2010). Molecular mechanisms of cranial neural crest cell 1183 migration and patterning in craniofacial development. Development 137, 2605-2621.

1184 Morarach, K., Mikhailova, A., Knoflach, V., Memic, F., Kumar, R., Li, W., Ernfors, P., and 1185 Marklund, U. (2020). Diversification of molecularly defined myenteric neuron classes revealed 1186 by single cell RNA-sequencing. Nat Neurosci. https://doi.org/10.1038/s41593-020-00736-X

1187 Nagy, N., and Goldstein, A.M. (2017). Enteric Nervous System Development: A Crest Cell's 1188 Journey From Neural Tube to Colon. Semin. Cell Dev. Biol. 66, 94-106.

1189 Nakamura, T., Gehrke, A.R., Lemberg, J., Szymaszek, J., and Shubin, N.H. (2016). Digits and 1190 fin rays share common developmental histories. Nature 537, 225-228.

1191 Nord, H., Dennhag, N., Muck, J., and Von Hofsten, J. (2016). Pax7 is required for 1192 establishment of the xanthophore lineage in zebrafish embryos. Mol. Biol. Cell 27, 1853-1862.

1193 Olden, T., Akhatar, T., Beckman, S.A., and Wallace, K.N. (2008). Differentiation of the 1194 Zebrafish Enteric Nervous System and Intestinal Smooth Muscle. Genesis 46, 484-498.

1195 van Otterloo, E., Li, W., Garnett, A., Cattell, M., Medeiros, D.M., and Cornell, R.A. (2012). 1196 Novel Tfap2-mediated control of soxE expression facilitated the evolutionary emergence of the 1197 neural crest. Development 139, 720-730.

1198 Parichy, D.M., Ransom, D.G., Paw, B., Zon, L.I., and Johnson, S.L. (2000). An Orthologue of 1199 the Kit-Related Gene Fms Is Required for Development of Neural Crest-Derived Xanthophores 1200 and a Subpopulation of Adult Melanocytes in the Zebrafish, Danio Rerio. Development 127, 1201 3031-3044. 
1202 Parker, H.J., Pushel, I., and Krumlauf, R. (2018). Coupling the roles of Hox genes to regulatory 1203 networks patterning cranial neural crest. Dev. Biol. 444, S67-S78.

1204 Parker, H.J., De Kumar, B., Green, S.A., Prummel, K.D., Hess, C., Kaufman, C.K., Mosimann, 1205 C., Wiedemann, L.M., Bronner, M.E., and Krumlauf, R. (2019). A Hox-TALE regulatory 1206 circuit for neural crest patterning is conserved across vertebrates. Nat. Commun. 10, 1182.

1207 Petratou, K., Subkhankulova, T., Lister, J.A., Rocco, A., Schwetlick, H., and Kelsh, R.N. 1208 (2018). A Systems Biology Approach Uncovers the Core Gene Regulatory Network Governing 1209 Iridophore Fate Choice From the Neural Crest. PLOS Genet. 14, e1007402.

1210 Petratou, K., Spencer, S.A., Kelsh, R.N., and Lister, J.A. (2019). The MITF paralog tfec is 1211 required in neural crest development for fate specification of the iridophore lineage from a 1212 multipotent pigment cell progenitor. BioRxiv 862011.

1213 Philippidou, P., and Dasen, J.S.S. (2013). Hox Genes: Choreographers in Neural Development, 1214 Architects of Circuit Organization. Neuron 80, 12-34.

1215 Poon, K.L., Richardson, M., Lam, C.S., Khoo, H.E., and Korzh, V. (2003). Expression pattern 1216 of neuronal nitric acid oxide synthase in embryonic zebrafish. Gene Expr. Patterns 3, 463-466.

1217 Qu, Z.D., Thacker, M., Castelucci, P., Bagyánszki, M., Epstein, M.L., and Furness, J.B. (2008). 1218 Immunohistochemical analysis of neuron types in the mouse small intestine. Cell Tissue Res. $1219334,147-161$.

1220 Quigley, I.K., and Parichy, D.M. (2002). Pigment pattern formation in zebrafish: A model for 1221 developmental genetics and the evolution of form. Microsc. Res. Tech. 58, 442-455.

1222 R Core Team (2020). R. R A Lang. Environ. Stat. Comput. R Found. Stat. Comput.

1223 Raffaeli, G., Cavallaro, G., Allegaert, K., Wildschut, E.D., Fumagalli, M., Agosti, M., Tibboel, 1224 D., and Mosca, F. (2017). Neonatal Abstinence Syndrome: Update on Diagnostic and 1225 Therapeutic Strategies. Pharmacother. J. Hum. Pharmacol. Drug Ther. 37, 814-823.

1226 Rajan, S.G., Gallik, K.L., Monaghan, J.R., Uribe, R.A., Bronner, M.E., and Saxena, A. (2018). 1227 Tracking neural crest cell cycle progression in vivo. Genesis 56, e23214.

1228 Rao, M., and Gershon, M.D. (2018). Enteric nervous system development: what could possibly 1229 go wrong? Nat. Rev. Neurosci. 19, 552-565.

1230 Reedy, M. V., Faraco, C.D., and Erickson, C.A. (1998). Specification and migration of 1231 melanoblasts at the vagal level and in hyperpigmented silkie chickens. Dev. Dyn. 213, 476-485.

1232 Rocha, M., Singh, N., Ahsan, K., Beiriger, A., and Prince, V.E. (2020). Neural crest 1233 development: insights from the zebrafish. Dev. Dyn. 249, 88-111.

1234 Rodrigues, F.S.L.M., Doughton, G., Yang, B., and Kelsh, R.N. (2012). A novel transgenic line 1235 using the Cre-lox system to allow permanent lineage-labeling of the zebrafish neural crest. 1236 Genesis 50, 750-757. 
1237 Rueden, C.T., Schindelin, J., Hiner, M.C., Dezonia, B.E., Walter, A.E., Arena, E.T., and 1238 Eliceiri, K.W. (2017). ImageJ2: ImageJ for the next generation of scientific image data. BMC 1239 Bioinformatics 18, 529.

1240 Roy-Carson, S., Natukunda, K., Chou, H., Pal, N., Farris, C., Schneider, S.Q., and Kuhlman, 1241 J.A. (2017). Defining the transcriptomic landscape of the developing enteric nervous system 1242 and its cellular environment. BMC Genomics 18, 290.

1243 Ruzicka, L., Howe, D.G., Ramachandran, S., Toro, S., Van Slyke, C.E., Bradford, Y.M., Eagle, 1244 A., Fashena, D., Frazer, K., Kalita, P., et al. (2019). The Zebrafish Information Network: new 1245 support for non-coding genes, richer Gene Ontology annotations and the Alliance of Genome 1246 Resources. Nucleic Acids Res. 47, D867-873.

1247 Satija, R., Farrell, J.A., Gennert, D., Schier, A.F., and Regev, A. (2015). Spatial reconstruction 1248 of single-cell gene expression data. Nat. Biotechnol. 33, 495-502.

1249 Sauka-Spengler, T., and Bronner-Fraser, M. (2008). A gene regulatory network orchestrates 1250 neural crest formation. Nat. Rev. Mol. Cell Biol. 9, 577-568.

1251 Saunders, L.M., Mishra, A.K., Aman, A.J., Lewis, V.M., Toomey, M.B., Packer, J.S., Qiu, X., 1252 McFaline-Figueroa, J.L., Corbo, J.C., Trapnell, C., et al. (2019). Thyroid hormone regulates 1253 distinct paths to maturation in pigment cell lineages. Elife 8, e45181.

1254 Schindelin, J., Arganda-Carreras, I., Frise, E., Kaynig, V., Longair, M., Pietzsch, T., Preibisch, 1255 S., Rueden, C., Saalfeld, S., Schmid, B., et al. (2012). Fiji: an open-source platform for 1256 biological-image analysis. Nat. Methods 9, 676-682.

1257 Schneider, C.A., Rasband, W.S., and Eliceiri, K.W. (2012). NIH Image to ImageJ: 25 years of 1258 image analysis. Nat. Methods 9, 671-675.

1259 Shepherd, I.T., Pietsch, J., Elworthy, S., Kelsh, R.N., and Raible, D.W. (2004). Roles for 1260 GFR $\alpha 1$ receptors in zebrafish enteric nervous system development. Development 131, 241-249.

1261 Simoes-Costa, M., and Bronner, M.E. (2016). Reprogramming of avian neural crest axial 1262 identity and cell fate. Science (80-. ). 352, 1570-1573.

1263 Simões-Costa, M., Tan-Cabugao, J., Antoshechkin, I., Sauka-Spengler, T., and Bronner, M.E. 1264 (2014). Transcriptome analysis reveals novel players in the cranial neural crest gene regulatory 1265 network. Genome Res. 24, 281-290.

1266 Singleman, C., and Holtzman, N.G. (2014). Growth and maturation in the zebrafish, Danio 1267 Rerio: A staging tool for teaching and research. Zebrafish 11, 396-406.

1268 Sobczak, M., Sałaga, M., Storr, M.A., and Fichna, J. (2014). Physiology, signaling, and 1269 pharmacology of opioid receptors and their ligands in the gastrointestinal tract: Current 1270 concepts and future perspectives. J. Gastroenterol. 49, 24-45.

1271 Soldatov, R., Kaucka, M., Kastriti, M.E., Petersen, J., Chontorotzea, T., Englmaier, L., 1272 Akkuratova, N., Yang, Y., Häring, M., Dyachuk, V., et al. (2019). Spatio-temporal structure of 1273 cell fate decisions in murine neural crest. Science (80-. ). 364, eaas9536. 
1274 Sperber, S.M., and Dawid, I.B. (2008). barx1 is necessary for ectomesenchyme proliferation 1275 and osteochondroprogenitor condensation in the zebrafish pharyngeal arches. Dev. Biol. 321, 1276 101-110.

1277 Sperber, S.M., Saxena, V., Hatch, G., and Ekker, M. (2008). Zebrafish dlx2a Contributes to 1278 Hindbrain Neural Crest Survival, Is Necessary for Differentiation of Sensory Ganglia and 1279 Functions With dlx1a in Maturation of the Arch Cartilage Elements. Dev. Biol. 314, 59-70.

1280 Stewart, R.A., Arduini, B.L., Berghmans, S., George, R.E., Kanki, J.P., Henion, P.D., and 1281 Look, A.T. (2006). Zebrafish foxd3 Is Selectively Required for Neural Crest Specification, 1282 Migration and Survival. Dev. Biol. 292, 174-188.

1283 Strausberg, R.L., Feingold, E.A., Grouse, L.H., Derge, J.G., Klausner, R.D., Collins, F.S., 1284 Wagner, L., Shenmen, C.M., Schuler, G.D., Altschul, S.F., et al. (2002). Generation and initial 1285 analysis of more than 15,000 full-length human and mouse cDNA sequences. Proc. Natl. Acad. 1286 Sci. U. S. A. 99, 16899-16903.

1287 Stuart, T., Butler, A., Hoffman, P., Hafemeister, C., Papalexi, E., Mauck, W.M., Hao, Y., 1288 Stoeckius, M., Smibert, P., and Satija, R. (2019). Comprehensive Integration of Single-Cell 1289 Data. Cell 177, 1888-1902.e21.

1290 Tambalo, M., Mitter, R., and Wilkinson, D.G. (2020). A single cell transcriptome atlas of the 1291 developing zebrafish hindbrain. Dev. 147, dev184143.

1292 Taylor, C.R., Montagne, W.A., Eisen, J.S., and Ganz, J. (2016). Molecular fingerprinting 1293 delineates progenitor populations in the developing zebrafish enteric nervous system. Dev. Dyn. 1294 245, 1081-1096.

1295 Theodore, L.N., Hagedorn, E.J., Cortes, M., Natsuhara, K., Liu, S.Y., Perlin, J.R., Yang, S., 1296 Daily, M.L., Zon, L.I., and North, T.E. (2017). Distinct Roles for Matrix Metalloproteinases 2 1297 and 9 in Embryonic Hematopoietic Stem Cell Emergence, Migration, and Niche Colonization. 1298 Stem Cell Reports 8, 1226-1241.

1299 Theveneau, E., and Mayor, R. (2012). Neural crest delamination and migration: From 1300 epithelium-to-mesenchyme transition to collective cell migration. Dev. Biol. 366, 34-54.

1301 Thisse, B., and Thisse, C. (2004). Fast Release Clones: A High Throughput Expression 1302 Analysis. ZFIN Direct Data Submission. (http://zfin.org).

1303 Thisse, C., and Thisse, B. (2005). High Throughput Expression Analysis of ZF-Models 1304 Consortium Clones. ZFIN Direct Data Submission. http://zfin.org.

1305 Thisse, B., Pflumio, S., Fürthauer, M., Loppin, B., Heyer, V., Degrave, A., Woehl, R., Lux, A., 1306 Steffan, T., Charbonnier, X.., et al. (2001). Expression of the zebrafish genome during 1307 embryogenesis. ZFIN Direct Data Submission. (http://zfin.org).

1308 Uribe, R.A., and Bronner, M.E. (2015). Meis3 is required for neural crest invasion of the gut 1309 during zebrafish enteric nervous system development. Mol. Biol. Cell 26, 3728-3740. 
1310 Uyttebroek, L., Shepherd, I.T., Harrisson, F., Hubens, G., Blust, R., Timmermans, J.P., and van 1311 Nassauw, L. (2010). Neurochemical coding of enteric neurons in adult and embryonic zebrafish 1312 (Danio rerio). J. Comp. Neurol. 518, 4419-4438.

1313 Vega-Lopez, G.A., Cerrizuela, S., and Aybar, M.J. (2017). Trunk neural crest cells: formation, 1314 migration and beyond. Int. J. Dev. Biol. 61, 5-15.

1315 Wagner, D.E., Weinreb, C., Collins, Z.M., Briggs, J.A., Megason, S.G., and Klein, A.M. 1316 (2018). Single-cell mapping of gene expression landscapes and lineage in the zebrafish embryo.

1317 Science (80-. ). 360, 981-987.

1318 Wang, H.H., Chen, H.S., Li, H.B., Zhang, H., Mei, L.Y., He, C.F., Wang, X.W., Men, M.C., 1319 Jiang, L., Liao, X. Bin, et al. (2014). Identification and functional analysis of a novel mutation 1320 in the SOX10 gene associated with Waardenburg syndrome type IV. Gene 538, 36-41.

1321 Wang, W. Der, Melville, D.B., Montero-Balaguer, M., Hatzopoulos, A.K., and Knapik, E.W. 1322 (2011). Tfap2a and Foxd3 regulate early steps in the development of the neural crest progenitor 1323 population. Dev. Biol. 360, 173-185.

1324 Williams, A.L., and Bohnsack, B.L. (2015). Neural crest derivatives in ocular development: 1325 Discerning the eye of the storm. Birth Defects Res. Part C Embryo Today Rev. 105, 87-95.

1326 Williams, R.M., Candido-Ferreira, I., Repapi, E., Gavriouchkina, D., Senanayake, U., Ling, 1327 I.T.C., Telenius, J., Taylor, S., Hughes, J., and Sauka-Spengler, T. (2019). Reconstruction of the 1328 Global Neural Crest Gene Regulatory Network In Vivo. Dev. Cell 51, 522-576.e7.

1329 Wilson, Y.M., Richards, K.L., Ford-Perriss, M.L., Panthier, J.J., and Murphy, M. (2004). 1330 Neural crest cell lineage segregation in the mouse neural tube. Development 131, 6153-6162.

1331 Wood, J.D., and Galligan, J.J. (2004). Function of opioids in the enteric nervous system. 1332 Neurogastroenterol. Motil. 16, 17-28.

1333 Yelon, D., Brauch, T., Halpern, M.E., Ruvisnsky, I., Ho, R.K., Silver, L.M., and Stainier, 1334 D.Y.R. (2000). The bHLH transcription factor Hand2 plays parallel roles in zebrafish heart and 1335 pectoral fin development. Development 127, 2573-2582.

1336 Yntema, C.L., and Hammond, W.S. (1954). The origin of intrinsic ganglia of trunk viscera from 1337 vagal neural crest in the chick embryo. J. Comp. Neurol. 101, 515-541.

1338 Zheng, G.X.Y., Terry, J.M., Belgrader, P., Ryvkin, P., Bent, Z.W., Wilson, R., Ziraldo, S.B., 1339 Wheeler, T.D., Mcdermott, G.P., Zhu, J., et al. (2017). Massively parallel digital transcriptional 1340 profiling of single cells. Nat. Commun. 8, 14049.

1341 Zoli, M. (2000). Distribution of Cholinergic Neurons in the Mammalian Brain with Special 1342 Reference to their Relationship with Neuronal Nicotinic Acetylcholine Receptors. In Neuronal 1343 Nicotinic Receptors. Handbook of Experimental Pharmacology, F. Clementi, D. Fornasari, and 1344 C. Gotti, eds. (Berlin, Heidelberg: Springer), pp. 13-30. 


\section{Figure Legends}

1348

1349 Figure 1. Single-Cell profiling strategy and cell population composition of posterior 1350 sox 10: $\mathrm{GFP}^{+}$cells from the posterior zebrafish during the embryonic to larval stage 1351 transition.

1352 (A) Confocal image of a sox10: $\mathrm{GFP}^{+}$embryo at 48 hpf; Hb: Hindbrain; Sc: Spinal cord. A: 1353 Anterior, P: Posterior, D: Dorsal, V: Ventral. Scale bar: $50 \mu \mathrm{M}$

1354 (B) Cartoon illustrations of a zebrafish embryo at 48-50 hpf and an early larval fish at 68-70 hpf 1355 depicted laterally to summarize the dissection workflow used to collect posterior sox 10:GFP ${ }^{+}$ 1356 cells.

1357 (C) Schematic of the 10X Genomics Chromium and data analysis pipeline.

1358 (D) tSNE plots showing the arrangement of Clusters 0-18 and where the major cell types 1359 identified among sox 10:GFP ${ }^{+}$cells arrange in the 48-50 hpf dataset.

1360 (E) tSNE plots showing the arrangement of Clusters 0-22 and where the major cell types 1361 identified among sox10:GFP ${ }^{+}$cells arrange in the 68-70 hpf dataset.

1362 (F,G) Dot plots of the identifying gene markers for each major cell type classification in the 48$136350 \mathrm{hpf}$ and 68-70 hpf datasets, respectively. Dot size depicts the cell percentage for each marker 1364 within the dataset and the color summarizes the average expression levels for each gene.

1366 Figure 1- figure supplement 1. Statistics on generation and filtering of single cell 1367 transcriptomes at 48-50 hpf and 68-70 hpf.

$1368(\mathbf{A}, \mathbf{B})$ Fluorescence activated cell sorting plots highlighting the $\mathrm{GFP}^{+}$cell population sorted at 1369 48-50 hpf (A) and 68-70 hpf (B).

1370 (C) Table of general statistics pertaining to the sequencing and alignment of reads from the Cell 1371 Ranger pipeline. Additional metrics provided were derived from the Seurat R package as 1372 described in the Materials \& Methods section.

1373 (D,E) Plots showing the feature selection for both the 48-50 hpf (D) and 68-70 hpf (E) datasets. 1374 Cells were selected such that they had fewer than 2500 features to reduce spuriously sorted 1375 cells.

1376 (F,G) Top 2000 most variably expressed genes were identified and used for further downstream 1377 identification of significant principal components, as described in the Materials \& Methods 1378 section.

1379 (H,I) Most significant principle components (top 20 for both datasets) were selected to be used 1380 for subsequent cluster identification and cell embedding in tSNE and UMAP spaces.

1382 Figure 1-figure supplement 2. Major cell type annotations among sox 10:GFP ${ }^{+}$cells.

1383 (A,B) Heatmap summarizing the top 10 genes significantly expressed in each cluster, for 48-50 1384 and 68-70 hpf, respectively. Relative expression levels within each cluster is summarized within 1385 the color key, where yellow to magenta color indicates high to low gene expression levels. 
1386 (C,D) Heatmaps summarizing the top 30 genes significantly expressed among the major cell 1387 types identified among sox10:GFP ${ }^{+}$cells, for 48-50 and 68-70 hpf, respectively. Relative 1388 expression levels within each major cell type cluster is summarized within the color key, where 1389 yellow to magenta color indicates high to low gene expression levels.

1390 (E,F) tSNE plots depicting the major cell type classification representative gene marker for 1391 each major cell type category, for 48-50 and 68-70 hpf, respectively. Relative expression levels 1392 are summarized within the color keys, where color intensity is proportional to expression level 1393 of each gene depicted.

1394

1395 Figure 1- figure supplement 3. Major cell type categories and cell cycle distributions of the 1396 scRNA-seq datasets.

1397 (A,B) tSNE plots summarizing the G1, S and G2/M phase cell cycle phase occupancies of the 1398 cells in the 48-50 and 68-70 hpf time points, respectively.

1399 (C,E) A tSNE plot depicting the expression of aurkb, a G2/M phase marker, within the 48-50 1400 and 68-70 hpf datasets, respectively. Relative expression levels are summarized within the color 1401 keys, where color intensity is proportional to expression level of each gene depicted.

1402 (D,F) A tSNE plot depicting the expression of $m c m 3$, a $\mathrm{S}$ phase marker, within the 48-50 and 1403 68-70 hpf datasets, respectively. Relative expression levels are summarized within the color 1404 keys, where color intensity is proportional to expression level of each gene depicted.

1405 (G) Bar graphs summarizing the cell cycle phase occupancies, as a fraction of cells within the 1406 total datasets for each time point.

1407 (H) Bar graphs summarizing the major cell type categories, as a fraction of cells within the total 1408 datasets for each time point.

1409 (I) Table summarizing the cell cycle genes used to demarcate cell cycle phase occupancy 1410 categories within the scRNA-seq datasets.

1411

1412 Figure 1- figure supplement 4. Table summarizing the top identity markers used for 1413 major cell type and subtype cellular classifications for each cluster at 48-50 and 68-70 hpf. 1414

1415 Figure 1- figure supplement 5. Identification of otic vesicle, muscle, and central nervous 1416 system (CNS) cellular populations

1417 (A) Panel of tSNE feature plots at 48-50 hpf that identify combinatorial expression of otic 1418 vesicle (otomp, cldna, cldn7b and epcam), muscle (ckmb, actclb, tnnt3a and tpma), or CNS 1419 (slc32al, gad1b, slc6a5, gata2a) markers. Cluster of interest denoted by black arrows.

1420 (B) Panel of tSNE feature plots at 68-70 hpf that identify combinatorial expression of otic 1421 vesicle markers (otomp, cldna, cldn7b and epcam) or muscle (ckmb, actc1b, tnnt3a and tpma).

1422 Cluster of interest denoted by black arrows.

1423 Figure 1- figure supplement 6. Identification of fin bud and sensory neuronal progenitor 1424 cellular populations 
1425 (A) Panel of tSNE feature plots of sensory neuronal progenitors at 48-50 hpf that show 1426 combinatorial expression of neurod4, neurod1, vim, and ngfrb, Cluster of interest denoted by 1427 black arrows.

1428 (B) Panel of tSNE feature plots of fin bud makers at 48-50 hpf (top) and 68-70 hpf (bottom) 1429 that show combinatorial expression of $t b x 5 a$, hand2, hoxd13a, and prrxla. Cluster of interest 1430 denoted by black arrows.

1431

1432 Figure 1- source data 1. List of marker genes per cluster in the sox10:GFP scRNA-seq 1433 datasets.

1434 Tables reporting the Seurat output for genes for each cluster at the 48-50 hpf (Tab 1) and 68-70 1435 hpf (Tab 2) time points, including p-values $(<0.01)$, average log-fold change $(\geq .25)$, adjusted p1436 values $(\leq 1.0)$, pct.1 summarizing proportion of cells expressing the individual gene in the 1437 cluster, pct.2 showing the proportion of cells expressing the individual gene in all other clusters 1438 in the dataset.

1439

Figure 2. Distinct pigment cell populations are present among sox10:GFP ${ }^{+}$cells during

1442 (A) Cartoon schematic depicting the model for neural crest delineation into pigment 1443 cell lineages and the genes that were used to identify each pigment cell population.

1444 (B) Dot plot identifying melanophore markers within the 48-50 hpf dataset. Dot size depicts the 1445 cell percentage for each marker within the dataset and the color summarizes the average 1446 expression levels for each gene.

1447 (C) tSNE plots depicting melanophore signature in the 48-50 hpf dataset. Relative expression 1448 levels are summarized within the color keys, where color intensity is proportional to expression 1449 level of each gene depicted.

1450 (D) Dot plot showing distinct pigment chromatophore markers within the 68-70 hpf dataset. Dot 1451 size depicts the cell percentage for each marker within the dataset and the color summarizes the 1452 average expression levels for each gene. M: melanophore markers; X: xanthophore markers; I: 1453 iridophore markers.

1454 (E-G) tSNE plots revealing the location of melanophores (E), xanthophores (F), and 1455 iridophores (G) in the 68-70 hpf dataset. Relative expression levels are summarized within the 1456 color keys, where color intensity is proportional to expression level of each gene depicted.

1457 (H) HCR against mitfa and $t f e c$ at 48-50 hpf reveals mitfa $^{+}$melanophores (white arrowhead) 1458 and mitfa $^{+} / t f e c^{+}$pigment progenitors (red arrowhead). Cropped panels show individual 1459 fluorescent channels.

1460 (I) HCR against mitfa and tfec at 68-70 hpf presents $m i t f a^{+}$melanophores (white arrowhead), $1461 \mathrm{tfec}^{+}$iridophores (blue arrowhead), and $\mathrm{mitfa}^{+} / \mathrm{tfec} \mathrm{c}^{+}$pigment progenitors (red arrowhead). 1462 Cropped panels show individual fluorescent channels.

1463 (J) HCR against mitfa and $x d h$ at 68-70 hpf shows $\mathrm{mitfa}^{+} / \mathrm{xdh}^{+}$xanthophores (orange 1464 arrowhead). Cropped panels show individual fluorescent channels.

1465 Scale bar in H-J: $50 \mu \mathrm{m}$. 
1467 Figure 2- source data 1. Melanophore populations, shared and unique genes at 68-70 hpf.

1468 Table summarizing the genes ("elements") exclusively found in Cluster 4, exclusively found in

1469 Cluster 18, and genes found in both Cluster 4 and 18 at the 68-70 hpf time point scRNA-seq

1470 dataset.

1471

1472 Figure 3. Global analysis of mesenchyme cell signatures among sox 10:GFP ${ }^{+}$cells.

1473 (A,B) A heatmap of signature mesenchyme identity genes within the major cell type classified 1474 cells at 48-50 and 68-70 hpf, respectively. Relative expression levels within each cluster is 1475 summarized within the color key, where red to blue color indicates high to low gene expression 1476 levels.

1477 (C) A cluster tree depicting the relationship between general and chondrogenic mesenchyme 1478 cellular subtypes.

1479 (D) Violin plots summarizing the expression levels for select mesenchyme identity markers 1480 within individual clusters at the 48-50 and 68-70 hpf time points, respectively. Data points 1481 depicted in each cluster represent single cells expressing each gene shown.

1482 (E,L) tSNE plots depicting the expression of prrxlb, barxl and twistla in the 48-50 and 68-70 1483 hpf datasets, respectively. Relative expression levels are summarized within the color keys, 1484 where color intensity is proportional to expression level of each gene depicted.

1485 (F-K) Whole mount HCR analysis reveals the spatiotemporal expression of prrxlb (F), barxl 1486 (G), twistla (H), sox:GFP (J) in $48 \mathrm{hpf}$ embryos. (I) A merge of barxl, prrxlb and twistla is 1487 shown. (K) A merge of barxl, prrxlb, twistla and sox10:GFP is shown. White arrowheads 1488 denote expression in posterior pharyngeal arch, while yellow arrowheads highlight fin bud 1489 expression.

1490 (M-R) Whole mount HCR analysis reveals the spatiotemporal expression of prrxlb (M), barxl 1491 (N), twistla (O), sox:GFP (Q) in $68 \mathrm{hpf}$ embryos. (P) A merge of barxl, prrxlb and twistla is 1492 shown. (R) A merge of barx1, prrxlb, twistla and sox10:GFP is shown. White arrowheads 1493 denote expression in posterior pharyngeal arch, while yellow arrowheads highlight fin bud 1494 expression.

1495 Ot: otic; Fb: Fin bud. Scale bar: $100 \mu \mathrm{m}$.

1496

1497 Figure 3- figure supplement 1. Whole mount in situ hybridization of select ENCC, 1498 mesenchyme and neural markers at 48-50 hpf.

1499 (A, $\left.\mathbf{A}^{\prime}\right)$ The marker sox10 is shown along the vagal region and within ENCC along the foregut 1500 in (A'; highlighted via arrowheads). Scale bar in A: $60 \mu \mathrm{M}$, in A': $40 \mu \mathrm{M}$.

1501 (B, B') Expression of phox $2 b b$ is shown within the hindbrain-axial level of the embryo, as well 1502 as within ENCC within the foregut (B'; highlighted via arrowheads). Scale bar in $\mathbf{A}: 60 \mu \mathrm{M}$, in 1503 A': $40 \mu \mathrm{M}$.

1504 (C,D) The mesenchyme markers mmp2 (C, highlighted via arrowheads) and foxcla (D; 1505 highlighted via arrowheads) are expressed within the posterior pharyngeal arches and the 1506 ventral mesenchyme.

1507 (E,F) The neural markers notchla $(\mathbf{E})$ and $d l a(\mathbf{F})$ are expressed within the hindbrain and spinal 1508 cord (arrowheads). (F) dla expression is seen in the ENCC (arrow). 
1509 Scale bar in C-F: $60 \mu \mathrm{M}$

1510

1511 Figure 4. Enteric neural crest cells and differentiating enteric neurons are present among 1512 posterior sox 10:GFP ${ }^{+}$cell populations.

1513 (A) tSNE feature plots reveal expression of core neural crest cell markers sox10, foxd3, crestin 1514 and tfap2a mapping to the neural crest cell cluster (red arrow).

1515 (B) tSNE feature plots depict expression of the enteric neural crest cell markers phox $2 b b$, ret, $1516 n g f r b$ and gfrala within the neural crest cell cluster (red arrow).

1517 Relative expression levels are summarized within the color keys in (A) and (B), where color 1518 intensity is proportional to expression level of each gene depicted.

1519 (C) A heatmap reveals expression levels of enteric neural crest cell markers across the 8 major 1520 cell populations captured in the 48-50 hpf data set (color key denotes cells types represented in 1521 color bar on top of heatmap). Neural crest cell cluster highlighted in black rectangle. Relative 1522 expression levels within each major cell type cluster is summarized within the color key, where 1523 yellow to magenta color indicates high to low gene expression levels.

1524 (D) Dot plot of expanded list of neural crest (green line) and enteric neural crest (purple line) 1525 cell markers across each major cell type within 48-50 hpf data set. Dot size depicts the cell 1526 percentage for each marker within the data set and the color summarizes the average expression 1527 levels for each gene.

1528 (E,F) Whole mount HCR analysis of $48 \mathrm{hpf}$ embryos reveals co-expression of enteric neural 1529 crest cell markers within the developing gut (dashed outline). Top panels depict merged images 1530 of color channels for each HCR probe. Lower panels represent grey-scale images of each 1531 separated channel corresponding to the magnified region of foregut (grey rectangle). Arrows 1532 depict regions where all markers are found to be co-expressed. Hb: Hindbrain, Sc: Spinal cord,

1533 pLLg: posterior Lateral Line ganglia, LL: Lateral Line. A: Anterior, P: Posterior, D: Dorsal, V: 1534 Ventral. Scale bar: $50 \mu \mathrm{M}$.

1535 (G) tSNE feature plots reveal expression levels of enteric neuron markers elavl3, phox $2 b b$, 1536 gfrala, nosl, vipb and ret, within a common region of a neuronal cluster (red arrow). Relative 1537 expression levels are summarized within the color keys, where color intensity is proportional to 1538 expression level of each gene depicted.

1539 (H) Dot plot depicts expression levels of pan-neuronal and enteric neuron specific markers 1540 across individual clusters generated within the original 68-70 hpf tSNE. Pan-neuronal markers 1541 found throughout clusters 5 and 12, with enteric neuron markers most prominently expressed 1542 within cluster 12. Dot size depicts the cell percentage for each marker within the data set and 1543 the color summarizes the average expression levels for each gene.

1544 (I) Whole mount HCR analysis depicts differentiating enteric neurons within the foregut region 1545 at $69 \mathrm{hpf}$ co-expressing nos1, phox $2 \mathrm{bb}$, vipb, and elavl3 (yellow arrow). Anterior: Left, 1546 Posterior: Right. Scale bar: $50 \mu \mathrm{M}$.

1548 Figure 5. Differentiating enteric neurons captured during key transitional stage of 1549 subtype diversification within 68-70 hpf sox 10:GFP ${ }^{+}$larval cells. 
1550 (A) tSNE plot reveals 5 distinct sub-clusters following the subset analysis and re-clustering of 1551 clusters 5 and 12 from the 68-70 hpf data set.

1552 (B) Dot plot depicts expression levels of enteric neuron markers across resulting Sub-clusters.

1553 Each marker was expressed at low levels in Sub-cluster 1 and were found to be expressed at 1554 higher levels within Sub-cluster 3.

1555 (C) tSNE feature plots further depict the expression of enteric neuron markers by illustrating the 1556 levels and localization of expression within the Sub-cluster architecture. Feature plots 1557 supplement dot plot and demonstrate the prominent expression of enteric neuron markers within 1558 Sub-cluster 3, which appears to emanate from Sub-cluster 1.

1559 (D,E) Violin and feature plots reveal expression levels of acetylcholine-associated and 1560 excitatory neuron markers reported to distinguish enteric IPANs. These markers were found in a 1561 discrete pocket of cells forming the distal-most region of Sub-cluster 3 (red arrow). Violin data 1562 points depicted in each Sub-cluster represent single cells expressing each gene shown.

1563 (F) Graphical model summarizes expression patterns observed in 68-70 hpf data set and HCR 1564 validation. Common enteric neuroblast capable of diverging into subsequent lineages, IPAN, 1565 inhibitory neuron, and interneuron through lineage restricted gene expression. $p b x 3 b$ promotes 1566 assumption of IPAN role through loss of nos 1 and vipb and begins expressing calb2a, ache and 1567 slc18a3a.

1568 (G) Whole mount HCR analysis reveals co-expression of IPAN markers, $p b x 3 b$ and calb2a, and 1569 inhibitory neurochemical markers, vipb and nosl (white arrows), within the foregut (dashed 1570 white line) at $68 \mathrm{hpf}$. Vesicular acetylcholine transferase, slc18a3a, was not observed in tandem 1571 with $p b x 3 b$ but was co-expressed with calb2a, vipb, and nos 1 (yellow arrow). Scale bar: $50 \mu \mathrm{M}$.

1572 (H) Feature plots reveal expression of opioid receptors, oprll and oprdlb within the 1573 differentiated enteric neuron Sub-Cluster 3.

1574 (I-N) Whole mount HCR analysis validates expression of oprll in combination with vipb and 1575 phox $2 b b$ (yellow arrows) in enteric neurons localized to the foregut region of a $68 \mathrm{hpf}$ embryo. 1576 Scale bar: $10 \mu \mathrm{M}$.

1578 Figure 5- figure supplement 1. Enteric neuron subtype diversification gene expression 1579 patterns seen in enteric neuron Sub-Clusters related to Figure 5D,E

1580 Panel of tSNE feature plots magnified and cropped to focus on progressively differentiating 1581 enteric neurons (highlighted by etvl expression). Subtype diversification and IPAN emergence 1582 depicted via combinatorial gene expression (etv1, ntnglaa, pbx3b, slc18a3a, calb2a, and ache) 1583 localized to the distal tip of Sub-cluster 3. Inhibitory neuron markers, nos 1, vip, and galanin 1584 (galn) were present within the pocket of diverging enteric subtypes.

1585

1586 Figure 5- figure supplement 2. Enteric and sympathetic neuron markers distinguished 1587 among common autonomic neuron precursors.

1588 UMAP analysis of Sub-Clusters depicts enteric and sympathetic neurons delineating from a 1589 common pool of autonomic neurons.

1590 (A) UMAP plot generated following re-clustering of Clusters 5 and 12 from the 68-70 hpf data 1591 set. 
1592 (B) Dot plot depicts expression levels of general autonomic neuron makers (asclla, hand2, 1593 phox $2 a$, phox $2 b b$ ), sympathetic neuron markers (th, $d b h$, lmol, insmla) and enteric neuron 1594 markers (vipb, etv1, nos 1, gfrala) within Sub-Clusters 0-4.

1595 (C) Dendrogram denotes similarity of Sub-Clusters based on average gene expression of each 1596 cell within the Sub-Clusters, which reveals transcriptomic distinction of enteric neuron Sub1597 Cluster 3.

1598 (D-F). Feature plots highlight the expression of autonomic, sympathetic and enteric neuron 1599 gene markers within UMAP Sub-Clusters.

1600

1601 Figure 5- source data 1. List of marker genes per Sub-Cluster, following subset and re1602 clustering of enteric Cluster 5 and 12 at 68-70 hpf.

1603 Table reporting the Seurat output for genes for each Sub-Cluster (0-4), including p-values 1604 (<0.01), average log-fold change (.25), adjusted p-values (1.0), pct.1 summarizing proportion of 1605 cells expressing the individual gene in the sub-cluster, pct.2 showing the proportion of cells 1606 expressing the individual gene in all other sub-clusters in the sub-data set.

1607 Figure 5- source data 2. List of enriched pathways within enteric neuron Sub-Cluster 3 1608 and genes present in specific opioid proenkephalin pathway identified following 1609 PANTHER Overrepresentation Test.

1610 Source Data table contains two sheets. Enriched Gene Pathways sheet lists the enriched 1611 pathways identified following the use of the statistical test, Fisher's exact test that compares the 1612 number of genes in a given pathway within the reference Danio rerio list to the number of 1613 genes in a given pathway within the enteric neuron Sub-Cluster 3 list. This analysis produced 161443 statistically overrepresented pathways. Column B: Number of genes within the given 1615 pathway present with Danio rerio reference list of 25888 genes. Column C: Number of genes 1616 within the given pathway present within Sub-Cluster 3 gene list. Column D: Number of 1617 pathway genes expected to be present within the Sub-Cluster 3 gene list based on the 1618 percentage of pathway genes present in the Danio rerio reference list. Column E: Denotes that 1619 more pathway genes were present in Sub-Cluster 3 gene list than expected. Column F: Fold 1620 enrichment of Sub-Cluster 3 pathway genes comparative to reference list. Column G: P-values 1621 calculated following Fisher's exact test comparing expected number of pathway genes to 1622 number of genes pathway genes in Sub-Cluster 3. Column H: P-value following Benjamini1623 Hochberg false discovery rate (FDR) correction. Opioid proenkephalin pathway sheet lists 1624 genes associated with this pathway that are present within the enteric neuron Sub-Cluster 3 gene 1625 list, notably, opioid receptor oprdlb.

1626

1627 Figure 6. Integrated atlas of posterior sox 10:GFP ${ }^{+}$cell types spanning the embryonic to 1628 larval transition.

1629 (A) Global UMAP embedding demonstrating the clustering of cell types across 48-50 hpf and 1630 68-70 hpf. Cell labels were transferred from the original curation to the new atlas after its 1631 creation, allowing for unbiased assessment of cell type organization. 
1632 (B) Previously identified mesenchyme clusters form a large discernible cluster marked by 1633 prrxlb, twistla, foxcla, and snaila, which was separated into both chondrogenic and general 1634 mesenchyme, as denoted by its differential expression of barxl and $d l x 2 a$. Importantly, nearly 1635 every 48-50 hpf cell type nests with a cluster at 68-70 hpf.

1636 (C) Pigment cells clusters reflect differentiation paths described in Figure 4A. Melanophores at 1637 48-50 hpf group near to the 68-70 hpf melanophore cluster, bipotent pigment progenitors 1638 bridges both the iridophores and melanophores. Xanthophores cluster separately, reflecting their 1639 distinct lineage of origin at this developmental window.

1640 (D) Detailed analysis of the larger neural/neuronal cluster shows clear progression of cell fates 1641 from progenitor to differentiating glia or neuron. We confirm the presence of a clear enteric 1642 neuronal population, which is distinct from other subtypes at this dataset.

1643

1644 Figure 6- figure supplement 1. Annotated sox 10:GFP ${ }^{+}$atlas labeled by cell types.

1645 (A) UMAP labeling the 27 new clusters formed after the generation of the Atlas.

1646 (B) Following label transfer integration, major cell type classifications group together into 1647 distinct clusters.

1648 (C) High resolution visualization of both clustering of original cluster labels as well as their 1649 position within the UMAP. Cell categories segregate in the dendrogram largely as expected 1650 from the UMAP visualization.

1651 (D) Additional markers shown by UMAP for validation of the neural/neuronal clusters.

1652

1653 Figure 6- figure supplement 2. Differential expression among pigment, mesenchyme and 1654 neural/neuronal subsets of the sox10:GFP ${ }^{+}$atlas

1655 (A) UMAP visualization of cells labeled by source identity (either 48-50 hpf or 68-70 hpf) 1656 following integration. All 48-50 hpf cells (pink) approximately map to a major cluster found at 1657 68-70 hpf (aqua).

1658 (B-D) Subset of the pigment clusters (B), the mesenchyme clusters (C), and the neural/neuronal 1659 clusters (D) highlighting several differentially expressed genes between the cells derived from 1660 each timepoint.

1662 Figure 6 - source data 1. List of marker genes per major cell type identity in the 1663 sox 10:GFP ${ }^{+}$merged atlas.

1664 Tables reporting the Seurat output for genes for each major cell type identity including p-values $1665(<0.01)$, average log-fold change $(\geq .25)$, adjusted $p$-values $(\leq 1.0)$, pct. 1 summarizing proportion 1666 of cells expressing the individual gene in the cluster identity category, pct.2 showing the 1667 proportion of cells expressing the individual gene in all cluster identity categories in the atlas 1668 dataset.

1669

1670 Figure 7. Description of Hox genes expressed across cell lineages within the sox10:GFP 1671 atlas.

1672 (A) Dot plot shows both the mean expression (color) as well as percent of cells (size) per 1673 lineage for zebrafish hox genes in the first 8 paralogy groups (PG). The full list of hox gene 
1674 expression profiles per lineage can be found in Figure 7 - figure supplement 1. Discrete hox 1675 profiles discern specific cell types, which is particularly evident in the enteric neuronal cluster.

1676 (B) Clustering of atlas lineages based hox expression profiles groups highlights robust core 1677 neural signature, which distinguishes the neural lineages from the remainder of the clades. 1678 Neural and glial progenitors formed an intermediate clade between the low-hox expressing 1679 lineages and the main neural branch. Additionally, the fin bud mesenchyme, which also has a 1680 highly distinctive hox profile, also forms a distinct clade. Subtle variations in hox expression by 1681 remaining lineages further are further reflected in the remaining portion of the dendrogram, 1682 however these are far less distinct.

1683 (C-D) Pairwise comparison of the fraction of cells in either the autonomic neural progenitor 1684 lineage (C) or the enteric neurons (D) for the first eight parology groups. Intersection of the 1685 gene pairs reflect the fraction of cells with expression for both genes with a $\log 2$ Fold change 1686 values $>0$, with the identical gene intersections along the primary diagon representing the total 1687 number of cells which express that gene in the lineage. Enteric neural hox signature was not 1688 only specific to this cell population, but also was abundantly coexpressed.

1689 (E) Summary panel describing the specific autonomic and enteric hox signatures detected. We 1690 found a common hox expression profile, which we refer to as the core signature, that is then 1691 modified across the specific lineages.

1692 (F-M) In situ validation of the chief enteric neural hox signature via hybridization chain 1693 reaction. phox $2 b b$ (F-J) labels enterically fated neurons at the level of the midgut in larval stage 1694 embryos fixed at 70-72hpf. White arrows highlight specific cells of interest. Key hox signature 1695 constituents hoxb5a (G) and hoxb5b $(\mathbf{H})$ or hoxd4a $(\mathbf{K})$ and hoxa5a $(\mathbf{L})$ were found to be co1696 expressed within phox $2 b b$ expressing cells (White Arrows). Scale bars in (I,M):50 $\mu \mathrm{m}$.

1698 Figure 7 - figure supplement 1. Comprehensive overview of hox expression profiles within 1699 the atlas.

1700 (A) Similar to Figure 7A, a comprehensive dot plot shows both the mean expression (color) as 1701 well as percent of cells per lineage (size) for zebrafish all hox genes. Discrete hox profiles 1702 discern specific cell types, which is particularly evident in the enteric neuronal cluster, as well 1703 as the fin bud mesenchyme.

1704 (B-I) Hindbrain expression patterns for enteric hox profiles. Autonomic neural marker phox $2 b b$ 1705 clearly marks the midbrain and hindbrain (hb) domains, as well as the pharyngeal arches (pa). 1706 Enterically fated cells can also clearly be seen along the tract of the gut (dash region), starting 1707 the foregut (fg). Anterior domains for hoxb5a (C), hoxb5b (D), hoxd4a (G), and hoxa5a (H) are 1708 represented by a vertical line. Overlapping regions can be approximated by the merged images 1709 (E, I). Scale in (B, F): $50 \mu \mathrm{m}$; dorsoventral-rostrocaudal axis defined in (F).

1710 (J) UMAP of the atlas demonstrating pervasive hox expression throughout the dataset. 1711 Expression was defined as having a $\log 2$ fold change $>0$. Approximately $85 \%$ of cells 1712 contained expression for at least one hox gene.

1713 (K-R) Feature plots representing the expression of selected hox genes within the atlas UMAP. 1714 hoxd4a $(\mathbf{K})$, hoxa5a $(\mathbf{L})$, hoxb5a $(\mathbf{M})$, hoxb5b $(\mathbf{N})$ all localize in varying degrees to the enteric 1715 neural signature, though hoxd4a also marks the mesenchymal clusters, as seen (A). hoxa $4 a(\mathbf{O})$ 
bioRxiv preprint doi: https://doi.org/10.1101/2020.06.14.150938; this version posted December 18,2020 . The copyright holder for this preprint (which was not certified by peer review) is the author/funder, who has granted bioRxiv a license to display the preprint in perpetuity. It is made available under aCC-BY-NC 4.0 International license.

1716 highlights its pervasive expression among the clusters. hoxal3b (P) and hoxal1b (Q) are key 1717 markers denoting the finbud mesenchyme. Alternative neural populations are further identified 1718 by their hoxa9a (R) expression profile, contrasting with the enteric populations. 
bioRxiv preprint doi: https://doi.org/10.1101/2020.06.14.150938; this version posted December 18,2020 . The copyright holder for this preprint (which was not certified by peer review) is the author/funder, who has granted bioRxiv a license to display the preprint in perpetuity. It is made available under aCC-BY-NC 4.0 International license.

\section{Figure 1}

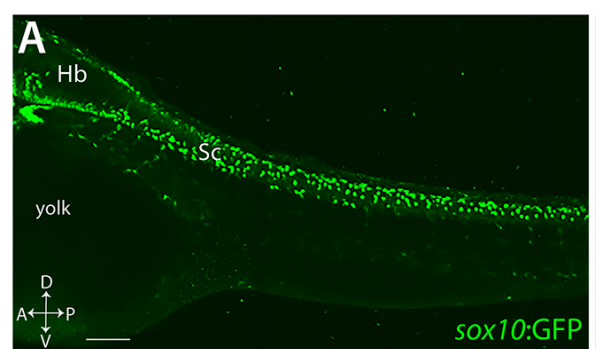

D Cell Populations by Cluster

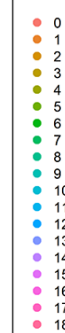

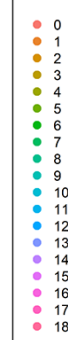

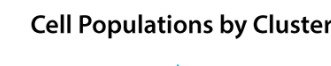

\section{$\mathbf{F}$}

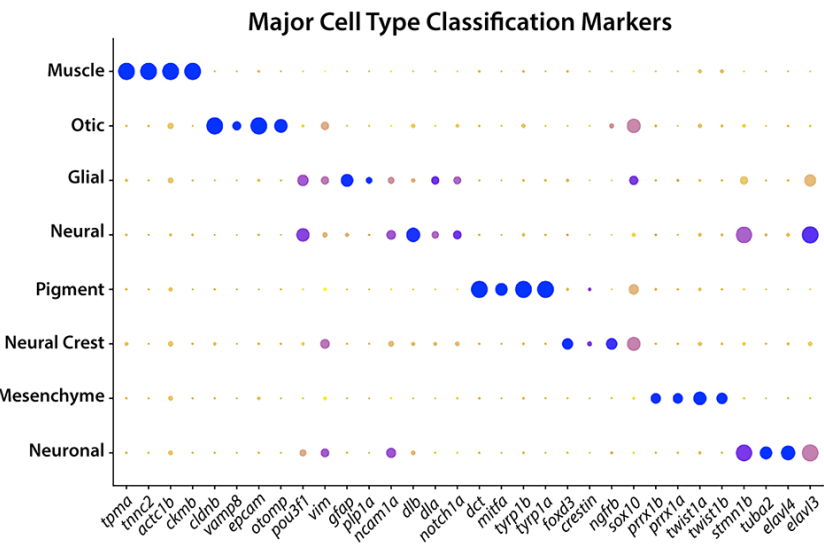

B 100 embryos, $48-50 \mathrm{hpf}$ Vagal/Trunk axial-level tissues dissected

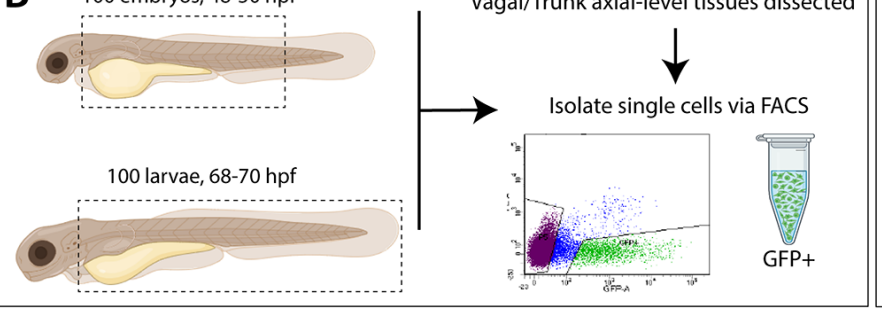

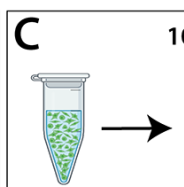

GFP+
10X Chromium single cell RNA-seq

2300 sox 10:GFP cells sequenced at $48-50 \mathrm{hpf}$ 74,017 mean reads per cell

2580 sox 10:GFP cells sequenced at $68-70 \mathrm{hpf}$

62,109 mean reads per cell

Transcript reads mapped $\rightarrow$ Computational analysis \&

to zebrafish genome

visualization of cell populations

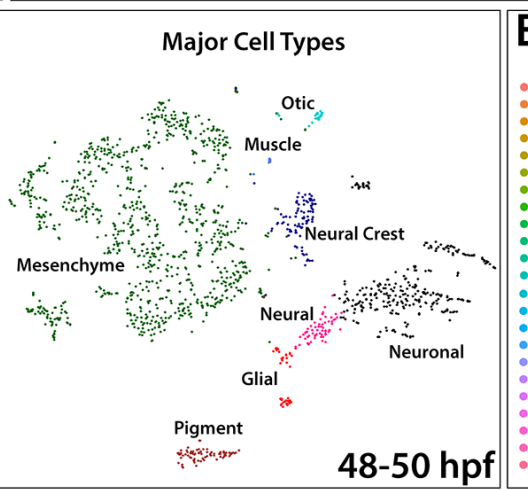

E Cell Populations by Cluster $0 \quad 0$

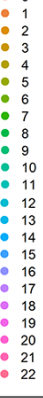

G

Major Cell Type Classification Markers

Major Cell Types

Otic

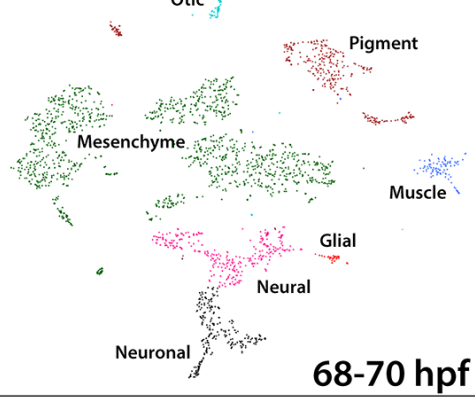

68-70 hpf

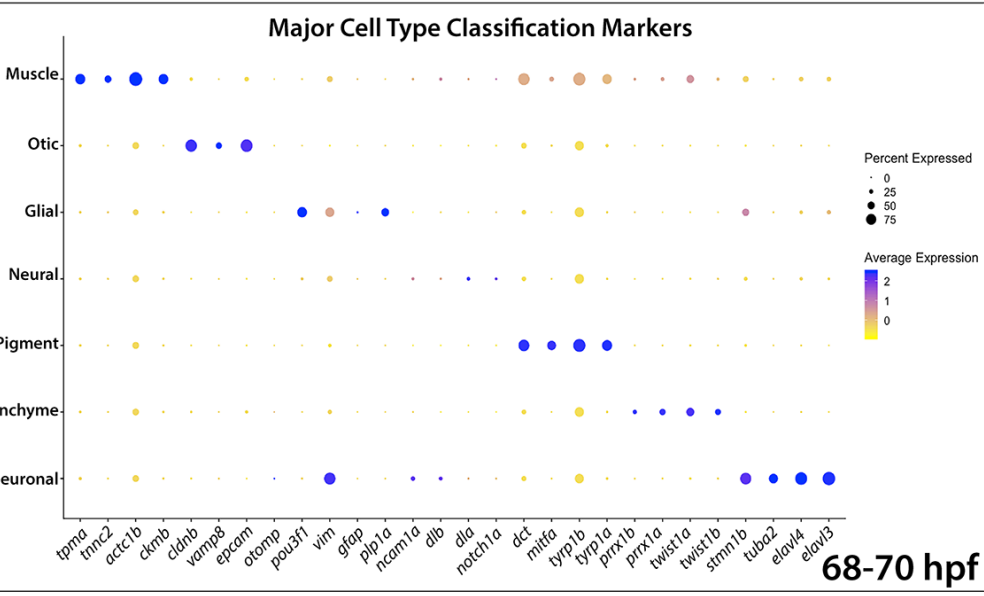




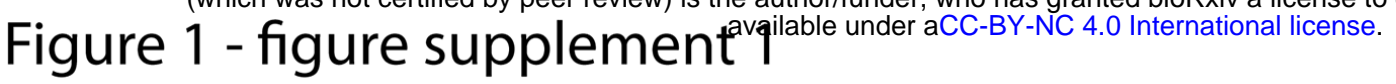

A

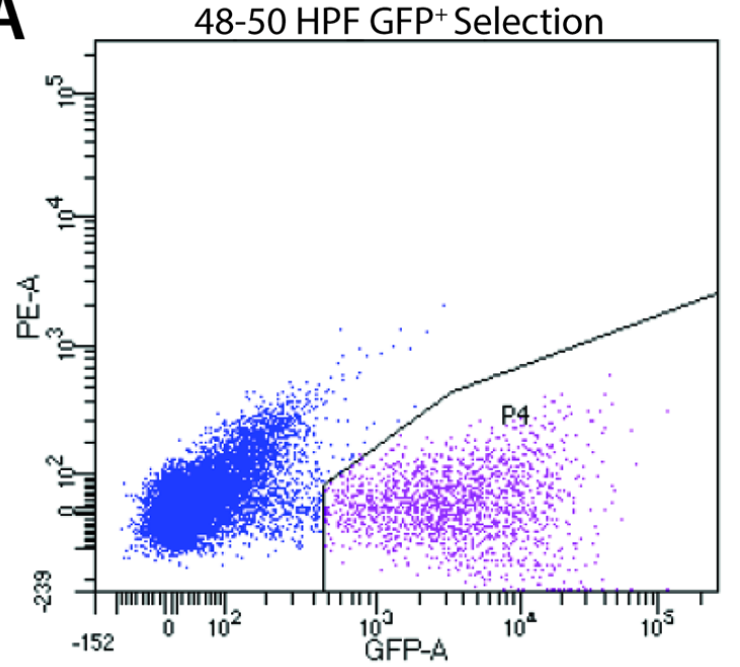

Sample Preparation

10x Chip Chemistry Kit

Post-FACS Cell Concentration (cells/ $\mu \mathrm{L}$ )

Number of Cells Loaded per Chip

PCR Cycles for CDNA Generation

CDNA for Library Generation (ng)

PCR Cycles for Library Generation

Estimated Number of Cells Captured

\section{Sequencing}

Mean Reads per Cell

Total Reads

Valid Barcodes

Sequencing Saturation

Q30 Bases in Barcode

Q30 Bases in RNA Read

Q30 Bases in Sample Index

Q30 Bases in UMI

\section{Genome Mapping}

Reference Transcriptome

Median Genes per Cell

Total Genes Detected

Fraction Reads in Cells

Median UMI Counts per Cell

Reads Mapped to Genome

Reads Mapped Confidently to Genome

Reads Mapped Confidently to Intergenic Regions

Reads Mapped Confidently to Intronic Regions

Reads Mapped Confidently to Exonic Regions

Reads Mapped Confidently to Transcriptome

Reads Mapped Antisense to Gene

Computational Resources

Cell Ranger Version

R Version

Seurat Version

Seurat Input Cells

Seurat Post-QC Cells

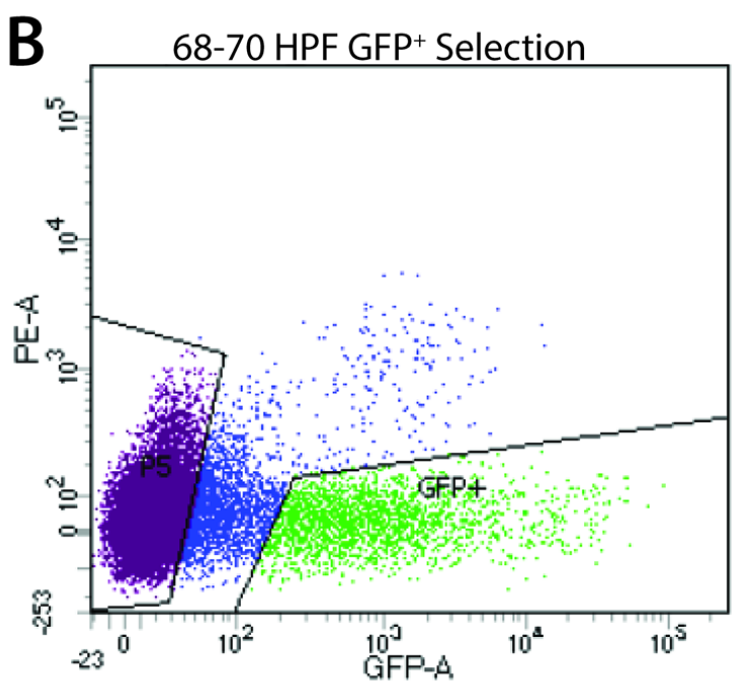

D

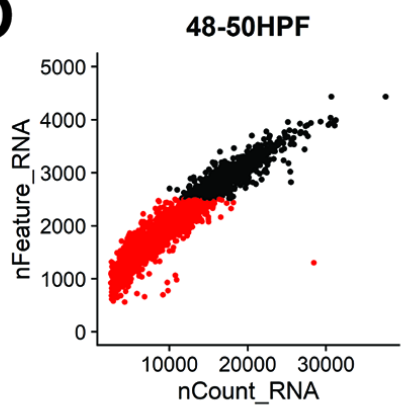

E

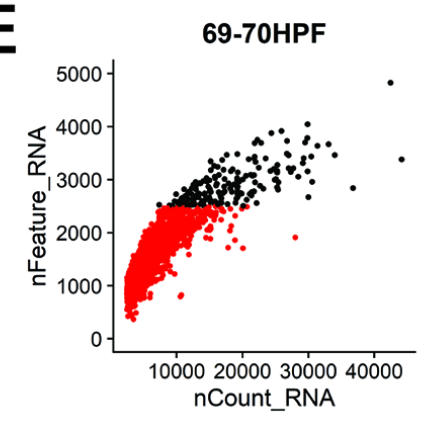

161

4669

4905

14

20

13

16

2300

50

12

2580

74,017

$170,241,062$

$97.30 \%$

$71.30 \%$

$96.80 \%$

$76.10 \%$

$93.60 \%$

$96.50 \%$

DanioGRCz10

2105

20,858

$69.00 \%$

10,753

$90.10 \%$

$89.10 \%$

$4.50 \%$

$3.90 \%$

$80.80 \%$

$78.10 \%$

$0.50 \%$

2.1.0

3.6.3

3.1.1

2300

62109

$160,243,113$

\begin{tabular}{l|l}
$75.00 \%$ & $\mathbf{G}$
\end{tabular}

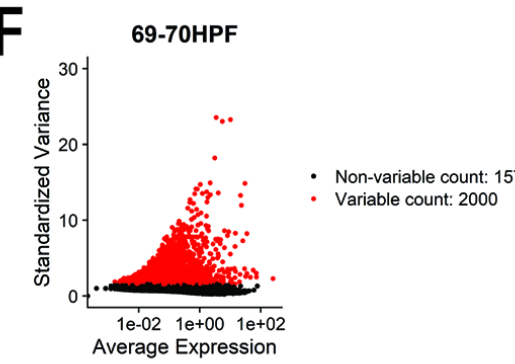

$97.20 \%$

$82.10 \%$

$97.30 \%$

$96.50 \%$

DanioGRCz10

1391

20,813

$58.70 \%$

5,097

$90.30 \%$

$89.00 \%$

$5.90 \%$

$4.30 \%$

$78.70 \%$

$75.80 \%$

$0.70 \%$

2.1.0

3.6.3

3.1.1

2580

1608

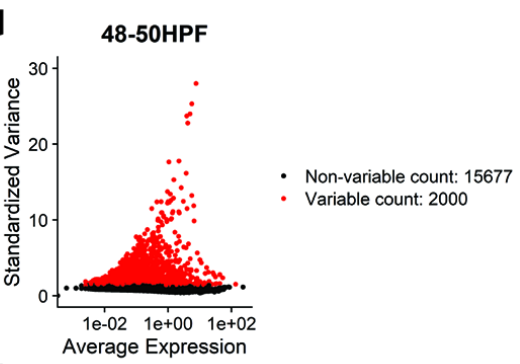

$\mathrm{H}$

48-50HPF

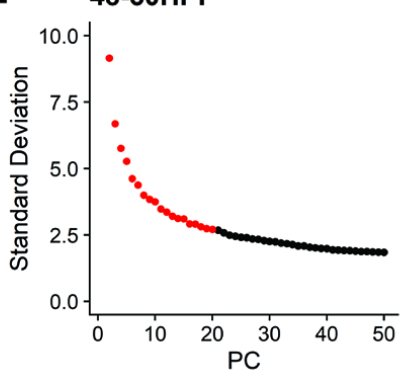

69-70HPF

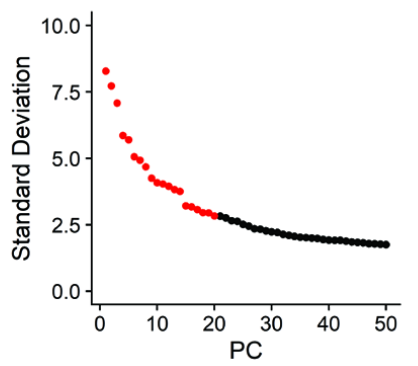


Fiogkurepeprifligitries Subpolemenđ2Q206.14.150938; this version posted December 18, 2020. The copyright holder for this preprint (wnich was not certified by peer review) is the author/funder, who has granted bioRxiv a license to display the preprint in perpetuity. It is made

A

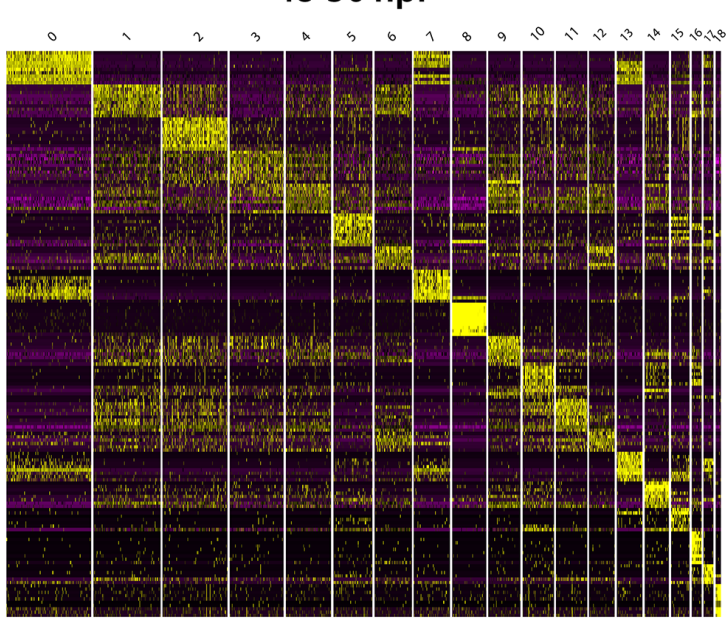

B

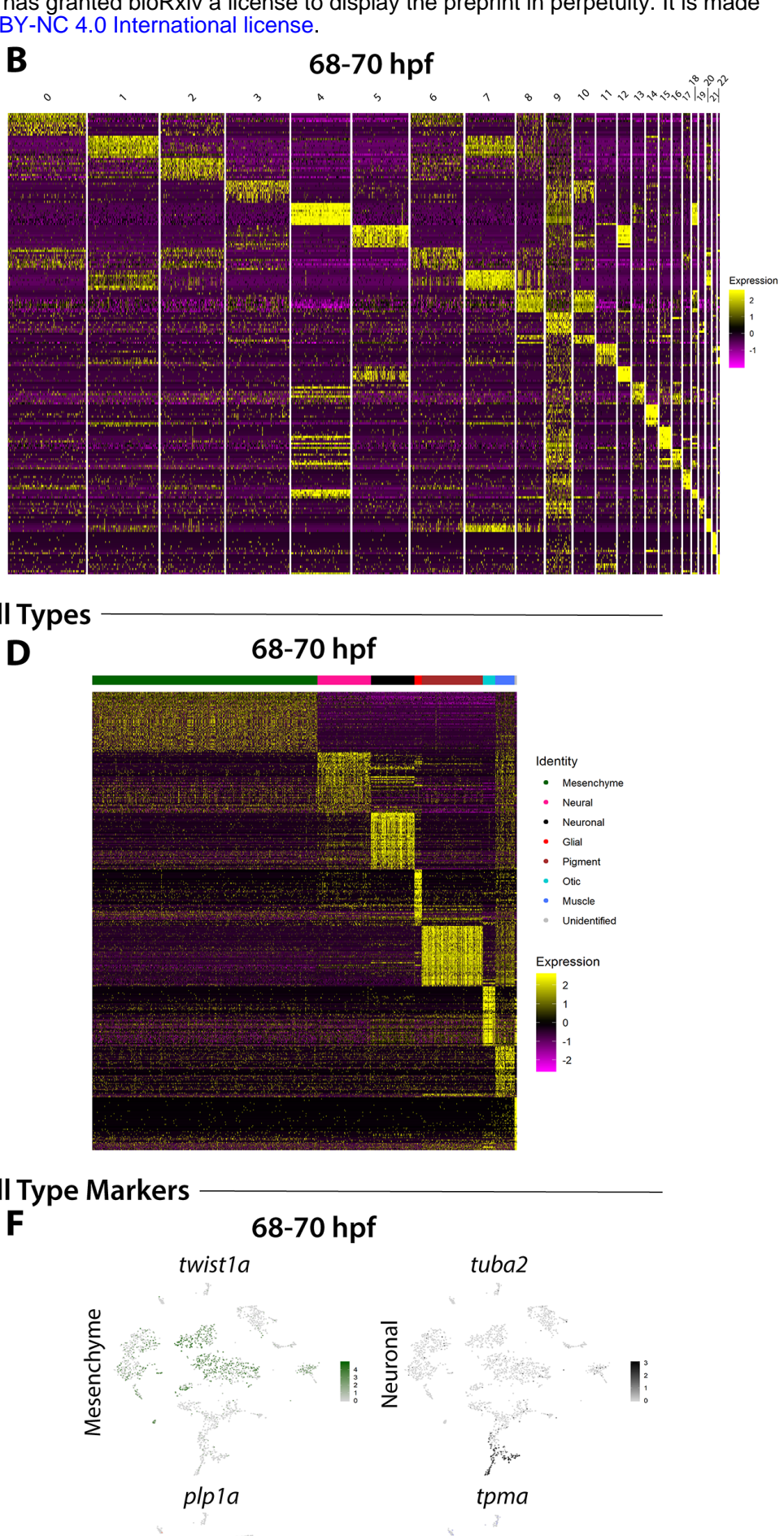

C

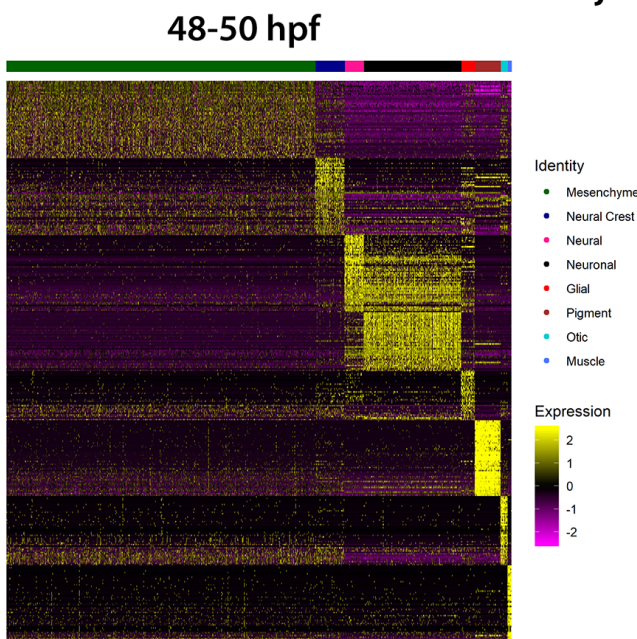

\section{Major Cell Types}

D

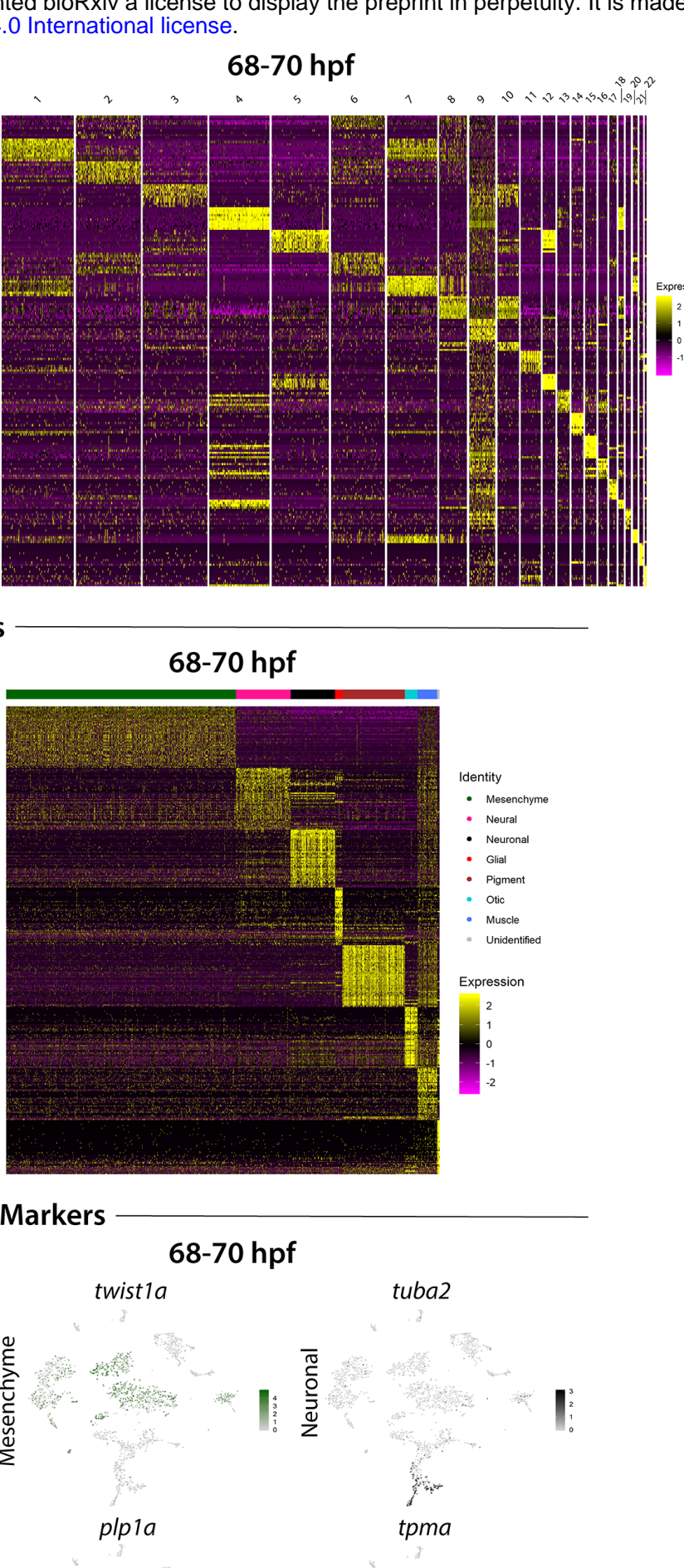

E

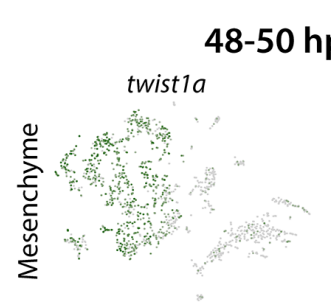

plp1a

$\frac{\bar{O}}{\mathrm{~V}}$

tyrp 1a

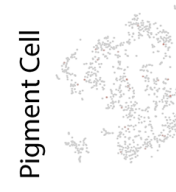

赵

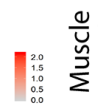

Major Cell Type Markers

$\mathbf{F}$

\section{8-70 hpf}

twist1a tuba2

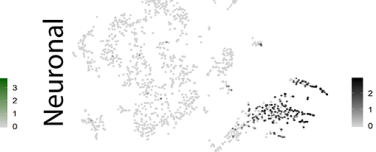

tpma

cldnb

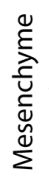

$$
\text { plp1a }
$$

$\begin{array}{ll} & \overline{0} \\ & \frac{1}{0} \\ 4 & \frac{1}{3} \\ 3 & \frac{1}{2} \\ : & \frac{1}{2}\end{array}$

$\frac{\sqrt{0}}{\bar{\sigma}}$ tpma
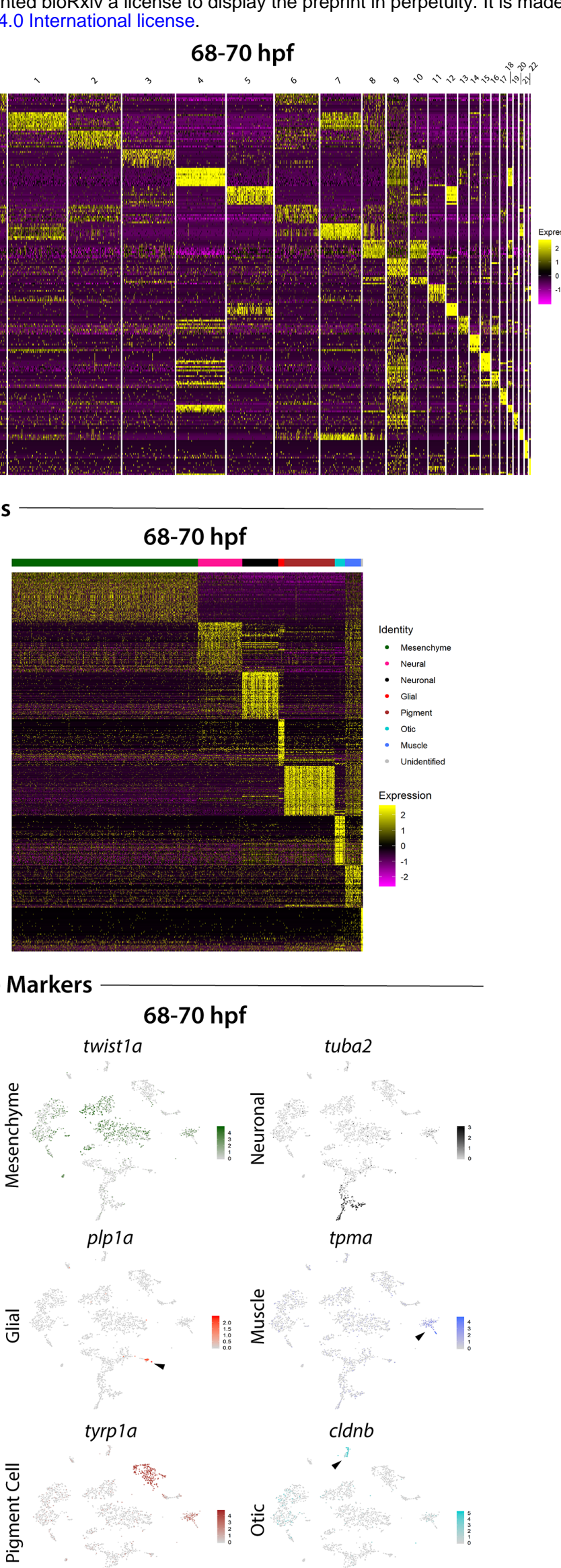

notch $1 a$

dla 
bioRxiv preprint doi: https://doi.org/10.1101/2020.06.14.150938; this version posted December 18, 2020. The copyright holder for this preprint (which was not certified by peer review) is the author/funder, who has granted bioRxiv a license to display the preprint in perpetuity. It is made available under aCC-BY-NC 4.0 International license.

Figure 1-figure supplement 3

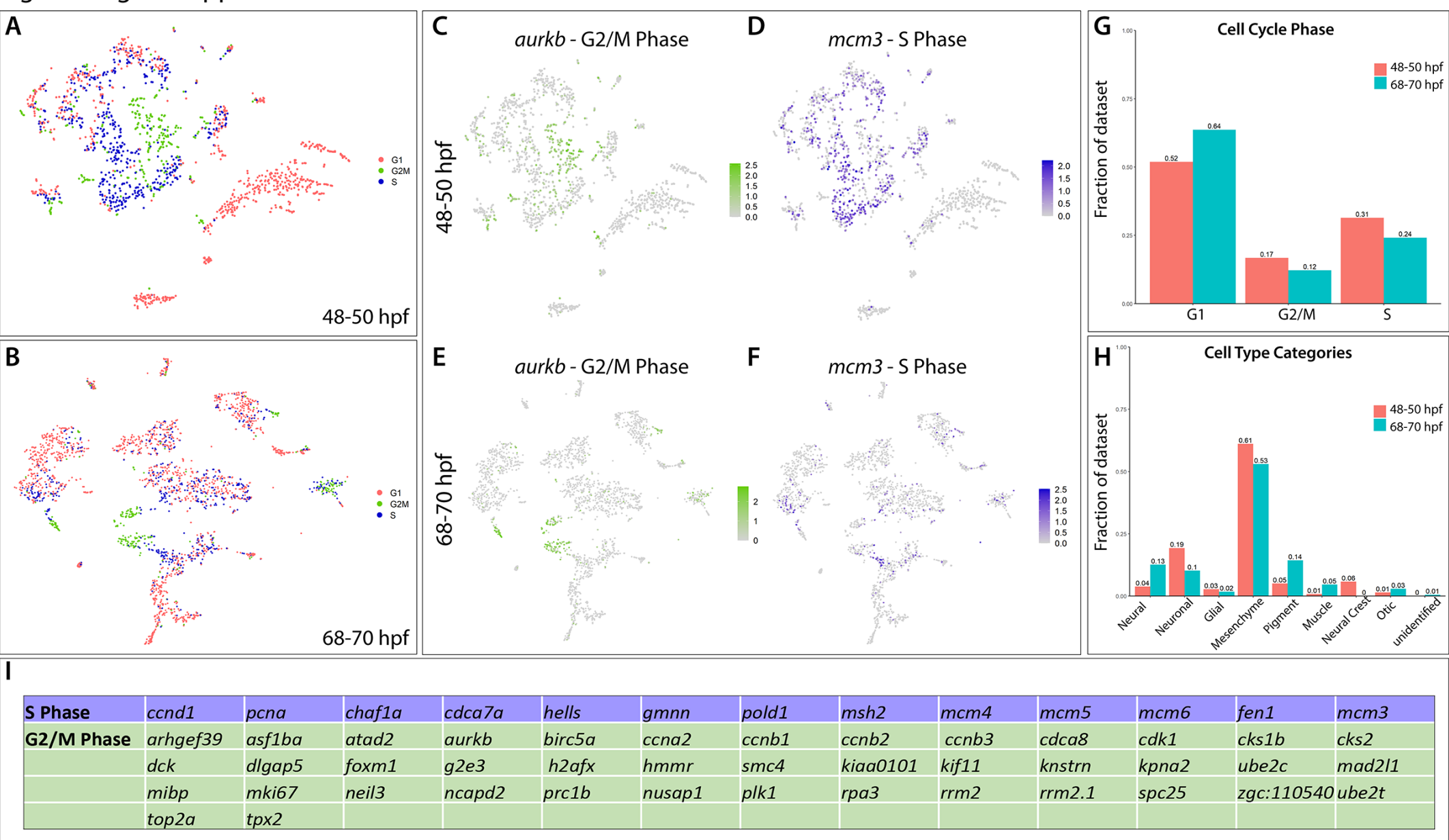



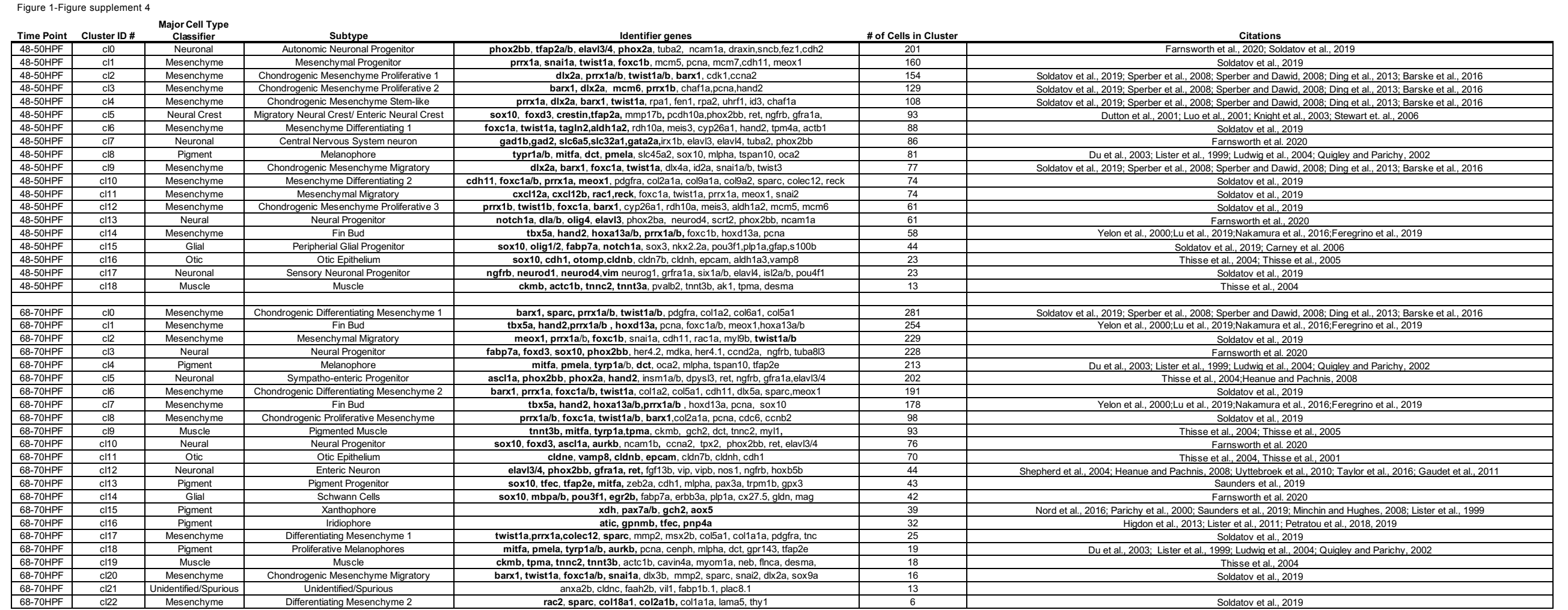


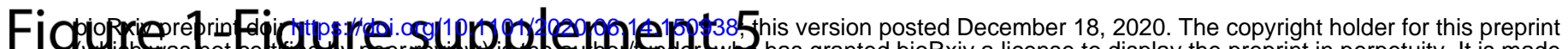

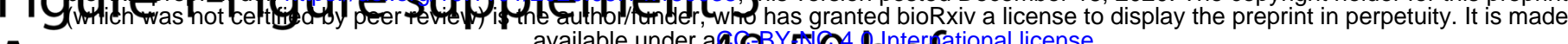
A available under $488^{3} 5^{+1} 0^{4} \cdot h^{n t} p^{\prime} f^{a t i o n a l ~ l i c e n s e . ~}$

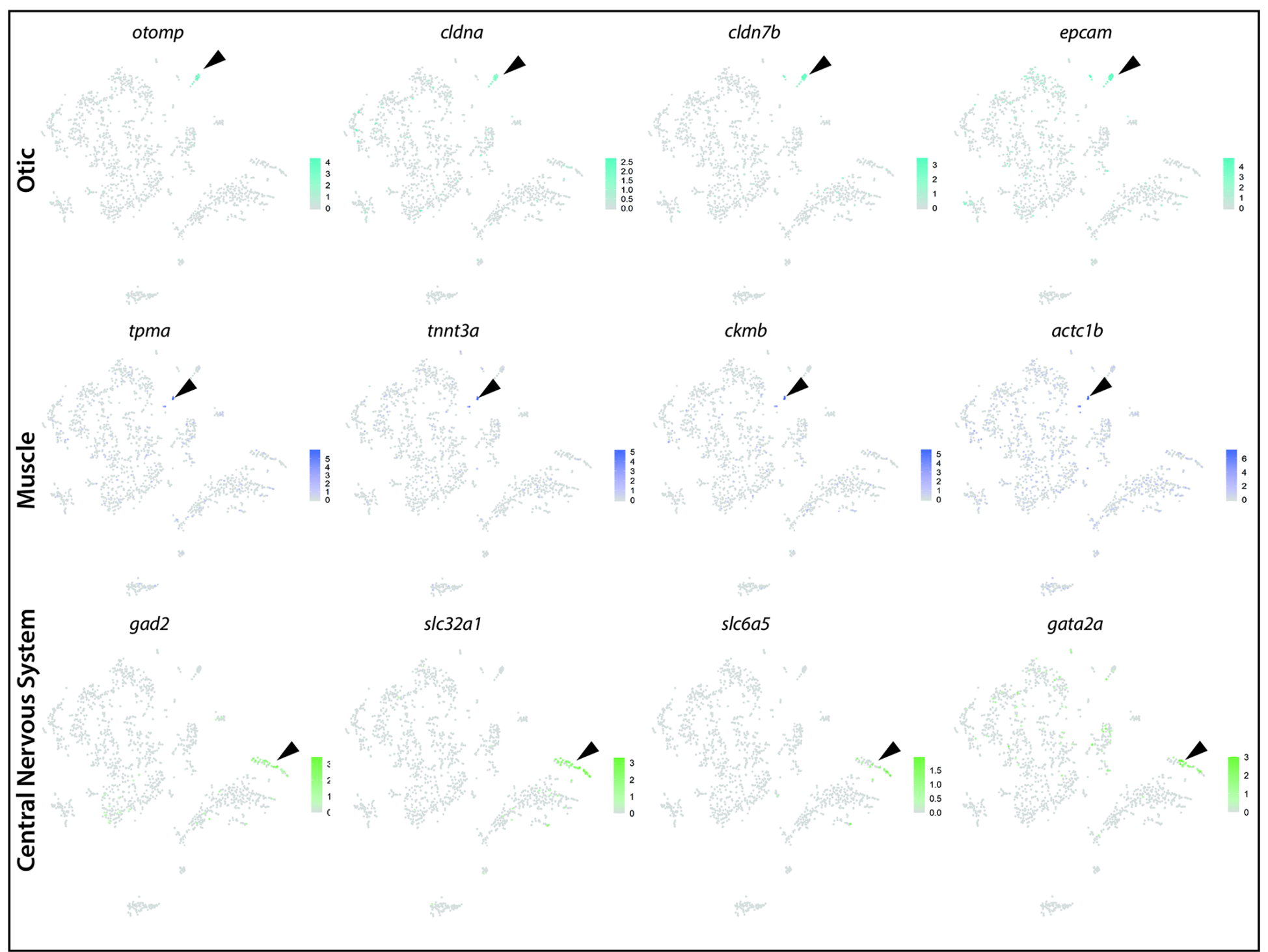

B

68-70 hpf

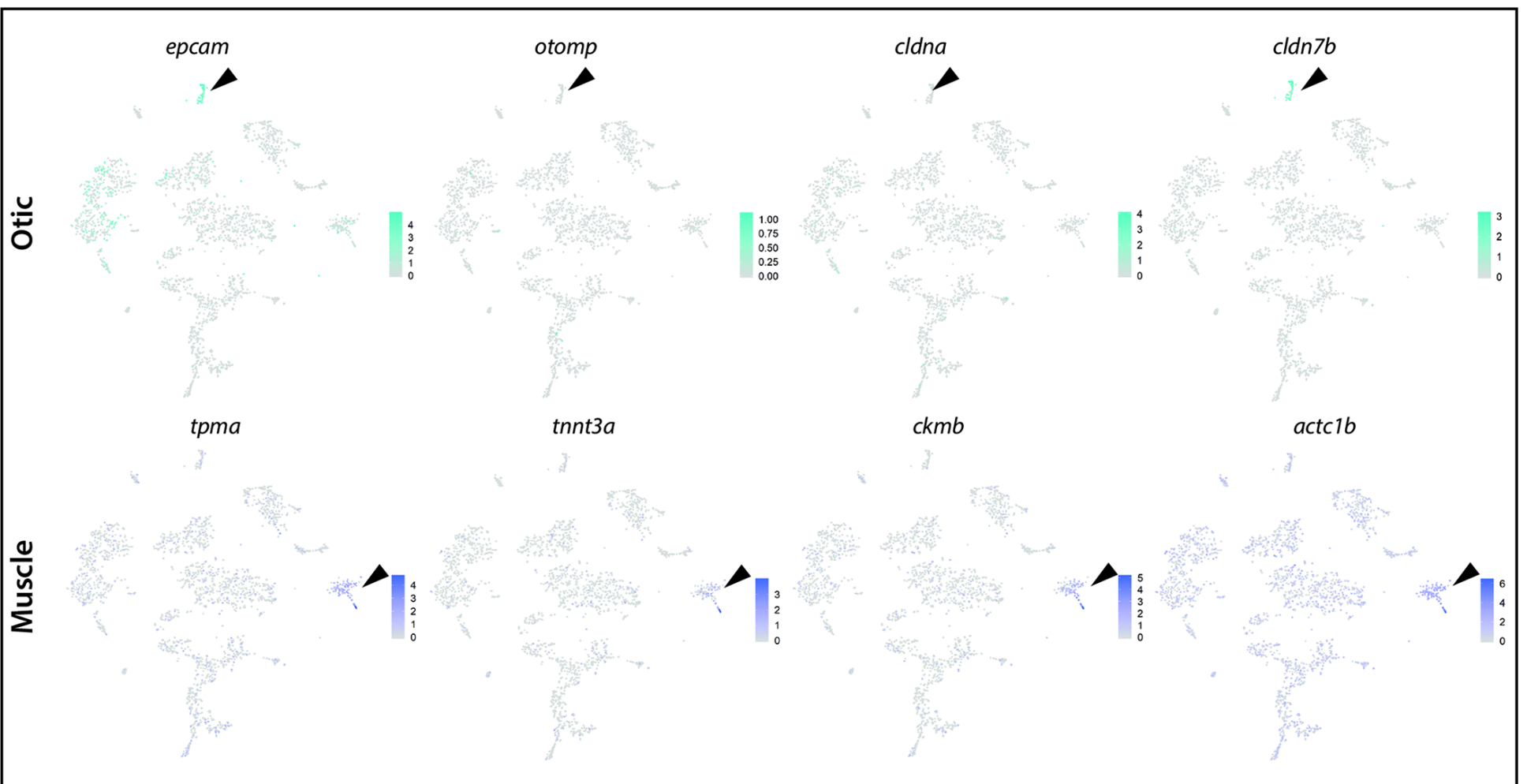




\section{Figure 1-Figure supplement 6}

\section{A \\ Sensory Nerons}

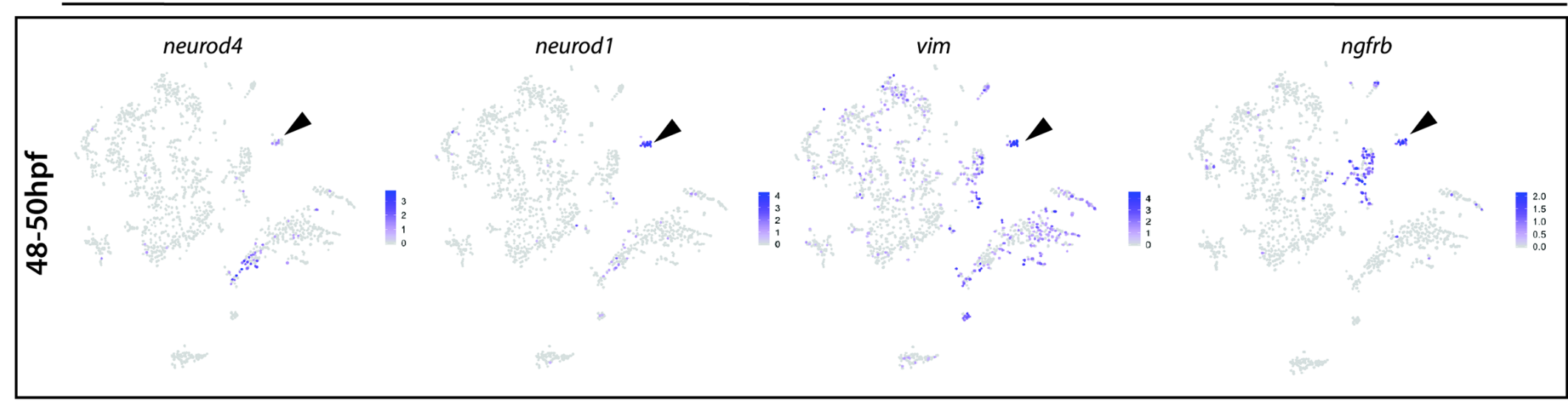

B

\section{Fin Bud}

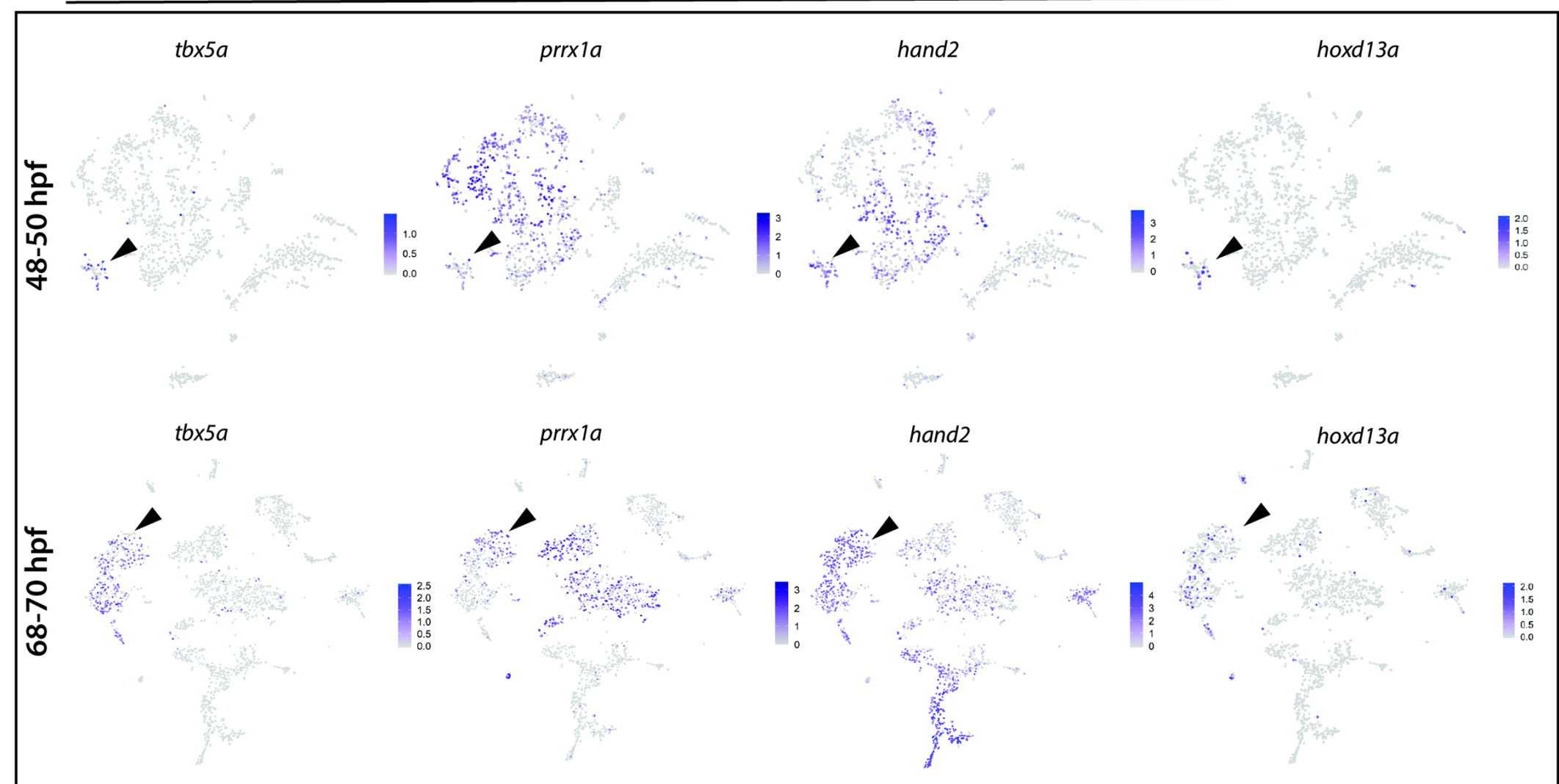


Figurenßv preprint doi: https://doi.org/10.1101/2020.06.14.150938; this version posted December 18,2020 . The copyright holder for this preprint A 48-50 hpf - Major Cell Types available under aCC-BY-NG B $^{0}$ International license 68 -70 hpf - Major Cell Types
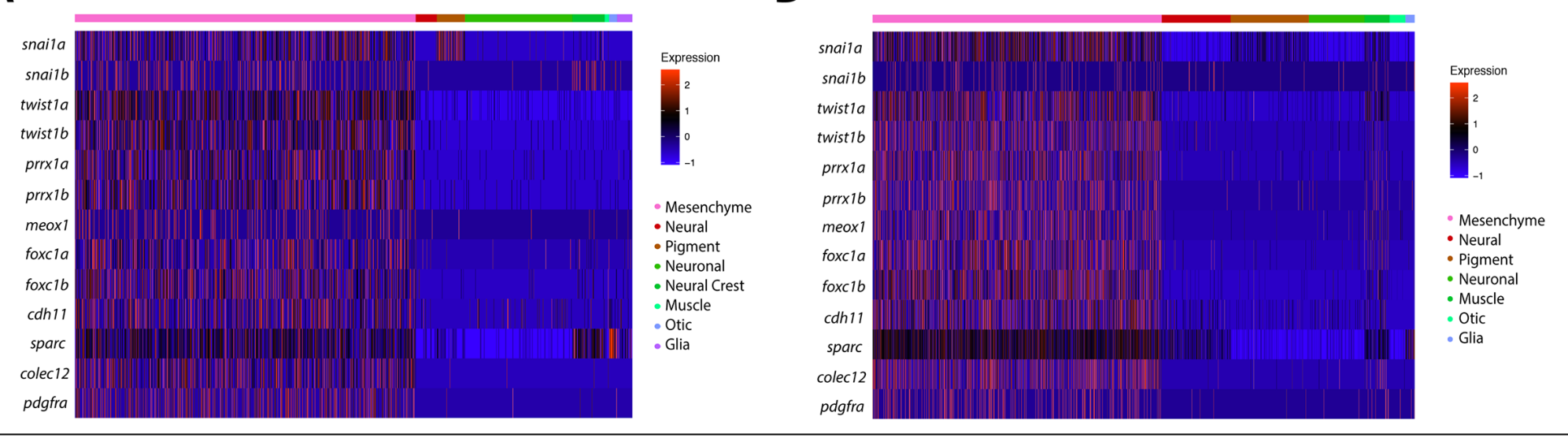

C

General Mesenchyme

Chondrogenic Mesenchyme
D
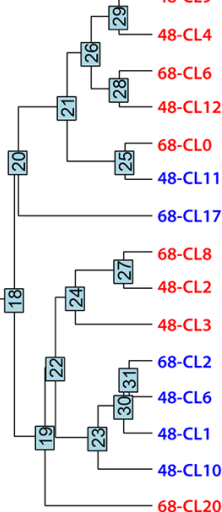

48-50 hpf

$68-70 \mathrm{hpf}$
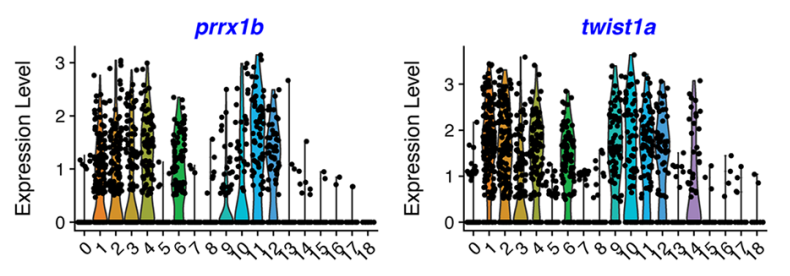

$d 1 \times 2 a$

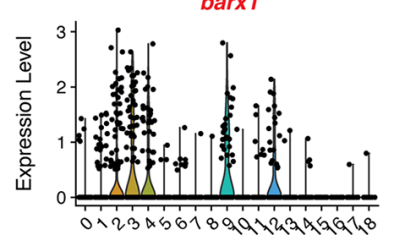

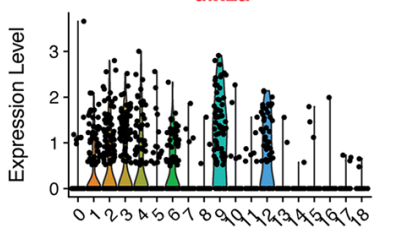

barx1

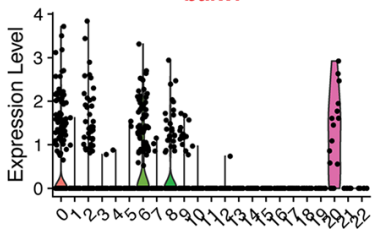

twist1a
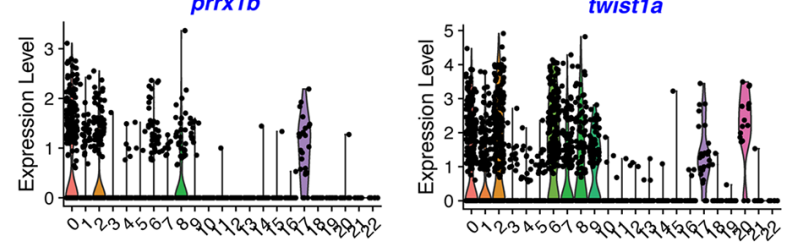

dlx2a

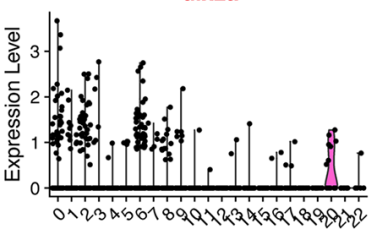

$\mathrm{E}$
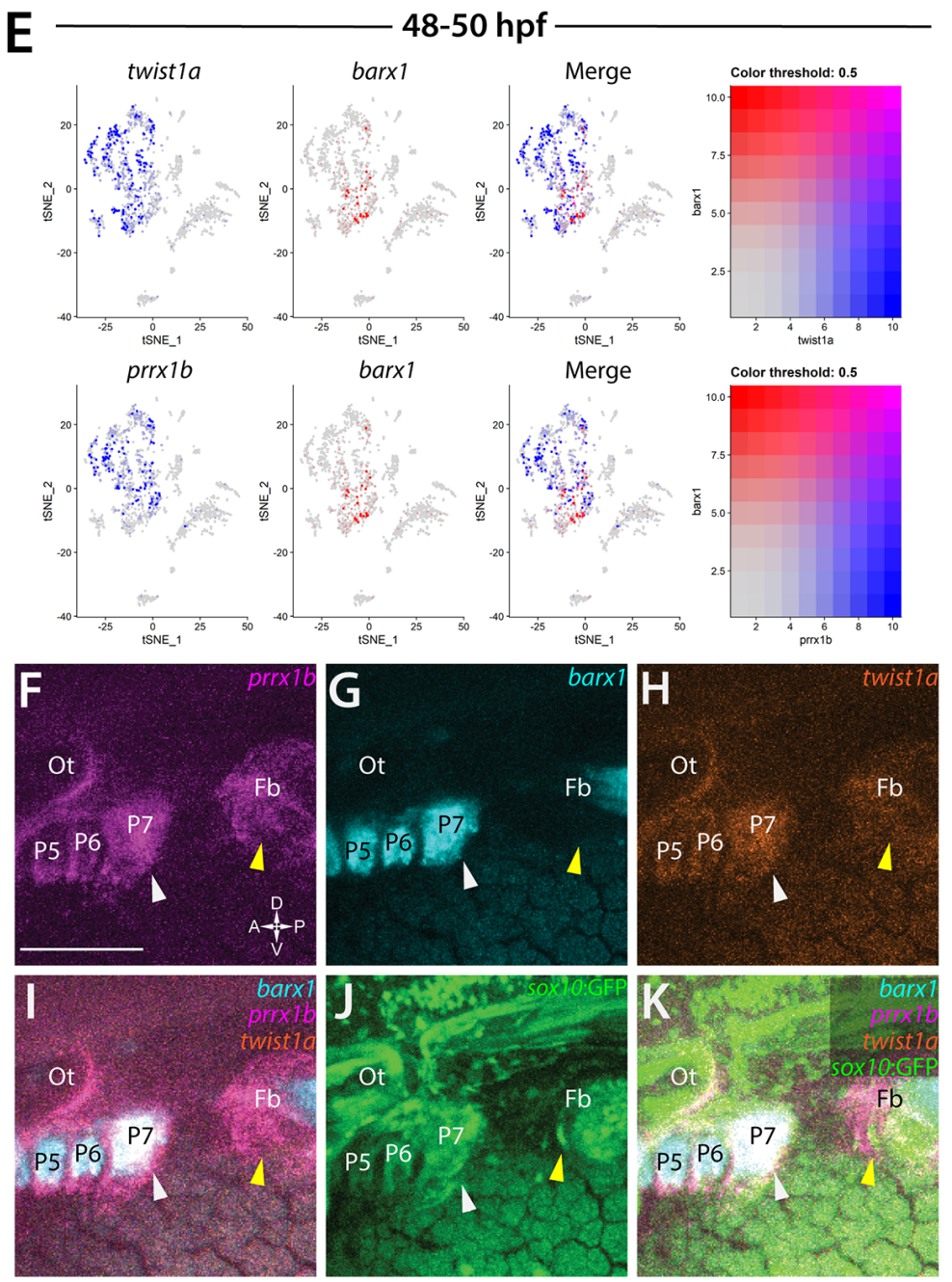
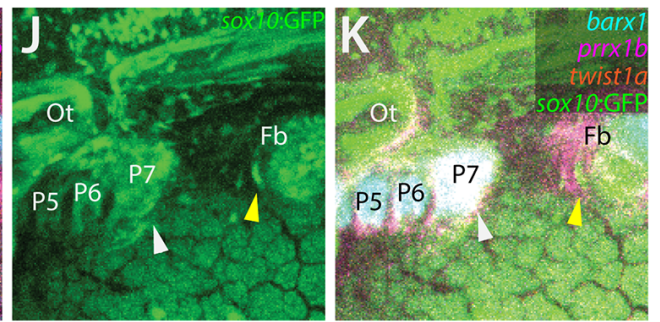

$\mathrm{L}$
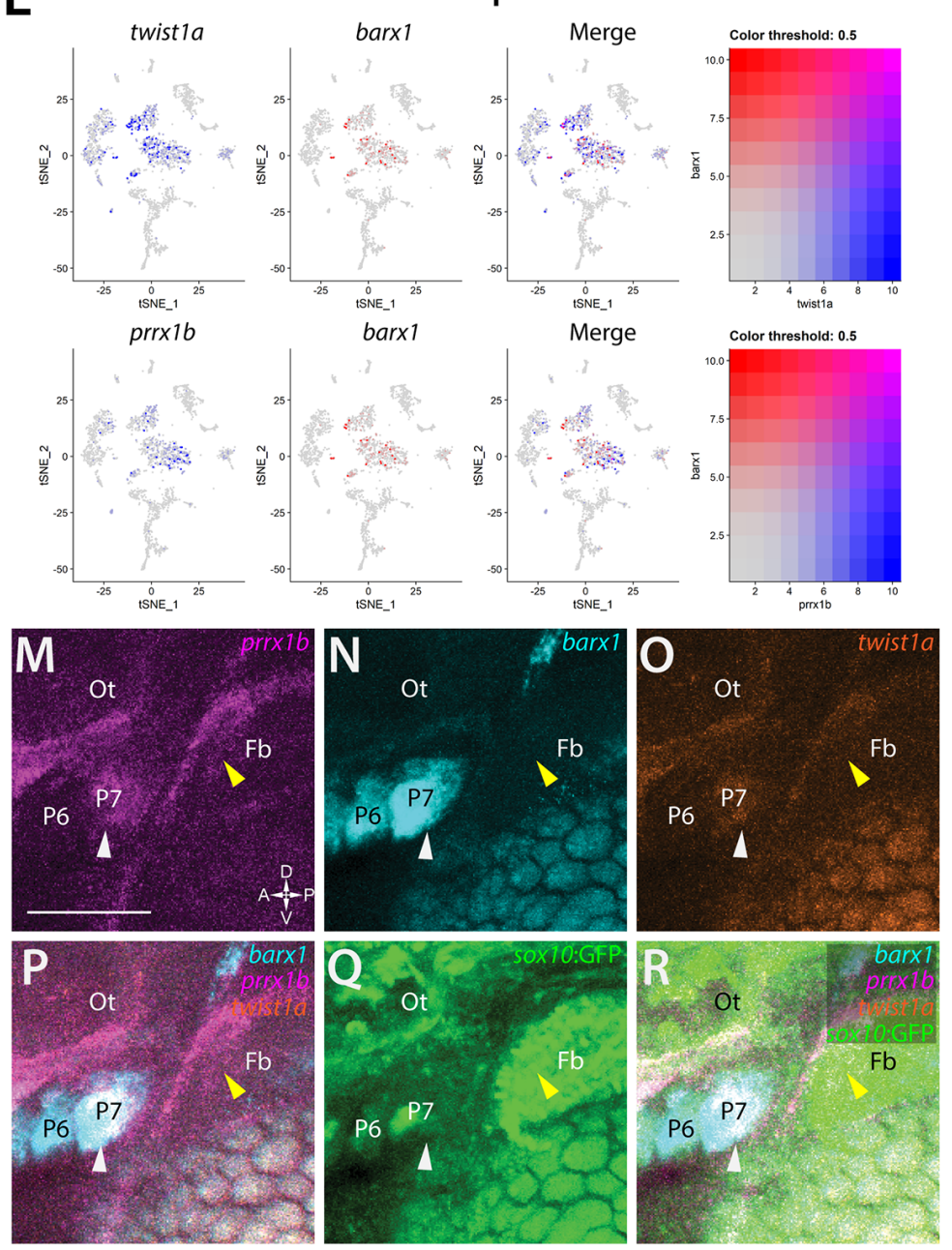
bioRxiv preprint doi: https://doi.org/10.1101/2020.06.14.150938; this version posted December 18,2020 . The copyright holder for this preprint (which was not certified by peer review) is the author/funder, who has granted bioRxiv a license to display the preprint in perpetuity. It is made available under aCC-BY-NC 4.0 International license.

\section{Figure 4}

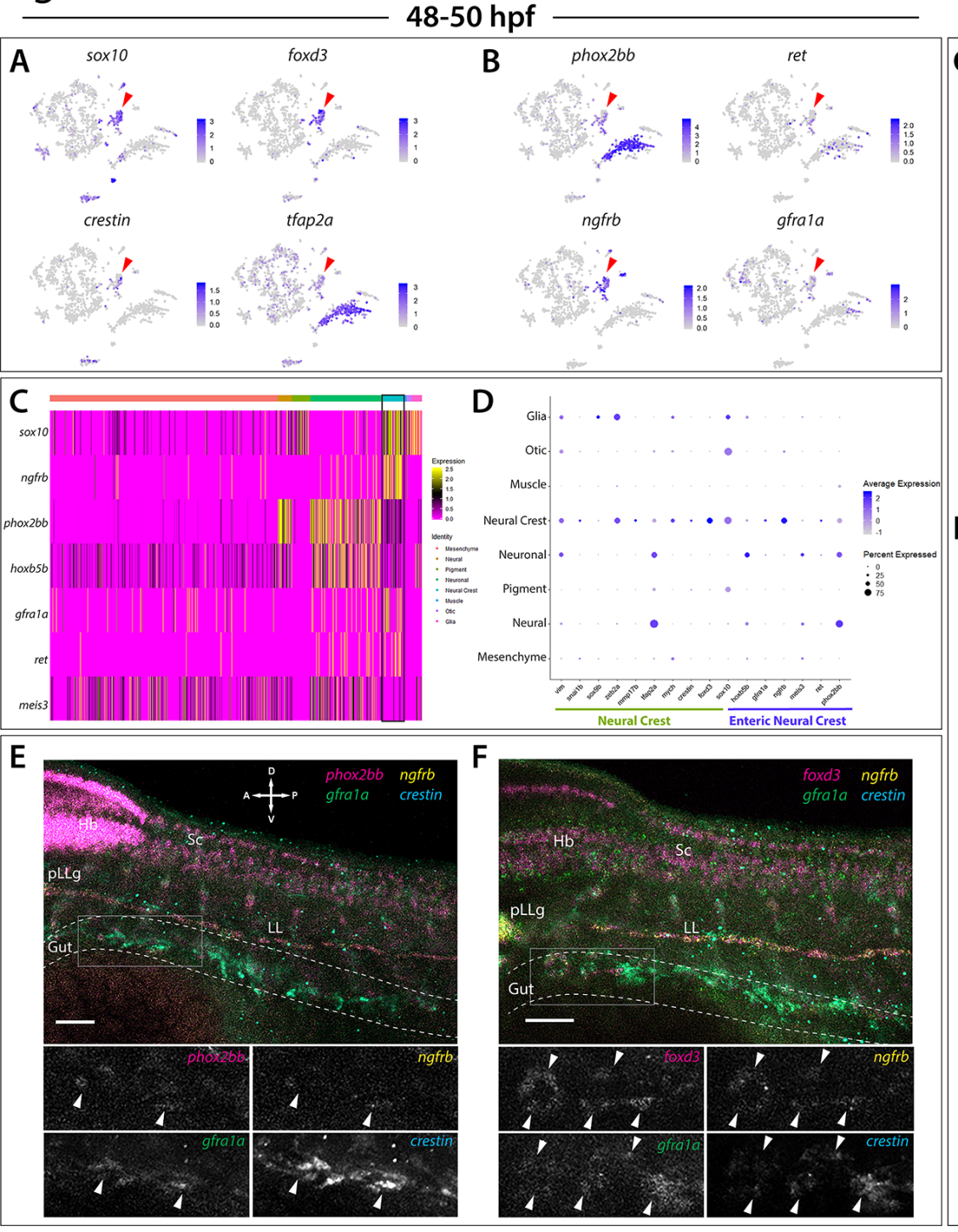

68-70 hpf

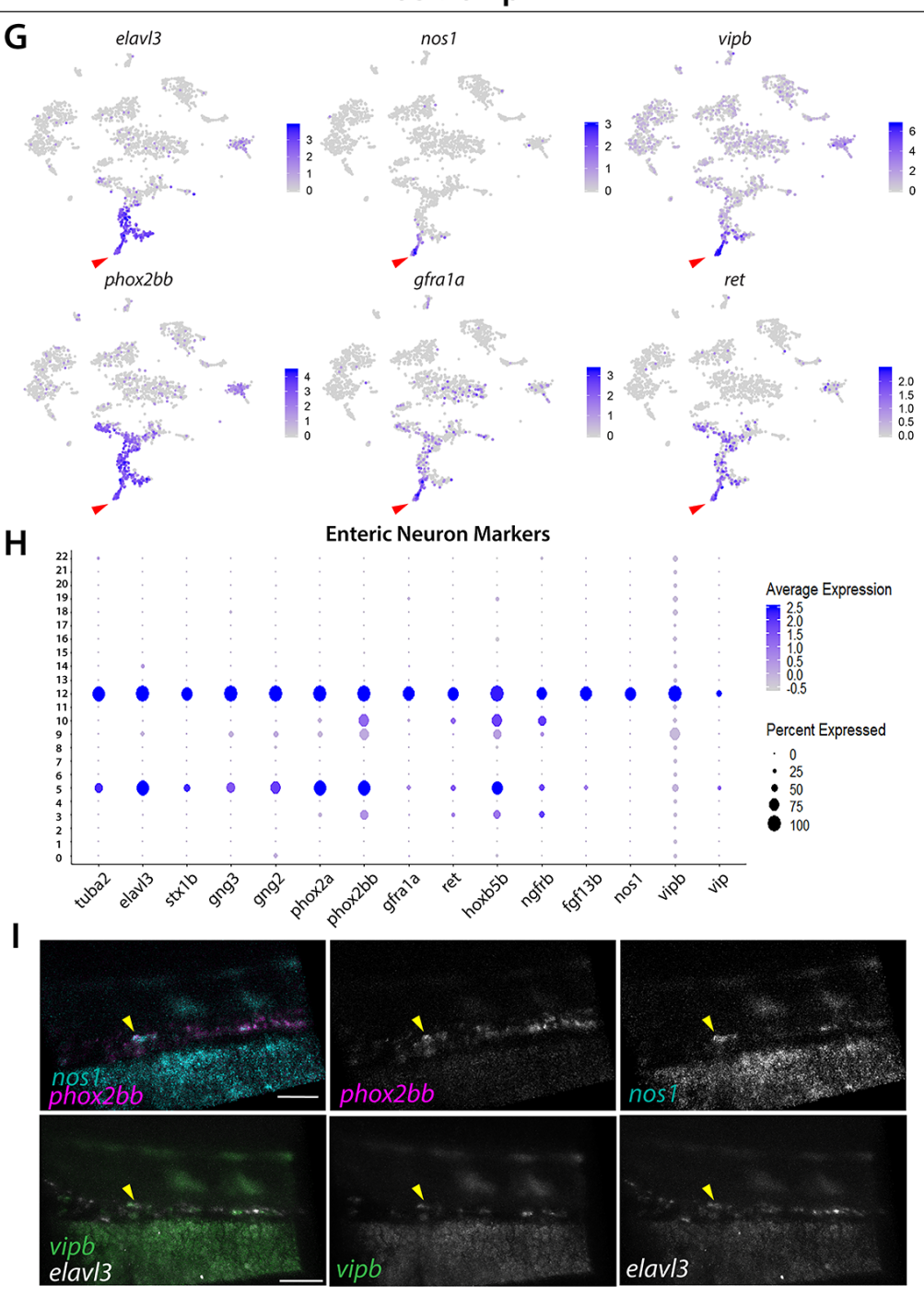


bioRxiv preprint doi: https://doi.org/10.1101/2020.06.14.150938; this version posted December 18, 2020. The copyright holder for this preprint (which was not certified by peer review) is the author/funder, who has granted bioRxiv a license to display the preprint in perpetuity. It is made available under aCC-BY-NC 4.0 International license.

Figure 5
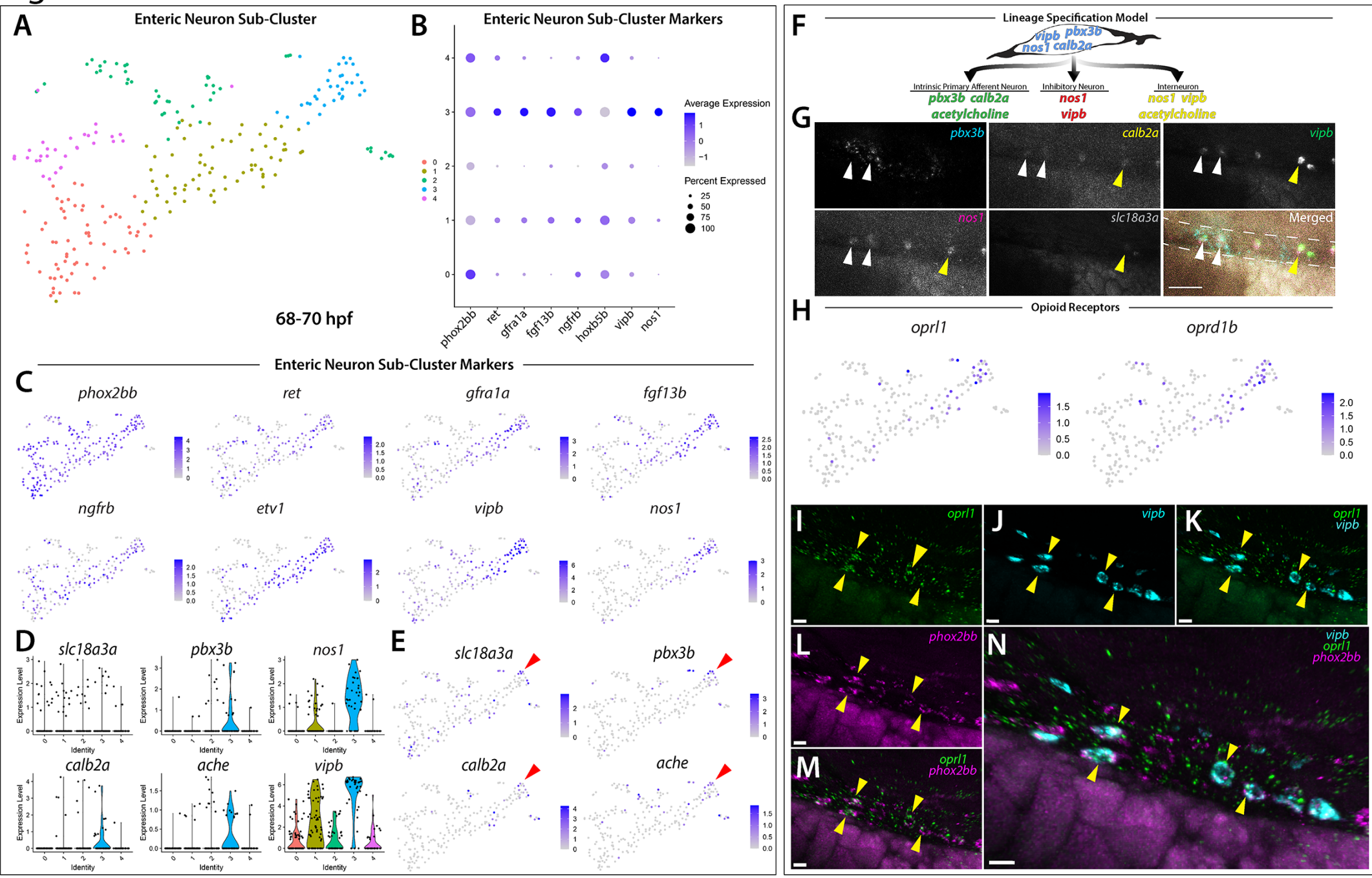
Figure 5 - figure supplement 2

\section{A}

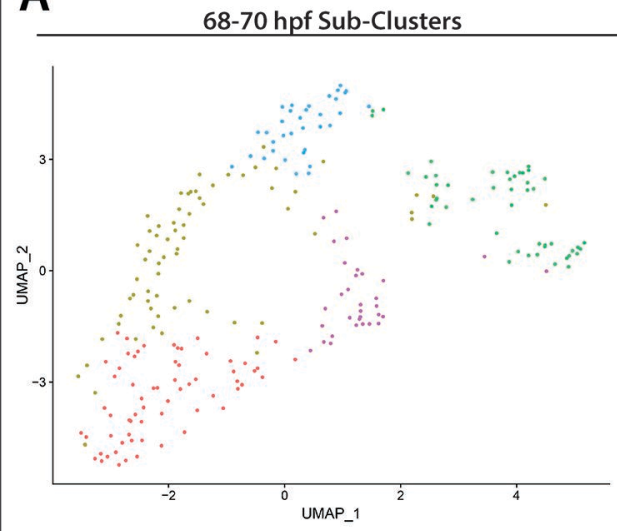

\section{D}

Autonomic neuron

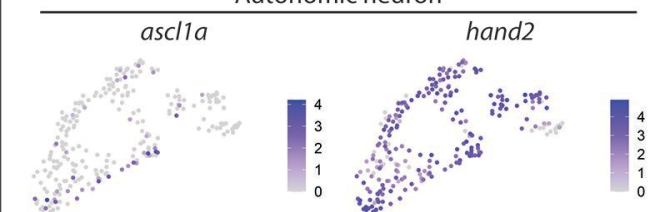

phox2a
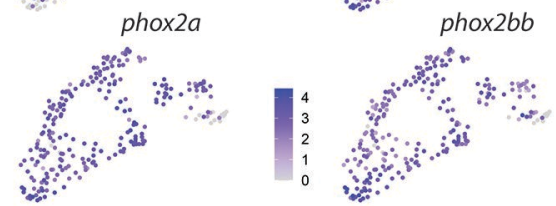

B

Sympatho-Enteric Neuron Makers

C

Sub-Cluster Dendrogram

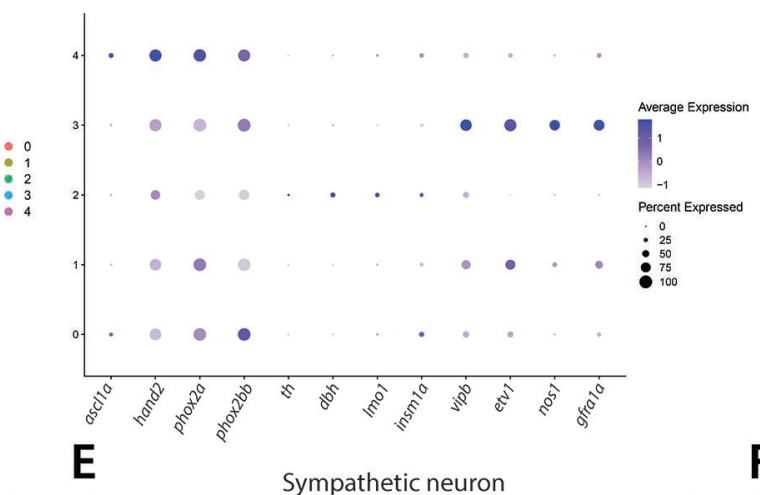

$d b h$

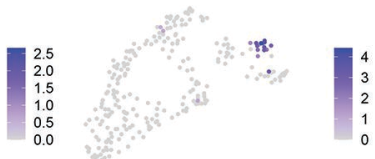

insm1a

Imo1

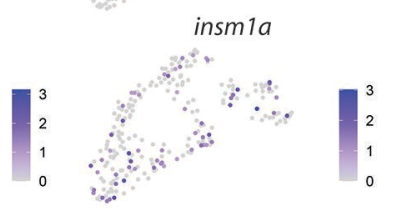

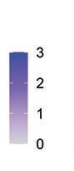

F

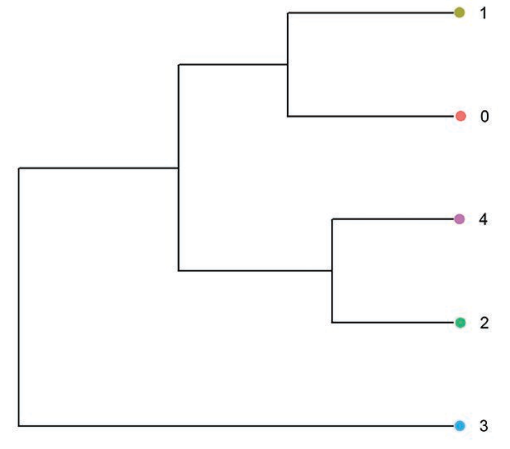

Enteric neuron

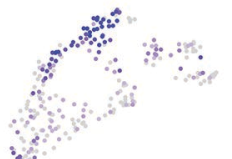

nos 1
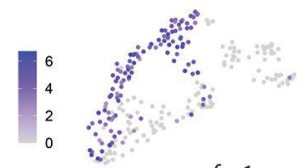

gfrala 
Ei hipRxiv pregrint/oi: https://doi.org/10.1101/2020.06.14.150938; this version posted December 18, 2020. The copyright holder for this preprint

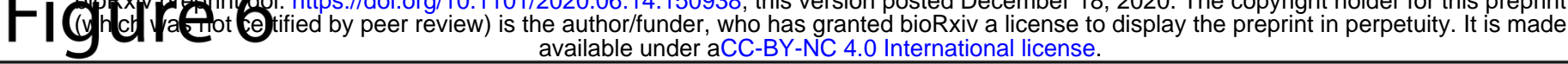
A Atlas
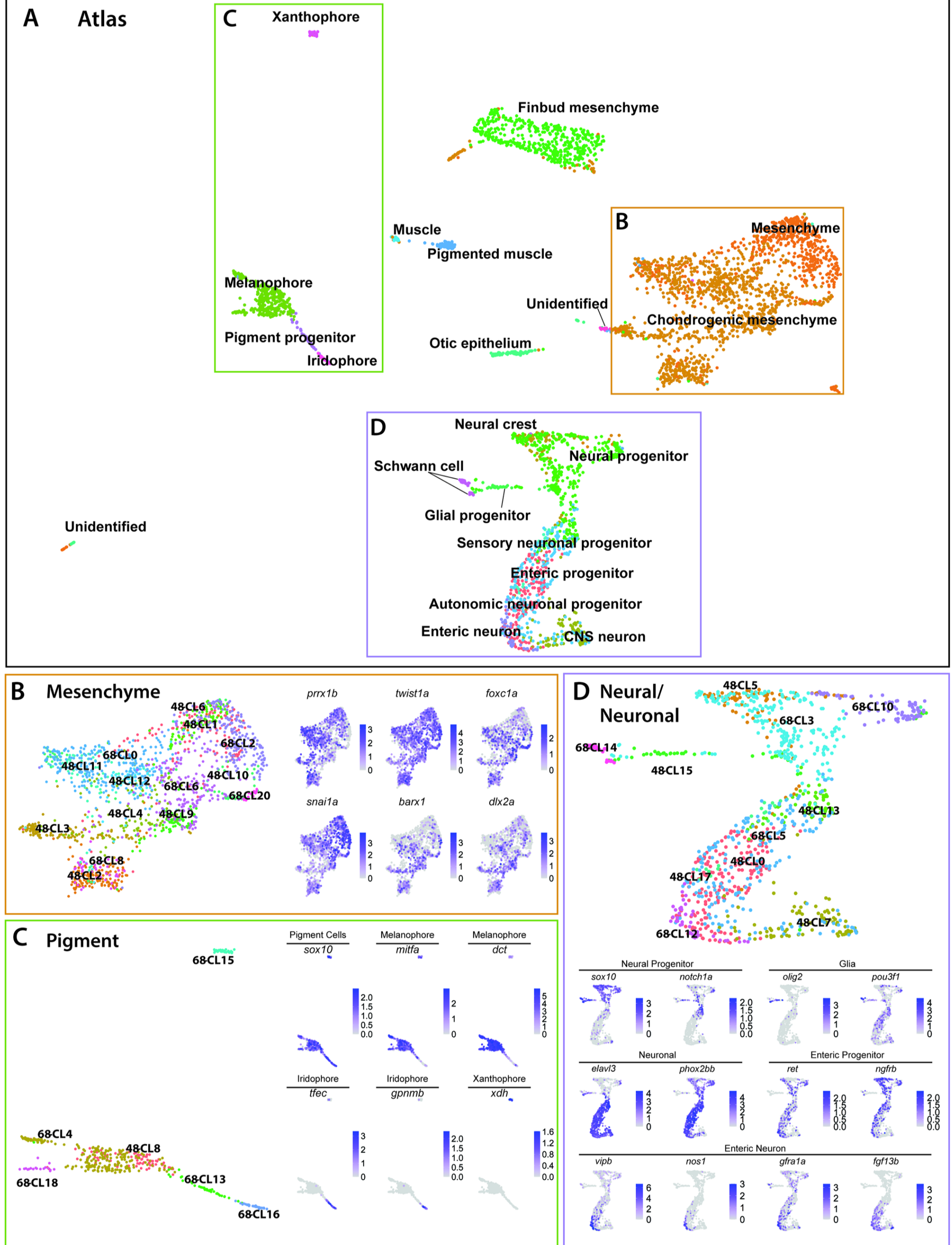
bioRxiv preprint doi: $\mathrm{https}$ //doi.org/10.1101/2020.06.14.150938; this version posted December 18,2020 . The copyright holder for this preprint (which was not certified by peer review) is the author/funder, who has granted bioRxiv a license to display the preprint in perpetuity. It is made available under aCC-BY-NC 4.0 International license.

Figure 6-figure supplement1

\section{A}

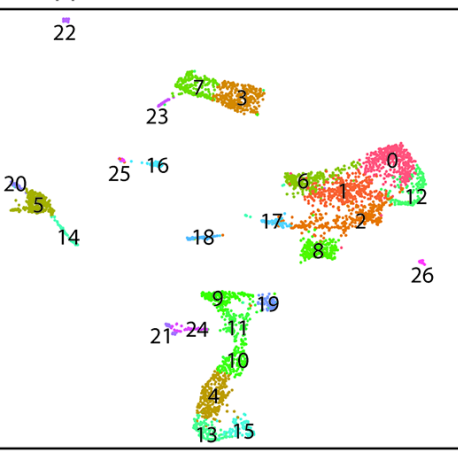

27

B

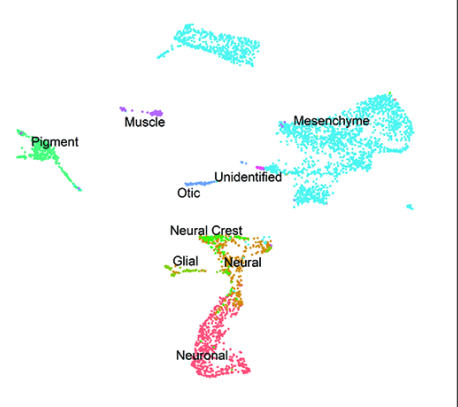

C

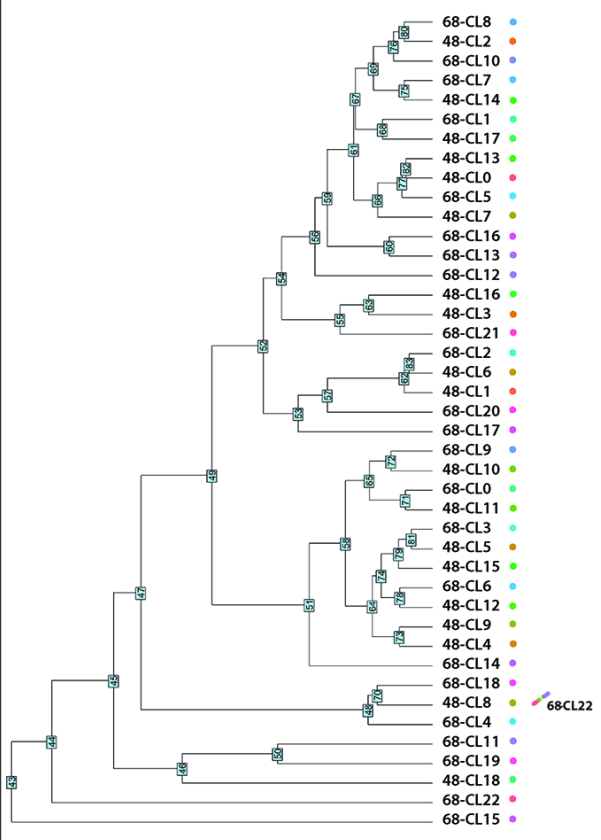

68c15
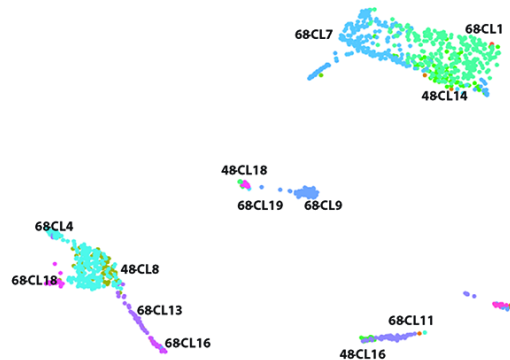

$48 \mathrm{Cl18}$ $68 \mathrm{CL} 19$
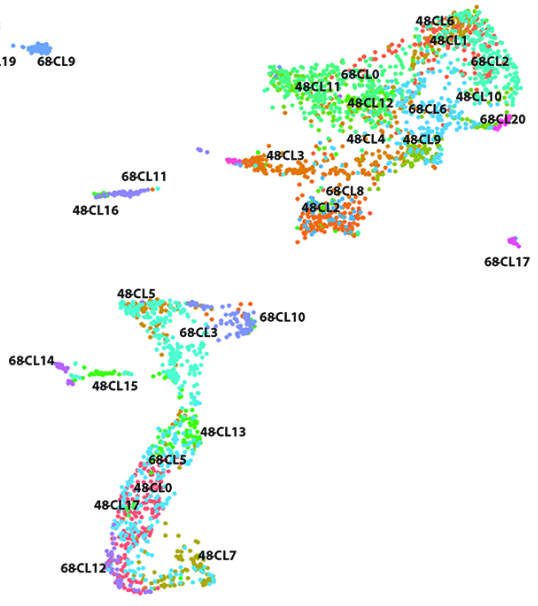

\section{D}

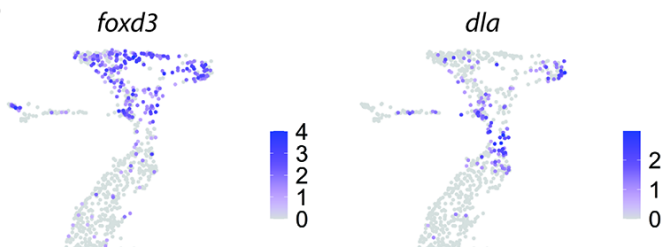

phox2a

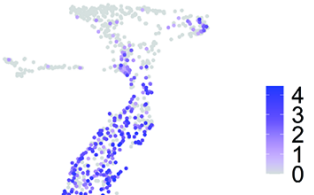

然

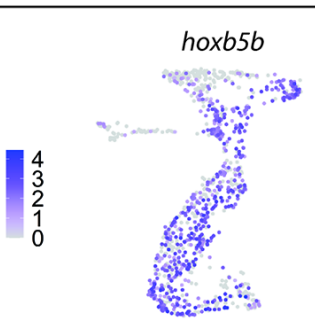

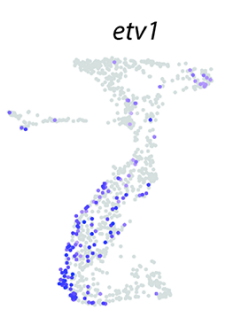

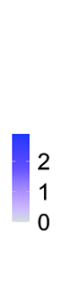

$p b \times 3 b$ 
Figure 7 - Figure Supplement 1
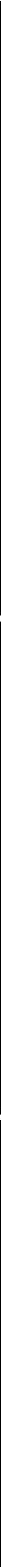

L hoxa5a

M hoxb5a

$\mathrm{N}$ hoxb5b

O hoxa4a

P hoxa13b

Q hoxa11b

R hoxa9a
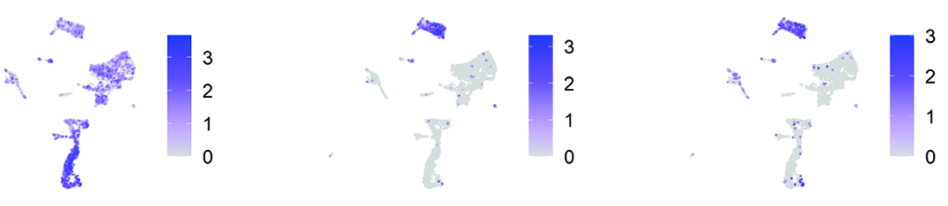